INSTITUTO DE PESQUISAS ENERGÉTICAS E NUCLEARES AUTARQUIA ASSOCIADA À UNIVERSIDADE

DE SÃO PAULO

\title{
DOSIMETRIA DOS SISTEMAS DE RADIOCIRURGIA ESTEREOTÁXICA COM ACELERADORES LINEARES EQUIPADOS COM COLIMADORES MICRO MULTI-LÂMINAS
}

\section{ANDRÉ MOZART DE MIRANDA VIEIRA}

Tese apresentada como parte dos requisitos para obtenção do Grau de Doutor em Ciências na Área de Tecnologia Nuclear - Aplicações.

Orientador:

Dra. Laura Natal Rodrigues

SÃO PAULO 


\section{AGRADECIMENTOS}

À Dra. Laura Natal Rodrigues pela orientação, dedicação, conselhos e a amizade que permitiram seguir adiante com este objetivo e tantos outros relacionados à Física Médica no Brasil.

Ao Dr. José Carlos da Cruz, Coordenador de Física Médica do Serviço de Radioterapia do Hospital Israelita Albert Einstein de São Paulo, com quem aprendi as enormes possibilidades de contribuição de um físico no hospital, por permitir acompanhar o seu trabalho e, de certa forma, absorver um pouco do seu conhecimento. Agradeço ainda pela disponibilidade e paciência em sanar dúvidas, discutir e transmitir diversos conceitos relacionados à Física Médica, os quais vão muito além do que simplesmente àqueles relacionados a este trabalho.

Ao Serviço de Radioterapia do Hospital Israelita Albert Einstein de São Paulo, pela oportunidade de desenvolver este trabalho. Agradeço aos Médicos, Técnicos, Biomédicas, Dosimetristas, ao pessoal de Enfermagem e Administrativo pela interação, troca de conhecimentos e também pelos momentos de descontração. De forma especial, agradeço aos Físicos Cleverson, Lourenço e Roberto, que me ensinaram muito não só profissionalmente, mas também no modo em como encarar a vida com bom humor. Obrigado pela ajuda, paciência e pela amizade.

Aos colegas de Pós Graduação, Cristiane, Eduardo, Juan, Márcio, Patrícia, Priscilla e Branco, por terem formado um grupo de trabalho e amizade fascinantes, tornando o caminho percorrido muito mais prazeroso.

Ao IPEN e ao Centro de Metrologia das Radiações pela oportunidade e pelo suporte disponibilizados. 
À CAPES pelo financiamento deste trabalho.

Agradeço à minha família que colaborou e me apoio incondicionalmente também neste objetivo. Muito obrigado. 


\section{RESUMO}

Neste trabalho, as doses absorvidas produzidas em água pelo feixe de radiação de um Acelerador Linear Clínico - CLINAC 600C ${ }^{\mathrm{TM}}$ (Varian), com feixes de fótons de $6 \mathrm{MV}$, foram avaliadas teórica e experimentalmente em configurações de campos quadrados, em seguida, em configurações de campos estreitos e circulares, obtidos com um colimador micro multi-lâminas - $\mathrm{mMLC} \mathrm{m} 3^{\mathrm{TM}}$ (BrainLab). A avaliação teórica foi feita por meio de cálculos com o Método de Monte Carlo.

As curvas de porcentagem de dose profunda - PDP e respectivas razões tecido máximo - TMRs derivadas, do CLINAC 600C, medidas experimentalmente, foram validadas por meio de comparações com valores de referência, bem como com medidas usando diferentes detectores. Os resultados indicam diferenças menores que 5\% pontualmente e em média menores que 1,5\% para cada campo avaliado, quando comparados aos valores do comissionamento anterior (realizado no ano de 1999) e aos valores da literatura. Na comparação das medidas feitas com câmara de ionização e com diodo, a média das diferenças pontuais das curvas de PDP foi de -0,6\% e as diferenças entre os perfis laterais de dose ficaram dentro de 1\%, na região plana. O diodo fornece medidas de perfil com melhor resolução espacial. Os fatores relativos de dose dos campos abertos, atualizados, concordam com os valores de referência anteriores dentro de 1,03\% de discrepância. As curvas de distribuição de dose absorvida em água, atualizadas, são, agora, consideradas de referência e permitem caracterizar o feixe desse CLINAC para o cálculo de dose em pacientes.

Os espectros de fótons resultantes das simulações por Monte Carlo com os códigos PENELOPE e MCNP concordam em aproximadamente 80\% dos pontos amostrados, sendo que as energias médias de $(1,6 \pm 0,3) \mathrm{MeV}$, com o MCNP, e de (1,72 \pm 0,08)MeV, com o PENELOPE, são coincidentes. O modelo de fonte simples do CLINAC 600C, criado com o código PENELOPE, permite calcular as distribuições de dose em água, de campos abertos, com discrepâncias da ordem de $\pm 1,0 \%$ na dose e de $\pm 0,1 \mathrm{~cm}$ na posição, se comparados a medidas experimentais. Esses valores de discrepância atingem os critérios propostos inicialmente para validar o modelo de simulação e garantir sua aplicabilidade nas avaliações dosimétricas da Radioterapia desse CLINAC.

A descrição geométrica do mMLC m3 para fins de simulação pelo Método de Monte Carlo, utilizando o código PENELOPE, foi considerada satisfatória ao permitir avaliar a transmissão desse colimador dentro de uma incerteza de $\pm 0,2 \%$ e calcular uma 
subdosagem média de $(11,4 \pm 2,0) \%$, devida ao efeito lingüeta-vão, que coincide com o valor determinado experimentalmente de $(12,5 \pm 2,7) \%$, específicos para esse projeto de colimador.

Os programas de simulação por Monte Carlo, que fazem o uso de um modelo de fonte simples do CLINAC 600C, combinado com o modelo completo do mMLC m3, permitiram calcular PDPs em água, de campos conformados, dentro do intervalo de $\pm 1 \%$ de discrepância, enquanto que os fatores relativos de dose de campos conformados pelo mMLC puderam ser calculados com incertezas que variam de 1 a $3 \%$ concordando com os valores experimentais. Esses campos avaliados representam campos próximos àqueles usados nos tratamentos.

Os resultados do trabalho garantem um conhecimento dosimétrico maior do colimador micro multi-lâminas $\mathrm{m} 3$, utilizado nas técnicas de radioterapia e radiocirurgia estereotáxica tridimensionais, e fornece uma ferramenta útil na avaliação das doses produzidas em configurações de campos complexas. 


\section{ABSTRACT}

In this work, absorbed dose to water produced by the radiation beam of a clinical linear accelerator - CLINAC 600C ${ }^{\mathrm{TM}}$ (Varian), with a photon beam of $6 \mathrm{MV}$, were evaluated both theoretically and experimentally. This determination includes square and circular field configurations, the last one obtained with a micro multileaf collimator mMLC $3^{\mathrm{TM}}$ (BrainLab). Theoretical evaluation was performed throughout Monte Carlo method.

Experimental measurements of Percentage Depht Dose - PDD and derived Tissue Maximum Ratio - TMR curves from CLINAC 600C were validated by comparison with reference values as well as with measurements using different detectors. The results indicate local differences smaller than $5 \%$ and average differences smaller than $1,5 \%$ for each evaluated field, if they are compared to the previous commissioning values (made in 1999) and to the values of literature. Comparisons of ionization chamber and diode result in an average local difference of $-0,6 \%$ for PDD measurements, and within $1 \%$ for lateral dose profiles, at depth, in the flat region. Diode provides measurements with better spatial resolution. Current output factors of open fields agree with reference values within 1,03\% of discrepancy level. Current absorbed dose distributions in water are, now, considered reference values and allow characterization of this CLINAC for patient dose calculation.

The photon spectra resulting from simulations with PENELOPE and MCNP codes agree approximately in $80 \%$ of the sampled points, in what average energies of $(1,6$ $\pm 0,3) \mathrm{MeV}$, with MCNP, and of $(1,72 \pm 0,08) \mathrm{MeV}$, with PENELOPE, are coincident. The created simple source model of the CLINAC 600C, using the PENELOPE code, allows one to calculate dose distributions in water, for open fields, with discrepancies of the order of $\pm 1,0 \%$ in dose and of $\pm 0,1 \mathrm{~cm}$ in position, if they are compared to experimental measurements. These values met the initial proposed criteria to validate the simulation model and guarantee its applicability in dosimetric evaluations of radiotherapy with this CLINAC.

The geometrical description of the mMLC m3 for Monte Carlo purposes, using the PENELOPE code, was considered satisfactory, providing the characterization of relevant physical parameters such as the transmission of the mMLC, within an estimated uncertainty of $\pm 0,2 \%$, and the average underdose of $(11,4 \pm 2,0) \%$, due the tongue and groove effect, which is coincident with the experimental value of $(12,5 \pm 2,7) \%$, for this particular collimator design. 
The Monte Carlo simulation codes which combine a single source model of the CLINAC 600C with the full m3 model, allows to calculate dose distributions in water for conformal beams within the discrepancy level of $\pm 1 \%$. However, output factors of conformal beams with the mMLC can be calculated with uncertainties varying from 1 to $3 \%$, when they are compared to experimental results. These evaluated fields represent, and come close to treatment fields.

The results of this work guarantee a better dosimetric knowledge of the micro multileaf collimator $\mathrm{m} 3$, which is used in three-dimensional stereotactic radiotherapy and radiosurgery techniques. This provides a useful tool in the evaluation of the mMLC as well as the absorbed doses produced in complex field configurations. 


\section{SUMÁRIO}

LISTA DE TABELAS

LISTA DE FIGURAS

GLOSSÁRIO

1 INTRODUÇÃO

2 FUNDAMENTOS TEÓRICOS

2.1 Fundamentos de Dosimetria

2.1.1 Dose Absorvida

2.1.2 Dosímetros

2.1.2.1 Câmara de Ionização __ 5

2.1.2.2 Filme Radiográfico__ 7

2.1.2.3 Diodo____ _ 9

2.2 Radiocirurgia e Radioterapia Estereotáxica__ 10

2.2.1 Controle de Qualidade em Radiocirurgia e Radioterapia Estereotáxica__ 12

2.3 Simulação pelo Método de Monte Carlo _ 14

2.3.1 Modelos de Simulação de CLINACs__ 18

2.4 Colimadores Multi-lâminas - MLC _ 20

2.4.1 Técnicas de Tratamento com MLC__ 22

2.5 Avaliação de Incertezas 28

2.5.1 Estimativa da Incerteza em Monte Carlo__ 28

2.5.2 Eficiência de Cálculo e Redução de Variâncias __ 30

3 REVISÃO BIBLIOGRÁFICA__ 32

4 OBJETIVOS $\quad 36$

5 MATERIAIS E MÉTODOS_ 37

5.1 Dosimetria do Acelerador Linear - Campos Abertos _ 37

5.1.1 Caracterização Dosimétrica do CLINAC___ 37

5.2 Simulação do CLINAC 38

5.2.1 PENELOPE___ 40

5.2.2 MCNP4C _ 49

5.3 Dosimetria do Acelerador Linear equipado com o mMLC

5.4 Cálculo de Dose Devido aos Campos Conformados pelo mMLC _ 53

6 RESULTADOS E DISCUSSÃO 55

6.1 Avaliação Dosimétrica do Acelerador Linear___ 55

6.1.1 Validação de Medidas Experimentais___

6.1.2 Simulação do Acelerador Linear Clínico __ 62

6.1.2.1 Simulação com PENELOPE___ 63

6.1.2.2 Simulação com MCNP4C __ 64

6.1.2.3 Espectro de Fótons de 6MV _ 67

6.1.2.4 Validação do Código de Simulação _ 69

6.2 Avaliação Dosimétrica do Acelerador Linear equipado com o mMLC _ 73

6.2.1 Transmissão e Efeito Lingüeta-Vão (Tongue and Groove) do m3 74

6.2.2 Campos Conformados pelo mMLC m3

7 CONCLUSÕES — 81

8 APÊNDICE — 13

9 REFERÊNCIAS BIBLIOGRÁFICAS___ 97 


\section{LISTA DE TABELAS}

Tabela 1: Exemplo de arquivo contendo a descrição por espaço de fases das partículas de um feixe, simuladas pelo método de Monte Carlo. Cada linha da tabela corresponde a uma partícula, seu tipo (1= elétron, 2= fóton, 3 = pósitron, etc), suas coordenadas de posição $\mathrm{x}, \mathrm{y}$ e z $(\mathrm{em} \mathrm{cm})$, seus cossenos diretores u, v, e w, sua energia (em MeV), e seu peso estatístico.

Tabela 2: Exemplo de arquivo de entrada user.in, contendo as variáveis iniciais, contidas no pacote original $^{[42]}$, e seus valores designados para simulação com o código PENELOPE.

Tabela 3: Exemplos de definições de superfícies no MCNP. 50

Tabela 4: Exemplo de arquivo de entrada user2, contendo as variáveis iniciais e seus valores designados para simulação com o código MCNP.

Tabela 5: Fatores Relativos de Dose - OF de campos quadrados, atualizados e medidos com a câmara RK, valores anteriores de referência e diferença percentual entre eles. Todos os valores de OF têm uma incerteza estimada de 0,003 .

Tabela 6: Sumário dos resultados obtidos para as três simulações com o MCNP (considerando três energias de corte para elétrons) e estimativa do tempo de simulação para obter o arquivo com espaço de fases adequado ( $10^{8}$ “partículas”) no plano $\mathrm{Z}=25 \mathrm{~cm}$.

Tabela 7: Intensidades relativas das energias do feixe de 6 MV do CLINAC 600C simuladas por Monte Carlo com PENELOPE e MCNP.

Tabela a1. Comparação entre os resultados do programa de verificação e os cálculos do sistema de planejamento em meios diferentes. 


\section{LISTA DE FIGURAS}

Figura 1: Radiografia de uma micro-câmara de ionização cilíndrica. 6

Figura 2: Representação esquemática de um diodo semicondutor utilizado como detector de radiação ionizante.

Figura 3: Sistema de imobilização e de localização estereotáxica. Esquerda: suporte para máscara termoplástica, máscara do paciente e caixa localizadora. Direita: Vista lateral do sistema posicionado no paciente com detalhe para uma das barras em forma de “Z” da caixa de localização, que definem o sistema estereotáxico de localização e permitem a reconstrução das diversas posições e estruturas nesse sistema (adaptados do manual da BrainLab ${ }^{[17]}$ ).

Figura 4: Esquema típico e componentes do modelo de um CLINAC para simulação pelo método de Monte Carlo.

Figura 5: Vista inferior de sistemas de colimadores multi-lâminas: (a) micro-colimador m3 da BrainLab com 52 lâminas, à esquerda , e (b) colimador Millennium da Varian com 120 lâminas, à direita.

Figura 6. Esquema de uma lâmina que forma parte de um sistema MLC e a denominação das suas especificações $^{[25]}$.

Figura 7: Vista frontal de vários sistemas comerciais de MLC, com o respectivo projeto de encaixe lingüeta vão (adaptado de Das e colaboradores ${ }^{[26]}$ ).

Figura 8: "Visão do feixe" de um campo conformado pelo MLC, acima, e posição da mesa de tratamento e cabeçote do acelerador, abaixo.

igura 9: "Visões do feixe" das entradas de um arco conformado fixo, acima, e correspondentes posições de mesa de tratamento e do cabeçote do acelerador, abaixo. Neste caso, a mesma configuração é mantida independente da movimentação do cabeçote do acelerador, e é escolhida como a média das projeções tridimensionais.

gura 10: "Visões do feixe" das entradas de um arco dinâmico, acima, e correspondentes posições de mesa de tratamento e do cabeçote do acelerador, abaixo. A conformação pelas lâminas é adaptada de acordo com as projeções tridimensionais da lesão alvo.

Figura 11: "Visões do feixe” de nove segmentos de um único campo de intensidade modulada para a mesma projeção do volume alvo do caso conformado (Figura 8). Na parte inferior estão representadas as configurações de mesa de tratamento e cabeçote do acelerador, que é sempre a mesma para um campo de intensidade modulada.

Figura 12: Na parte superior mostra-se um esquema com o padrão de intensidades resultante da composição dos diversos sub-campos. Abaixo está representado um esquema do acelerador com a posição relativa da mesa de tratamento com a disposição do cabeçote do acelerador para o campo definido acima. __ 27

Figura 13: Acelerador Linear Clínico Varian 600C do Hospital Israelita Albert Einstein.

Figura 14: Exemplo de trajetórias em água das partículas geradas com o simulador SHOWER a partir de um feixe inicial de elétrons de $6 \mathrm{MeV}$.

Figura 15: Superfícies quadráticas não planas definidas por equações quadráticas na forma reduzida e seus índices utilizados na equação 24 (adaptada de Salvat e colaboradores ${ }^{[42]}$ ).

Figura 16: Objeto simulador antropomórfico construído através de superfícies quadráticas e visualizadas com o programa GVIEW3D.

Figura 17: Gráfico das curvas de PDP em água do campo $10 \mathrm{~cm}$ x $10 \mathrm{~cm}$ medidas com a câmara RK, do BJR25 e da dosimetria antiga (1999), também com a câmara RK.

Figura 18: Gráfico das diferenças das curvas de PDP entre dados das medidas novas (dezembro de 2006) e antigas (julho de 1999), de campos quadrados de $4 \mathrm{~cm}$ x $4 \mathrm{~cm}$ a $40 \mathrm{~cm}$ x $40 \mathrm{~cm}$.

Figura 19: Gráfico das diferenças das curvas de TMR entre dados das medidas novas (dezembro de 2006) e antigas (julho de 1999), de campos quadrados de $5 \mathrm{~cm}$ x $5 \mathrm{~cm}$ a $40 \mathrm{~cm}$ x $40 \mathrm{~cm}$.

Figura 20: Gráfico das diferenças das curvas de PDP entre dados das medidas novas (dezembro de 2006) e valores do BJR25, de campos quadrados de $4 \mathrm{~cm} \mathrm{x} 4 \mathrm{~cm}$ a $40 \mathrm{~cm}$ x $40 \mathrm{~cm}$.

Figura 21: Gráfico das diferenças das curvas de TMR entre dados das medidas novas (dezembro de 2006) e valores do BJR25, de campos quadrados de $4 \mathrm{~cm}$ x $4 \mathrm{~cm}$ a $40 \mathrm{~cm}$ x $40 \mathrm{~cm}$.

Figura 22: Gráfico das diferenças das curvas de PDP medidas com a RK e com diodo, de campos quadrados de $2 \mathrm{~cm} \times 2 \mathrm{~cm}$ a $25 \mathrm{~cm}$ x $25 \mathrm{~cm}$.

Figura 23: Gráfico dos perfis laterais de dose em água do campo $10 \mathrm{~cm} \mathrm{x} 10 \mathrm{~cm}$ medidos a $1,5 \mathrm{~cm}$ de profundidade com a câmara RK e com o diodo.

Figura 24: Principais componentes do CLINAC 600C para fins de simulação em Monte Carlo. Figura gerada com o programa GVIEW3D do PENELOPE. 
Figura 26: Fluência dos fótons no plano $Z=25 \mathrm{~cm}$, segmentado por superfícies cilíndricas, após simulação através da parte fixa do acelerador.

Figura 27: Energia média dos fótons no plano $Z=25 \mathrm{~cm}$, segmentado por superfícies cilíndricas e por energia, após simulação através da parte fixa do acelerador.

Figura 28: Exemplo de amostragem espacial de partículas (fótons em azul e elétrons em vermelho) no plano $\mathrm{Z}=25 \mathrm{~cm}$, após simulação através da parte fixa do acelerador, gerada com o MCNP.

Figura 29: Espectro de Energia dos fótons no plano $Z=25 \mathrm{~cm}$, após simulação através da parte fixa do acelerador.

Figura 30: PDP em água do campo 10cmx10cm utilizando as duas técnicas de simulação com o código PENELOPE, (a) Em vermelho, obtida com a descrição por espaço de fases; (b) em azul, obtida com o modelo de fonte espectral.

igura 31: Perfil em água a 1,5 cm de profundidade do campo $10 \mathrm{~cm}$ x10 cm utilizando o modelo de fonte espectral na simulação com o código PENELOPE e valores experimentais medidos com diodo.

Figura 32: Perfil em água a $10 \mathrm{~cm}$ de profundidade do campo $10 \mathrm{~cm}$ x $10 \mathrm{~cm}$ utilizando o modelo de fonte espectral na simulação com o código PENELOPE e valores experimentais medidos com diodo. ura 33: Diferença entre os perfis do campo $10 \mathrm{~cm}$ x $10 \mathrm{~cm}$, medidos experimentalmente e calculados por MC, correspondente aos perfis da Figura 31 ( a 1,5 cm de profundidade) e da Figura 32 ( a $10 \mathrm{~cm}$ de profundidade), avaliados na região de alto gradiente de dose. ra 34: Visualização de uma das lâminas do mMLC, em um corte transversal em 2D, à esquerda; e numa visualização em $3 \mathrm{D}$, à direita.

Figura 35: Esquema com quatro das lâminas do mMLC m3 e as trajetórias típicas da radiação transmitida intra-lâminas e entre-lâminas.

Figura 36: Distribuição de fótons obtida da simulação do mMLC fechado (à esquerda); Filme radiográfico irradiado para avaliar a transmissão do mMLC (à direita).

Figura 37: Filme radiográfico do efeito lingüeta-vão (“togue and groove”) (à esquerda) e gráfico dos perfis de dose para avaliar esse efeito, medido com filme e simulado por Monte Carlo (à direita). __ 77

Figura 38: Comparação das PDPs, experimental e simulada por MC, em água, do campo circular de diâmetro $1,8 \mathrm{~cm}$ (representado no detalhe em verde).

Figura 39: Comparação das PDPs, experimental e simulada por MC, em água, do campo circular de diâmetro $6,0 \mathrm{~cm}$ (representado no detalhe em verde).

Figura 40: Fatores Relativos de Dose a $5 \mathrm{~cm}$ de profundidade em água, obtidos de medidas experimentais com câmara de ionização A16 e simulados por MC, de campos circulares conformados pelo mMLC m3.

Figura a1. Tela do arquivo em formato de texto exportado pelo sistema de planejamento com as posições das

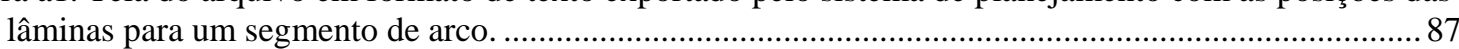

Figura a2. Tela com os resultados do cálculo para oito segmentos que formam um campo de tratamento.....90

Figura a3. Comparação da dose total entre os valores calculados pelo programa de verificação e os valores calculados pelo sistema de planejamento para os 42 tratamentos de crânio. . 8 


\section{GLOSSÁRIO}

3DCRT

Radioterapia Conformada Tridimensional (da sigla em inglês para

Three Dimensional Conformal Radiation Therapy). Técnica de radioterapia em que os órgãos e estruturas do paciente são levados em conta tridimensionalmente para definição dos campos de radiação.

CLINAC Acelerador linear clínico. É um LINAC com capacidades úteis para uso clínico, como rotação do cabeçote do acelerador, colimadores para formar campos quadrados e retangulares e com movimento de rotação, mesa de tratamento móvel, filtros físicos, suportes para bandejas e blocos de campos, raios laser de localização, feixes aplainados para garantir distribuições de dose uniformes, luz de campo como indicador de distância, etc.

IMRT Radioterapia de Intensidade Modulada (da sigla em inglês para Intensty Modulated Radiation Therapy). Técnica de radioterapia em que a intensidade do feixe varia através do campo de tratamento. Em geral, a modulação do feixe é feita com o uso de MLCs e utiliza um SPTC com capacidade de realizar o planejamento inverso, no qual são definidas as intensidades de cada campo.

Kerma Energia cinética entregue por unidade de massa (da sigla em inglês para Kinetic Energy Released per unit Mass). Grandeza que quantifica a energia média transferida pela radiação indiretamente ionizante, como fótons e nêutrons, à radiação diretamente ionizante sem importar o que acontece após essa transferência.

LINAC Acelerador linear (acrônimo para o nome em inglês Linear Accelerator). Um tipo de acelerador de partículas no qual as partículas são aceleradas em linha reta, seja por um campo elétrico estacionário quanto por meio de campos elétricos com radiofreqüência. Os LINACs mais comuns aceleram elétrons, produzindo feixes de elétrons, ou ainda produzindo feixes de fótons quando se utilizam alvos metálicos para produção de raios X por bremsstrahlung.

MC

Monte Carlo. Método que fornece soluções numéricas para uma variedade de problemas matemáticos por meio de experimentos de amostragem estatística. O método ganhou o nome em homenagem a cidade de Monte Carlo, no principado de Mônaco, famosa por seus cassinos contendo dados, roletas e diversos jogos de azar, nos quais se observa a natureza estatística dos jogos. 
MLC

Colimador Multi-Lâminas ou Multi-Folhas (da sigla em inglês para

Multi Leaf Collimator). Equipamento que dá forma aos campos de radiação provenientes de uma unidade de tratamento (em geral de um CLINAC), bloqueando áreas que não se deseja irradiar e permitindo a passagem livre do feixe nas áreas desejadas. É composto de diversas lâminas de material de alta densidade que se movem através do feixe num determinado padrão. As lâminas convencionais possuem espessuras de $0,5 \mathrm{~cm}$ a $1,0 \mathrm{~cm}$ (projetadas no isocentro da unidade de tratamento).

mMLC Colimador Micro Muti-Lâminas (da sigla em inglês para micro MLC). Um tipo de MLC em que as lâminas possuem espessuras menores que as convencionais, tipicamente menores ou iguais a $0,3 \mathrm{~cm}$ no isocentro.

PDP

Porcentagem de Dose Profunda. Curva da distribuição de dose num material ao longo do eixo central do feixe de radiação. Em geral, a curva é normalizada ao valor de dose do ponto de máximo para um determinado campo de referência e para uma mesma distância SSD fixa, de um dado feixe.

PSF Fator de Espalhamento de Pico (da sigla em inglês para Peak Scatter Factor). Razão da dose em um pequeno volume de água, à profundidade de $d_{\text {máx }}$, medida em ar e a dose no mesmo ponto de medida em um objeto simulador de água, definida para uma mesma distância fonte detector e mesmo tamanho de campo.

SAD Distância fonte eixo (da sigla em inglês para Source to Axis Distance).

SPTC Sistema de Planejamento de Tratamento Computadorizado. Programa computacional destinado ao cálculo de dose em uma representação do paciente. Os SPTCs modernos são capazes de reconstruir uma representação tridimensional do paciente a partir de imagens de tomografia computadorizada, desenhar estruturas de interesse nessa representação, definir entradas e formas dos campos de radiação e realizar o cálculo de dose nas diversas estruturas utilizando os dados dosimétricos do feixe real.

SSD

Distância fonte superfície (da sigla em inglês para Source to Surface

Distance).

Terma Energia total entregue por unidade de massa (da sigla em inglês para Total Energy Released per unit Mass). Quantidade utilizada nos métodos de convolução para o cálculo de dose, sendo o produto do coeficiente de atenuação de massa pela fluência de energia. 
TMR

Razão Tecido Máximo (da sigla em inglês para Tissue Maximum

Ratio). É um caso especial de TPR, definido para a profundidade de referência igual à profundidade de máxima dose. A curva de TMR representa a curva da distribuição de dose num material ao longo do eixo central do feixe de radiação para uma geometria SAD em que o detector permanece numa posição fixa. Em geral, a curva é normalizada ao valor de dose do ponto de máximo para um determinado campo de referência (definido no isocentro da unidade de irradiação), de um dado feixe.

TPR Razão Tecido Phantom (da sigla em inglês para Tissue Phantom Ratio). É a relação entre a dose num ponto arbitrário, no eixo central, de um objeto simulador (phantom) e a dose num ponto de referência (tipicamente $5 \mathrm{~cm}$ ou $10 \mathrm{~cm}$ ), no eixo central, do objeto simulador. Os pontos de dose se referenciam sempre na geometria isocêntrica, mantendo iguais tanto o tamanho de campo quanto a distância fonte-ponto de medida, mas variando a distância fonte-superfície e a profundidade dentro do objeto simulador.

$\mathbf{T P R}_{\mathbf{2 0 , 1 0}}$ Razão entre os TPRs medidos a $20 \mathrm{~cm}$ e $10 \mathrm{~cm}$ de profundidade em água. O valor do $\mathrm{TPR}_{20,10}$ atualmente representa um especificador de qualidade do feixe, para fótons de megavoltagem, substituindo o Potencial de Aceleração Nominal.

UM

Unidade Monitora. Unidade de controle temporal dos CLINACs em que o feixe de radiação está ligado. Usualmente os feixes dos CLINACs são calibrados para fornecerem 1cGy/UM em água, ou seja a dose de 1cGy por UM, numa determinada profundidade de referência em condições de referência de campo e distância. 


\section{INTRODUÇÃO}

O objetivo de um tratamento utilizando radiações ionizantes é depositar dose absorvida para danificar ou destruir uma lesão alvo, ao mesmo tempo em que minimiza os efeitos tóxicos nos tecidos normais e estruturas de risco próximas à lesão ${ }^{[1-}$ 4]. Diversas melhorias na técnica radioterápica foram sendo incorporadas nos últimos anos, incluindo os avanços na tecnologia dos aceleradores lineares clínicos CLINACs, na capacidade de processamento computacional, nas técnicas de posicionamento e imobilização, e na dosimetria dos feixes de radiação.

Um dos avanços recentes mais significativos na radioterapia foi a introdução comercial dos colimadores multi-lâminas - MLCs ${ }^{[1],[5-7]}$ que podem ser anexados como colimação adicional nos aceleradores existentes. Os MLCs, além de substituírem os blocos para conformação dos campos de radiação, possibilitam a realização de técnicas especiais de radioterapia como o arco conformado e a radioterapia de intensidade modulada - IMRT (da sigla em inglês para Intensity Modulated Radiation Therapy). Os benefícios e a complexidade advindos dessa capacidade têm levado à criação de novos protocolos de tratamento, fornecendo assim um grande potencial ${ }^{[5-7]}$ para um maior controle das várias patologias tratadas.

Em contrapartida aos avanços e melhorias obtidos com as novas tecnologias há um aumento na complexidade tanto dos sistemas de liberação e controle de dose quanto dos sistemas de planejamento de tratamento computadorizados - SPTCs, requerendo uma crescente sofisticação na garantia da qualidade dessas técnicas. A Organização Mundial da Saúde - OMS justificou a necessidade de Garantia de Qualidade em Radioterapia ${ }^{[8]}$ com a finalidade de minimizar os erros no planejamento e administração da dose ao paciente, e ainda, de aproveitar as características superiores dos equipamentos modernos. A Agência Internacional de Energia Atômica - IAEA através do documento técnico TECDOC- $1151^{[8]}$ ressalta ainda que, aos argumentos da OMS, dever-se-ia adicionar outro, que é prover o método mais simples e eficaz para a redução de acidentes em radioterapia. Os procedimentos específicos para garantir a qualidade em radiocirurgia e radioterapia estereotáxica com aceleradores lineares foram sendo desenvolvidos desde a sua introdução na década de 1980, porém para técnicas de colimação circular, como o "Programa de Garantia de Qualidade em Radiocirurgia Estereotáxica”, de Hartmann ${ }^{[9]}$, e o relatório do TG $42^{[10]}$ da AAPM, ambos de 1995, 
por isso ainda há uma escassez de trabalhos que abordem as técnicas que utilizam os MLCs.

O Método de Monte Carlo é considerado o mais apropriado para descrever os feixes de radiação em configurações simples ou complexas ${ }^{[11,12]}$, como os feixes dos CLINACs e a sua interação com a região irradiada (paciente, detector, objetos simuladores, etc), possibilitando assim o estudo em regiões de interface de tecidos, bem como o conhecimento dos diferentes componentes no processo de deposição de energia. Por ainda requerer um tempo computacional relativamente longo para obter distribuições de dose com precisão adequada, o método atualmente não é o mais difundido nas clínicas e hospitais como opção de SPTC, apesar de já existirem sistemas que utilizem o princípio da simulação por Monte Carlo ${ }^{[13]}$. No entanto, pesquisadores e fabricantes têm trabalhado nessa vertente, criando técnicas para torná-lo mais rápido e possivelmente mais comum nos próximos anos. Nas aplicações em Medicina, como é o caso da teleterapia com acelerador linear, é essencial que o código de simulação seja adequado para o tipo de radiação e para os meios, seja com relação à base de dados (seções de choque, poderes de frenagem e dispersão) para os meios materiais, com relação à física do transporte de radiação nesses meios, ou ainda com relação às diferentes técnicas de simulação de cada código. Quando isto é possível, os resultados de simulação por Monte Carlo permitem assegurar a credibilidade dos resultados e utilizá-los em diversos estudos dosimétricos, servindo, deste modo, como referência na avaliação de algoritmos de SPTCs, na obtenção de fatores de correção dos detectores, na avaliação do impacto causado por acessórios e modificadores de feixe, e assim sucessivamente. 


\section{FUNDAMENTOS TEÓRICOS}

\subsection{Fundamentos de Dosimetria}

Medidas de radiação e de seus efeitos requerem diversas especificações a respeito do campo de radiação em um determinado ponto de interesse. A dosimetria das radiações lida com os métodos para uma determinação quantitativa da energia depositada em um dado meio por radiações direta ou indiretamente ionizantes. Algumas grandezas físicas e unidades foram definidas para descreverem os feixes de radiação, entre elas a fluência de fótons e a fluência de energia, enquanto outras foram definidas para descrever a interação desses feixes com a matéria, como o kerma (energia cinética entregue por unidade de massa), o terma (energia total entregue por unidade de massa), os poderes de frenagem e a dose absorvida. Essas grandezas estão bem descritas por Attix $^{[2]}$, Johns e Cunningham ${ }^{[3]}$, Khan ${ }^{[4]}$ e Podgorsak $^{[11]}$.

\subsubsection{Dose Absorvida}

A dose absorvida é uma grandeza física não-estocástica aplicável tanto para radiações diretamente quanto indiretamente ionizantes. Para o caso de radiações indiretamente ionizantes como revisado por Podgorsak ${ }^{[11]}$, a energia é entregue à matéria em duas etapas: na primeira etapa, a radiação indiretamente ionizante transfere energia às partículas carregadas secundárias, resultando no kerma; na segunda etapa, essas partículas carregadas transferem parte de sua energia cinética ao meio e parte de sua energia é perdida na forma de perda radiativa (por exemplo: bremsstrahlung e aniquilação em vôo).

A dose absorvida está relacionada à grandeza física estocástica energia entregue (ou cedida) na matéria. A dose absorvida é definida como a energia média $\bar{E}$ entregue pela radiação ionizante à matéria de massa $m$ em um volume finito $V$ :

$$
D=\frac{d \bar{E}}{d m}
$$


A energia entregue $\bar{E}$ é a soma de todas as energias que entram no volume de interesse menos todas as energias que saem do volume, levando em conta qualquer processo de conversão entre massa e energia que ocorra dentro do volume. No caso dos elétrons, que depositam energia ao longo de suas trajetórias dentro do meio, a absorção da energia não ocorre no mesmo local da transferência de energia, esta última descrita pelo kerma.

A unidade de dose absorvida é o joule por kilograma (J/kg), a qual foi dada o nome especial de gray (Gy).

\subsubsection{Dose Absorvida em Radioterapia}

A Comissão Internacional de Unidades e Medidas de Radiação (ICRU) recomenda uma exatidão global de $\pm 5 \%^{[14,15]}$ na dose entregue ao volume alvo em radioterapia. Este valor é baseado na análise da resposta dos tecidos à irradiação e na avaliação das incertezas envolvidas na liberação de dose ao paciente.

Uma das partes mais importantes que antecede o processo de liberação da dose ao paciente é a calibração dos feixes de fótons e elétrons produzidos nos equipamentos de radioterapia externa e a verificação da sua taxa de dose, como revisado por Podgorsak $^{[11]}$. A taxa de dose em um equipamento de radioterapia indica-se como a taxa de dose em um ponto $P$ em uma profundidade de referência $d_{\text {ref }}$ em um objeto simulador equivalente à água, a uma distância nominal fonte-superfície e para um tamanho de campo de referência $10 \times 10 \mathrm{~cm}^{2}$, definido na superfície do objeto simulador ou no isocentro do equipamento. A taxa de dose para equipamentos de raios$\mathrm{X}$, nas faixas de energia superficial e de ortovoltagem, e de unidades de cobaltoterapia é expressa em Gy/min, enquanto que para aceleradores clínicos é dada em Gy/UM, sendo UM correspondente a uma unidade monitora.

\subsubsection{Dosímetros}

Um dosímetro é um aparelho, instrumento ou sistema, que juntamente com seu leitor forma um sistema dosimétrico, capaz de medir ou avaliar, seja direta ou indiretamente, grandezas físicas tais como exposição, kerma, dose absorvida ou dose 
equivalente, ou ainda suas derivadas no tempo (taxas) ou grandezas relacionadas às radiações ionizantes.

Em radioterapia busca-se determinar, de forma mais exata possível, a dose absorvida na água, em um ponto específico, e sua distribuição espacial, bem como derivar a dose em um órgão de interesse do paciente. Nesse contexto, as propriedades de um dosímetro, segundo Podgorsak ${ }^{[11]}$, que devem ser caracterizadas são exatidão (ou acurácia), precisão, linearidade, dependência com a dose e a taxa de dose, dependência energética, dependência direcional e resolução espacial. Como nem todos os dosímetros podem satisfazer todas as características desejáveis escolhe-se o dosímetro mais conveniente para cada situação, tal como, por exemplo, o caso das câmaras de ionização que são recomendadas para calibração absoluta dos feixes de radiação, enquanto filmes radiográficos são adequados para obter distribuições de dose e outros podem ser mais adequados para verificação da dose.

\subsubsection{Câmara de Ionização}

As câmaras de ionização são utilizadas em radioterapia, radiodiagnóstico e radioproteção para a determinação da dose. Uma câmara de ionização é basicamente uma cavidade cercada de uma parede de material condutor e um eletrodo central coletor $^{[2] ~[3] ~[4] ~[11] ~}$. A parede e o eletrodo estão separados por um isolante para reduzir a corrente de fuga quando se aplica uma determinada tensão de polarização à câmara. Medidas com câmaras abertas, ou em contato com o ar externo, requerem correções devidas às mudanças na massa de ar dentro do volume da câmara, causadas pelas variações de pressão e temperatura ambientes.

A câmara de ionização mais popular é a câmara cilíndrica do tipo Farmer com 0,6 $\mathrm{cm}^{3}$ de volume sensível, usada na calibração absoluta dos feixes em radioterapia. No entanto, tem-se difundido o uso de câmaras cilíndricas de volumes pequenos, por exemplo, com diâmetro de 2 mm como a da Figura 1, ou ainda menores. As câmaras de volume pequeno são utilizadas principalmente nas verificações de dose, mas também podem auxiliar no levantamento de dados dosimétricos para comissionamento dos feixes de radiação, como indicado por Podgorsak ${ }^{[11]}$. 




Figura 1: Radiografia de uma micro-câmara de ionização cilíndrica.

Uma câmara de ionização pode ser considerada como um capacitor no qual a corrente ou a carga é induzida pela ação do feixe de radiação. O baixo sinal produzido deve ser medido por um equipamento muito sensível, no caso um eletrômetro. É desejável que o eletrômetro possua um circuito de alimentação de energia que permita selecionar a magnitude e a polaridade da tensão aplicada, permitindo que se conheça a resposta da câmara, em termos de eficiência de coleção de cargas para cada feixe em particular.

Os procedimentos a serem seguidos quando um feixe de radiação é calibrado são descritos nos chamados protocolos de dosimetria, tais como o da Agência Internacional de Energia Atômica (IAEA) ${ }^{[16]}$. Estes procedimentos asseguram um alto nível de consistência na determinação da dose entre os diferentes centros de Radioterapia em um determinado país e também entre um país e outro.

Na prática clínica, a câmara de ionização é a ferramenta mais utilizada para a determinação da dose absorvida por meio da utilização de coeficientes de calibração que asseguram a rastreabilidade com padrões nacionais e internacionais. Os protocolos fornecem o formalismo apropriado e os dados necessários para relacionar a calibração da câmara de ionização em um laboratório padrão com a medição da dose na água em condições de referência no feixe clínico. Atualmente são usados os protocolos baseados em coeficientes de calibração de dose absorvida na água. Estes coeficientes são obtidos geralmente em feixes de Cobalto 60 nos laboratórios de dosimetria de calibração secundária (SSDLs).

A primeira etapa na utilização de um protocolo é a determinação do sinal da câmara corrigindo a carga da câmara pelas grandezas de influência que possam afetar o 
sinal da câmara $\left(M_{Q_{0}}\right)$. A dose absorvida na água na profundidade de referência de um feixe de qualidade de referência Qo é dada por:

$$
D_{w, Q_{0}}=M_{Q_{0}} N_{D, w, Q_{0}}
$$

O termo $N_{D, w, Q_{o}}$ é o coeficiente de calibração em termos de dose absorvida na água, obtido no laboratório de calibração secundária. As grandezas de influência que devem ser levadas em conta nas medidas da câmara são a temperatura, pressão e umidade do ar, tensão e polaridade aplicadas, corrente de fuga da câmara e os efeitos do cabo da câmara.

Seguindo este procedimento, a dose absorvida pode ser obtida e comparada com a dose em condições de referência.

\subsubsection{Filme Radiográfico}

Os filmes radiográficos ${ }^{[4,11]}$ desenvolvem funções importantes em radiodiagnóstico, radioterapia e radioproteção. Servem como detector de radiação, dosímetro relativo, dispositivo de exposição e meio de arquivo de informação.

Os filmes radiográficos são construídos sobre uma base fina de plástico (acetato ou resina de poliéster) contendo uma emulsão sensível à radiação (grãos de brometo de prata $\mathrm{AgBr}$ suspensos em base gelatinosa) que reveste uniformemente um ou ambos os lados da base. A ionização do AgBr em grãos, como resultado da interação com a radiação, forma uma imagem latente no filme. A imagem é visível somente quando o filme é revelado, sendo que os grãos expostos à radiação se reduzem à prata metálica. O filme é então fixado através de uma solução que dissolve o brometo de prata e a gelatina que não foram expostos à radiação, e por fim é enxaguado e seco.

A luz transmitida é função da opacidade do filme e pode ser medida em termos da densidade óptica (OD) com equipamento de medição (densitômetros). Como leitores de OD são utilizados os densitômetros, densitômetros a laser, digitalizadores automáticos (“scanner”), etc. Em geral, o leitor consiste de uma fonte luminosa, uma pequena abertura pela qual a luz é direcionada e um detector de luz (fotocélula) para medir a luz transmitida através do filme. 
A densidade óptica é defina como

$$
O D=\log _{10}\left(I_{o} / I\right)
$$

em que $I_{o}$ é a intensidade inicial de luz sem o filme e $I$, a intensidade transmitida através do filme. O filme contém grãos com aproximadamente 1 a $2 \mu$ m de diâmetro e após ser processado e lido no seu respectivo instrumento de leitura oferece uma resolução espacial excelente em duas dimensões, que pode chegar cerca de $20 \mu \mathrm{m}$. Ainda são vantagens dos filmes radiográficos a disponibilidade comercial, a robustez, a independência com a taxa de dose e o registro das medidas. O registro que poderia perder-se com o envelhecimento ou atuação de elementos externos pode ser garantido permanentemente com a sua digitalização.

Devido à presença da prata $(Z=45)$ e pelo fato do efeito fotoelétrico variar com o cubo do número atômico, o filme dosimétrico apresenta dependência energética, que é mais crítica para a radiação espalhada abaixo de $150 \mathrm{keV}$. Com isso, a faixa na qual o filme pode ser utilizado como dosímetro é limitada segundo o seu tipo e energia do feixe de radiação. Os filmes não expostos à radiação exibem densidade óptica de fundo (“fog”); nos filmes expostos à densidade óptica liquida é obtida subtraindo-se essa densidade de fundo.

Em radioterapia são utilizados filmes de exposição direta, filmes para simulação, filmes de chassi metálico para imagens portais, etc. As aplicações típicas dos filmes dosimétricos incluem dosimetria relativa para feixes de elétrons, controle da qualidade dos equipamentos (p.ex. coincidência de campo luminoso e de radiação, isocentricidade do colimador, do sistema de suporte funcional, mesa de tratamento, etc.), simetria e planura do feixe, distribuições de dose, verificação de técnicas de tratamento (controle da qualidade pré-tratamento), imagens portais e comissionamento de equipamentos.

Idealmente, a relação entre a dose e a OD deve ser linear, mas isto nem sempre acontece. Algumas emulsões são lineares, outras são lineares em uma determinada faixa de dose e outras não são lineares. A curva dose versus OD é conhecida como curva sensitométrica ou curva característica $H \& D$, em homenagem a Hurter e Driffield, os primeiros pesquisadores a caracterizar a resposta de filmes 
fotográficos à luz. A curva mencionada deve ser estabelecida para cada tipo de filme utilizado antes de cada medida dosimétrica.

Em radioterapia, os filmes radiográficos dosimétricos, como o Kodak XOmat V® ou o Kodak EDR-2 ${ }^{\circledR}$, são utilizados para verificação de dados dosimétricos, para o comissionamento de equipamentos e para o controle da qualidade pré-tratamento de campos de IMRT.

\subsubsection{Diodo}

Um diodo dosimétrico ${ }^{[2,4,11]}$ é um diodo semicondutor de junção p-n, produzido em base de silício com material tipo p (p-Si), ou tipo n (n-Si), e dopado na superfície com material oposto, como representado na Figura 2. Ambos os tipos de diodo, n-Si ou p-Si estão disponíveis comercialmente, porém apenas o tipo p-Si é adequado como dosímetro em radioterapia ${ }^{[11]}$, uma vez que sofre menos dano pela radiação e tem uma corrente de fuga muito menor.

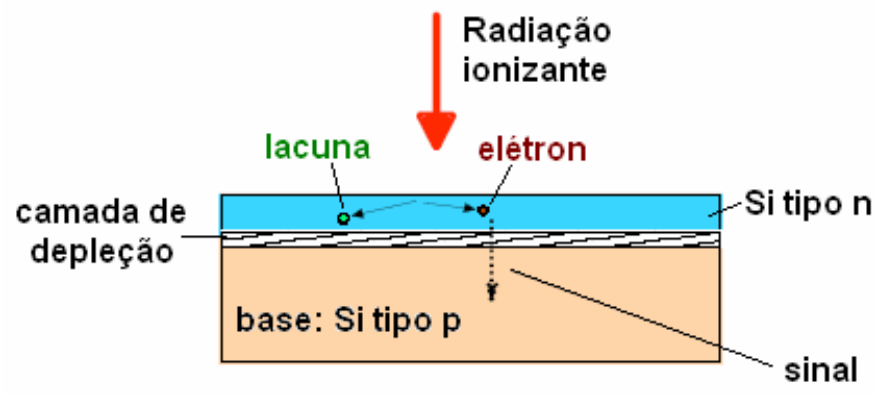

Figura 2: Representação esquemática de um diodo semicondutor utilizado como detector de radiação ionizante.

A radiação produz pares elétron-lacuna (e-l) no corpo do dosímetro, incluindo a camada de depleção. As cargas (ou portadores minoritários de carga) produzidas no corpo do dosímetro, dentro do comprimento de difusão, se difundem na região de depleção. Elas são arrastadas pela região de depleção sob a ação do campo elétrico devido ao potencial intrínseco. Desta forma gera-se uma corrente na direção reversa no diodo.

Diodos são mais sensíveis e menores em tamanho do que as câmaras de ionização típicas. São dosímetros relativos e não devem ser usados para calibração de feixes, uma vez que sua sensibilidade muda com o uso repetido devido ao dano 
produzido pela radiação. Os diodos são particularmente úteis nas medidas em objetos simuladores, como por exemplo, em campos pequenos usados em radiocirurgia estereotáxica ou em áreas de alto gradiente de dose, como nas regiões de penumbra. Eles também são freqüentemente usados para medidas de dose em profundidade para feixes de elétrons. Para uso com equipamentos de varredura, em objetos simuladores de água, eles são encapsulados com um material a prova d’água. Quando usados nas medidas de dose em profundidade de feixes de elétrons, os diodos medem diretamente a distribuição de dose, o que não ocorre com as medidas com câmara de ionização.

Diodos são amplamente usados na dosimetria in vivo de rotina nos pacientes ou para medidas de dose na bexiga ou no reto. Diodos para dosimetria in vivo são encapsulados em um material extra a fim de prover o "build-up” requerido e, por isso, devem ser escolhidos apropriadamente, dependendo do tipo e qualidade de feixe clínico. O encapsulamento também protege o diodo do dano por radiação.

Os diodos devem ser calibrados quando forem ser usados para dosimetria in vivo, e diversos fatores de correção devem ser aplicados para o cálculo da dose. A sensibilidade dos diodos depende do histórico de radiação, por isso a calibração deve ser repetida periodicamente.

Os diodos mostram uma variação na resposta de dose com a temperatura, e isto é particularmente importante para tratamentos longos, com a dependência do sinal da taxa de dose, deve-se tomar cuidado com diferentes distâncias foco-pele, com a dependência angular (direcional) e com a dependência energética, mesmo para variações pequenas na composição espectral dos feixes de radiação, já que isso é importante para medidas de doses de entrada e de saída.

\subsection{Radiocirurgia e Radioterapia Estereotáxica}

Neste trabalho será discutido apenas o uso do acelerador linear clínico CLINAC 600C, com feixes de fótons de $6 \mathrm{MV}$ para radioterapia Os feixes de fótons de $6 \mathrm{MV}$ provenientes de aceleradores lineares provavelmente são os mais utilizados em um serviço de radioterapia que possua esse tipo de equipamento. Pela sua versatilidade são adequados para diversas regiões de tratamento e técnicas disponíveis, desde as modalidades conformacionais convencionais, até as técnicas especiais, tais como IMRT, 
radiocirurgia e irradiação corporal total - TBI. Outros equipamentos estão disponíveis atualmente no mercado ${ }^{[1,5,11]}$, entre eles os equipamentos de teleterapia com fonte radioativa de Co-60, a unidade Gamma Knife para radiocirurgia, os cíclotrons com feixes de prótons e partículas pesadas, o equipamento de tomoterapia, e os aceleradores compactos embutidos em braços robóticos.

Do ponto de vista da liberação do tratamento a radioterapia é realizada em várias sessões, com uma pequena dose diária (na prática convencional é de 1,8 a 2,0 Gy), enquanto que a radiocirurgia se desenvolveu como a técnica realizada em apenas uma única sessão, com a liberação de uma dose alta (em geral, acima de 10,0 Gy), requerendo assim um alto grau de exatidão tanto na dose liberada como na localização do volume alvo, assemelhando-se a um procedimento cirúrgico. A radiocirurgia inicialmente era aplicada exclusivamente a lesões intracraniais bem determinadas e relativamente pequenas, e para isso utilizava um sistema rígido de fixação do crânio e um sistema de coordenadas estereotáxicas que permite a localização das estruturas internas a partir das imagens médicas, daí o nome radiocirurgia estereotáxica ${ }^{[1,9,10]}$. No entanto, a aplicação da radiocirurgia se expandiu para outras regiões anatômicas, podendo usar sistemas de fixação e localização estereotáxica, bem como sistemas que não utilizam esses fixadores (os chamados sistemas “frameless”). Na radiocirurgia com CLINACs dá-se preferência às técnicas de irradiação em forma de arco, que diminuem o nível de dose nos tecidos normais ao mesmo tempo em que concentram a distribuição de dose no volume alvo.

Atualmente, desde que o sistema de planejamento permita, é possível realizar a combinação de características da teleterapia e da radiocirurgia estereotáxica em uma única técnica, somando-se os benefícios radiobiológicos do fracionamento de dose com o alto grau de localização proporcionado pelo sistema estereotáxico. Para o caso da radioterapia estereotáxica de crânio, o anel ou arco estereotáxico é substituído pelo sistema de fixação por máscara termoplástica (ver Figura 3) para permitir o tratamento fracionado em várias sessões. Neste exemplo, a caixa de localização contém barras radiopacas em forma de "Z” que definem o sistema estereotáxico nas imagens médicas geradas com o conjunto posicionado no paciente, o que permite reconstruir as posições das diversas estruturas internas no sistema estereotáxico. 

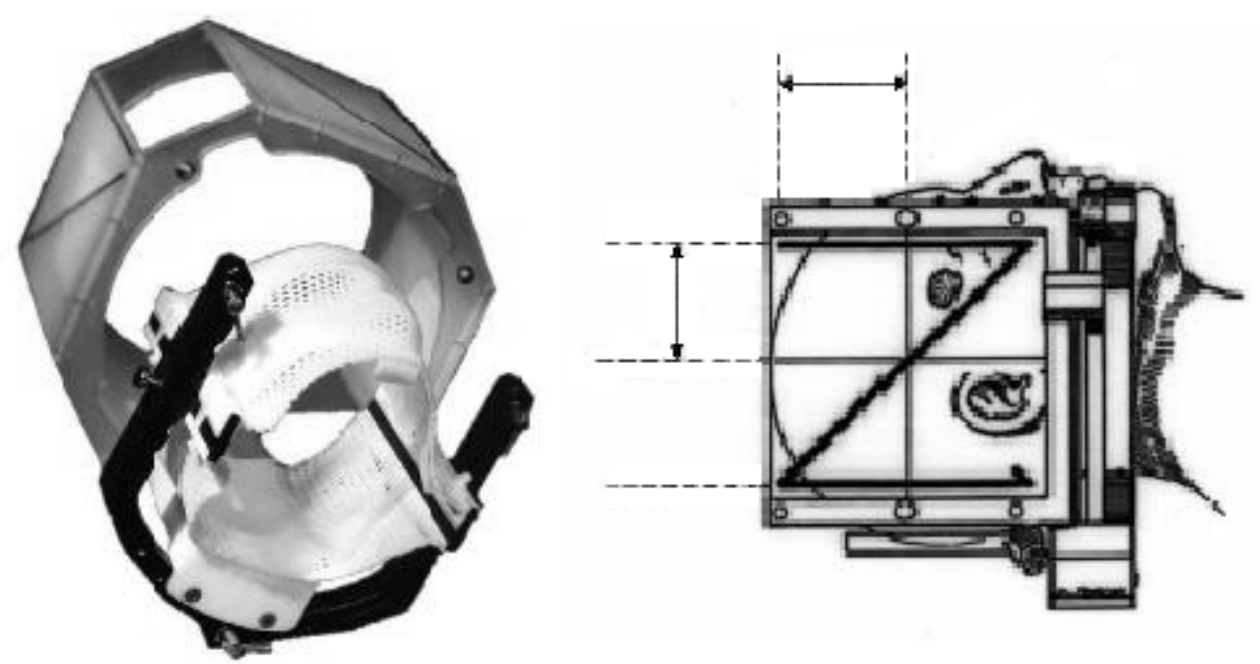

Figura 3: Sistema de imobilização e de localização estereotáxica. Esquerda: suporte para máscara termoplástica, máscara do paciente e caixa localizadora. Direita: Vista lateral do sistema posicionado no paciente com detalhe para uma das barras em forma de "Z" da caixa de localização, que definem o sistema estereotáxico de localização e permitem a reconstrução das diversas posições e estruturas nesse sistema (adaptados do manual da BrainLab $\left.^{[17]}\right)$.

\subsubsection{Controle de Qualidade em Radiocirurgia e Radioterapia Estereotáxica}

A Organização Mundial da Saúde - OMS justificou a necessidade de Garantia de Qualidade em Radioterapia ${ }^{[8]}$ embasada nos seguintes argumentos:

- $\quad$ A Garantia de Qualidade minimiza os erros na planificação de tratamentos e na administração da dose ao paciente e, portanto, melhora os resultados da radioterapia, aumentando a taxa de remissões e diminuindo a taxa de complicações e reincidências;

- A Garantia de Qualidade permite a intercomparação consistente de resultados entre centros de radioterapia distintos, tanto em nível nacional como internacional, garantindo uma dosimetria e administração do tratamento de forma mais uniforme e exata;

- As características superiores dos equipamentos modernos de radioterapia não podem ser aproveitadas completamente sem um programa de garantia de qualidade, de forma que se alcance um elevado nível de exatidão e consistência. 
A Agência Internacional de Energia Atômica através do documento técnico TECDOC- $1151^{[8]}$ ressalta ainda que, aos argumentos da OMS, dever-se-ia adicionar outro, cuja importância se viu aumentada recentemente:

- Um programa de Garantia de Qualidade é o método mais simples e eficaz de reduzir acidentes em radioterapia.

Existem numerosas publicações que, em maior ou menor grau de profundidade, discutem diferentes aspectos da Garantia de Qualidade em radioterapia convencional, como o já citado TECDOC- $1151^{[8]}$ e o relatório do TG-40 ${ }^{[18]}$ da AAPM. A complexidade e o crescente uso dos sistemas de planejamento por computador fizeram com que o tema, por si só, merecesse publicações específicas, como o TG53 ${ }^{[19]}$ da AAPM, e o TRS 430 $0^{[20]}$ da IAEA, .e mais recentemente o TECDOC1540 ${ }^{[21]}$ da IAEA para aceitação e comissionamento desses sistemas. As novas técnicas de tratamento disponíveis, somadas à introdução de diversos acessórios e melhorias em todas as etapas do tratamento (sistemas de imobilização e localização, aquisição e tratamento de imagens, sistemas de planejamento, dosimetria e técnicas de irradiação) fazem com que grande parte da pesquisa e do desenvolvimento no controle de qualidade em radioterapia esteja em constante evolução, o que é observado no grande número de publicações existente atualmente.

As técnicas de radiocirurgia são caracterizadas pelo método particular com que atingem o objetivo de entregar a dose prescrita ao alvo com uma queda nítida na dose fora do volume alvo. As técnicas se baseiam em combinações específicas de rotações de cabeçote do acelerador e mesa ou cadeira ${ }^{[9,10]}$. Medidas de garantia de qualidade devem ser tomadas para garantir, por exemplo, que não há movimento inadvertido da mesa, além de prevenir colisões entre o cabeçote e a mesa, os suportes e o paciente. Uma técnica de imobilização rígida, usando fixação do crânio com pinos, não garante a ausência de movimento do paciente e dos órgãos. Por isso, uma possível movimentação do anel estereotáxico durante o procedimento radiocirúrgico, e a interferência ou artefato causado pelo sistema de imobilização nas imagens devem ser avaliados. De acordo com o relatório de Hartmann e colaboradores ${ }^{[9]}$, um programa de garantia de qualidade em radiocirurgia estereotáxica deve incluir testes para o sistema 
de localização e imobilização esterotáxico, testes dosimétricos e do sistema de planejamento, e testes da liberação do tratamento.

Os testes e medidas que compõem o processo de controle de qualidade devem ser específicos para cada tipo de unidade de tratamento (CLINAC, unidade de Co-60, unidade de ortovoltagem, simulador, equipamento de braquiterapia, etc.), estabelecendo dessa forma os procedimentos de medida ou técnicas a serem seguidos. Os níveis de tolerância estabelecidos durante os testes de aceite e comissionamento indicam quando uma mudança é inaceitável, e com isso conduz à adoção de correções rápidas a fim de garantir que o tratamento dos pacientes se dê de acordo com sua planificação. São os níveis de tolerância que vão assegurar uma alta qualidade nos tratamentos de radioterapia. No caso de haver desvios excessivos em relação aos níveis obtidos, a utilização do equipamento deve ser restrita àqueles tipos de tratamentos nos quais a influência destes desvios seja mínima.

\subsection{Simulação pelo Método de Monte Carlo}

Devido ao caráter probabilístico da interação da radiação com a matéria o método de Monte Carlo é adequado para descrever os processos que envolvem radiações ionizantes $^{[12] ~[22]}$, como, por exemplo, a descrição dos feixes produzidos pelos CLINACs. Os elementos da teoria de probabilidades formam o primeiro passo no entendimento do método de Monte Carlo.

Considerando a teoria de probabilidades, seja $f(x)$ a função densidade de probabilidade de um sistema (no caso unidimensional) cuja variável aleatória $x$ é contínua, então $f\left(x_{0}\right) d x$ descreve a probabilidade de observar um valor $x_{0}$ tal que $x<x_{0} \leq$ $x+d x$. Por exemplo, se $\mathrm{x}$ é a posição dentro de um meio material homogêneo $\mathrm{e}$ uniforme no qual um fóton sofre interação do tipo efeito fotoelétrico, $f(x)$ será sua função densidade de probabilidade, determinada pela seção de choque para a energia desse fóton no meio de interação ${ }^{[12][22]}$.

Em geral as principais características de uma função densidade de probabilidade (caso unidimensional) são:

$$
\text { - } \quad f(x) \geq 0
$$


já que probabilidades são positivas, por definição.

$$
\text { - } \quad \int_{a}^{b} f(x) d x=1
$$

com $x \in[a, b]$, ou seja, a função é normalizada e engloba todo o espaço amostral.

$$
-\infty<a<b<+\infty
$$

ou seja, $a$ e $b$ podem ser quaisquer números reais desde que $a$ seja menor que $b$.

A distribuição de probabilidades cumulativa associada com cada uma dessas funções de distribuição de probabilidades (caso unidimensional) é

$$
F(x)=\int_{a}^{x} f\left(x^{\prime}\right) d x^{\prime}
$$

com $x \in[a, b]$ e $F(x) \in[0,1]$. Como o próprio nome diz esta função inicialmente é zero e cresce até a unidade ao fim do seu intervalo de definição.

Pela sua definição, pode-se correlacionar a função distribuição de probabilidade cumulativa com números aleatórios, representados aqui por $\xi$ e distribuídos uniformemente no mesmo intervalo de definição.

$$
\xi=F(x)
$$

$\operatorname{com} \xi \in[0,1]$

Se $F(x)$ é uma função que pode ser invertida, em geral todas as funções o são numericamente ainda que não analiticamente, tem-se que:

$$
x=F^{-1}(\xi)
$$


A inversão, apesar de que em princípio sempre é possível, às vezes não é prática devido à sua complexidade matemática. Nestes casos, se recorre a outros métodos como o Método de Rejeição, ou a combinação entre estes métodos.

\section{Validade do Método de Monte Carlo}

Caso Bidimensional:

Para uma função $z(x, y)$ que governa um processo estocástico de duas variáveis, $x$ e $y$, o valor esperado de observar um evento $y$ é dado pela seguinte relação:

$$
<z(y)>=\int_{-\infty}^{\infty} z(x, y) \cdot f(x) d x
$$

A função densidade de probabilidade $f(x)$ está associada à variável $x$ unicamente e $<z(y)>$ é a probabilidade marginal de $y$.

A técnica convencional de Monte Carlo, dados $z(x, y)$ e $f(x)$, estima o valor esperado $<z(y)>$ em valores discretos de $y$. O valor estimado, representado por $z_{M C}$ é dado por:

$$
z_{M C}(y)=\frac{1}{N} \sum_{i=1}^{N} z\left(\xi_{i}, y\right)
$$

em que $\xi_{\imath}$ é uma amostra gerada de $f(x)$.

Pela lei dos Grandes Números este valor estimado converge ao valor esperado:

$$
\lim _{N \rightarrow \infty} z_{M C}(y)=<z(y)>
$$

Na prática, um valor $N$ grande de amostras é suficiente para obter resultados conclusivos, desde que haja convergência ao valor esperado. Como $N$ é dependente de cada problema, é conveniente continuar as simulações até que se alcance a precisão desejada, relacionada à variância dos dados. 


\section{Geração de Números Aleatórios}

Os códigos de Monte Carlo em geral utilizam números aleatórios de uma distribuição uniforme entre 0 e 1 . Várias técnicas de geração foram desenvolvidas nas últimas décadas ${ }^{[2]}{ }^{[22]}$. Um bom gerador não deve produzir artefatos, ou seja, deve prover uma distribuição aproximadamente aleatória. No entanto, para os computadores atuais as seqüências de números gerados possuem um período. $\mathrm{O}$ ideal é que este período seja virtualmente infinito, suficientemente grande para não produzir a reiniciação da seqüência durante as simulações práticas. O método mais utilizado atualmente é o chamado método de congruência linear multiplicativa ${ }^{[12]}{ }^{[22]}$. Dado um módulo $M$, um multiplicador $A$, e uma semente inicial $\xi_{o}$, os números aleatórios são gerados por:

$$
\xi_{i}=\left(A \cdot \xi_{i-1}+B\right) \cdot \bmod M
$$

em que B é uma constante.

\section{Transporte de Fótons}

Nos meios materiais em geral, fótons sofrem poucas interações, comparados às partículas carregadas. Com a velocidade crescente de processamento dos computadores, a simulação individual de cada interação pode ser feita levando em conta as seções de choque para a energia do fóton e o meio material onde se dá o processo. Mesmo assim, existem diversas técnicas para acelerar o processo e otimizar as simulações diminuindo, desta forma, as incertezas que podem ser avaliadas por métodos estatísticos.

\section{$\underline{\text { Transporte de Elétrons }}$}

Para elétrons (e partículas carregadas em geral) seria muito difícil dar seguimento a todas as interações físicas na maioria das aplicações práticas. Este aspecto motivou a criação de técnicas de simulação que combinam as interações individuais com interações de descrição macroscópica. A perda de energia durante a técnica de 
histórias condensadas (descrição macroscópica) varia de um código Monte Carlo a outro; mas em geral se dividem em duas classes ${ }^{[12,22]}$. Na Classe I, caso do MCNP4C, todas as interações se agrupam utilizando um conjunto pré-determinado de passos, ao final do qual as interações são selecionadas por amostragem aleatória. Na Classe II, caso do PENELOPE, somente colisões de tipo menor são agrupadas, nas quais a perda de energia ou a deflexão angular são pequenas, enquanto as de tipo maior, ou catastróficas, são selecionadas individualmente.

\subsubsection{Modelos de Simulação de CLINACs}

Os modelos de simulação de feixes de campos abertos de fótons provenientes dos CLINACs utilizam os componentes mostrados na Figura 4,e podem ser divididos em duas categorias. Na primeira categoria realiza-se a simulação completa do CLINAC e utilizam-se as partículas resultantes diretamente nos cálculos de dose e fluência em objetos simuladores, ou armazena-se a informação do espaço de fases dessas partículas, possivelmente em diversos níveis de planos do CLINAC para uso posterior. Os principais componentes do cabeçote do acelerador e que influenciam o feixe de radiação são um feixe de elétrons inicial, um alvo para a produção de raios $\mathrm{X}$ por bremsstrahlung, um colimador primário, um filtro aplainador, uma câmara de ionização monitora, um espelho para a luz de campo, os colimadores secundários (mandíbulas) X e Y, responsáveis pela colimação dos campos de tratamento, e eventuais outros acessórios, como um MLC ou os filtros físicos. 


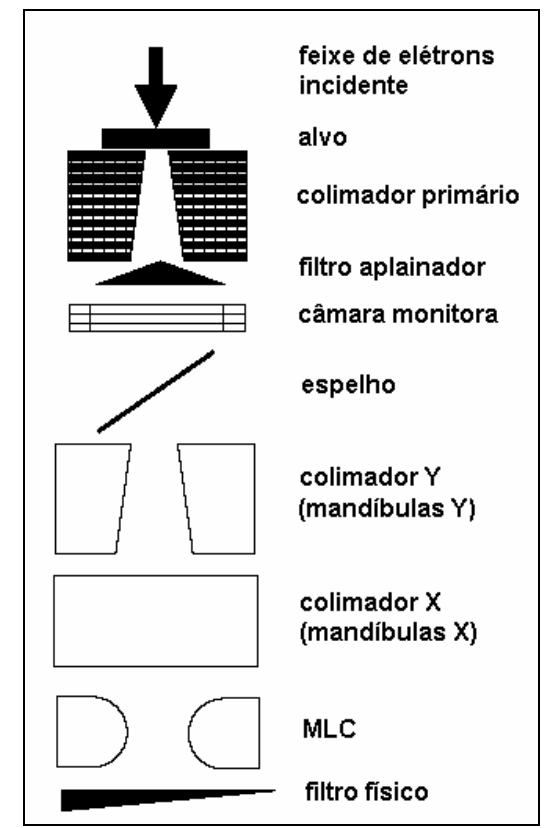

Figura 4: Esquema típico e componentes do modelo de um CLINAC para simulação pelo método de Monte Carlo.

Nessa primeira categoria, chamada de descrição por espaço de fases, armazena-se informação do tipo, energia, posição, direção, histórico prévio, etc, de milhões de partículas (fótons, elétrons, pósitrons), que pode ser amostrada para o transporte adicional das partículas no restante da geometria (o próprio CLINAC, um detector ou um objeto simulador). Se o plano do espaço de fases estiver situado na janela de saída do CLINAC, ele representa o CLINAC, tornando-se assim um CLINAC virtual $^{[13]}$.

Na segunda categoria, calculam-se as distribuições diferencias de energia, de posição ou angular, em qualquer combinação dessas, em histogramas de uma, duas ou três dimensões. Isto, em geral, é feito para diversas sub-fontes de partículas no CLINAC e é chamada de modelo de fonte. O CLINAC é, então, substituído por uma ou mais dessas sub-fontes que constituem o CLINAC virtual. A categoria que usa o modelo de fonte freqüentemente inicia-se a partir da informação coletada do espaço de fases.

Modelos de fonte inevitavelmente acarretam em aproximações, uma vez que eles condensam informações de partículas individuais em histogramas, enquanto que toda a informação das partículas individuais é preservada na categoria de espaço de fases. A correlação entre ângulo, energia e posição das partículas pode ser parcialmente 
ou completamente perdida dependendo do grau de complexidade do modelo de fonte. A desvantagem de trabalhar com o espaço de fases é a grande quantidade de informação que deve ser armazenada e a velocidade de amostragem, que é mais baixa durante a recuperação de toda essa informação. Além disso, aproximações no modelo do CLINAC resulta em incertezas na descrição por espaço de fases.

Tabela 1: Exemplo de arquivo contendo a descrição por espaço de fases das partículas de um feixe, simuladas pelo método de Monte Carlo. Cada linha da tabela corresponde a uma partícula, seu tipo ( 1 = elétron, 2 = fóton, $3=$ pósitron, etc), suas coordenadas de posição x, y e z (em cm), seus cossenos diretores u, v, e w, sua energia (em MeV), e seu peso estatístico.

\begin{tabular}{|c|c|c|c|c|c|c|c|c|}
\hline tipo & $\mathrm{x}$ & $\mathrm{y}$ & $\mathrm{z}$ & $\mathrm{u}$ & $\mathrm{v}$ & $\mathrm{w}$ & $\mathrm{E}$ & peso \\
\hline 2 & $-5,900$ & 0,681 & $-25,0$ & $-0,230$ & 0,025 & $-0,973$ & 3,929 & 1,0 \\
\hline 2 & $-4,607$ & 3,127 & $-25,0$ & $-0,181$ & 0,123 & $-0,976$ & 1,485 & 1,0 \\
\hline 2 & $-0,843$ & 2,550 & $-25,0$ & $-0,032$ & 0,100 & $-0,994$ & 0,580 & 1,0 \\
\hline 1 & $-1,896$ & 3,950 & $-25,0$ & $-0,075$ & 0,155 & $-0,985$ & 0,659 & 1,0 \\
\hline 2 & $-1,557$ & 3,028 & $-25,0$ & $-0,061$ & 0,122 & $-0,991$ & 4,462 & 1,0 \\
\hline 2 & 3,387 & 0,512 & $-25,0$ & 0,136 & 0,021 & $-0,991$ & 0,856 & 1,0 \\
\hline 2 & $-1,925$ & 3,564 & $-25,0$ & $-0,076$ & 0,141 & $-0,987$ & 4,998 & 1,0 \\
\hline 2 & 2,191 & 4,397 & $-25,0$ & 0,087 & 0,177 & $-0,980$ & 1,928 & 1,0 \\
\hline
\end{tabular}

\subsection{Colimadores Multi-lâminas - MLC}

Os colimadores multi-lâminas (MLC) ${ }^{[1,5,6,11]}$ estão tornando-se cada vez mais comuns nos serviços de Radioterapia e são responsáveis pela evolução recente dos sistemas de Radioterapia Conformada Tridimensional (3DCRT). Os MLCs, além de substituírem os blocos para conformação dos campos de radiação, permitem a realização de técnicas especiais de radioterapia como o arco dinâmico ${ }^{[23,24]}$ e a radioterapia de intensidade modulada - IMRT ${ }^{[5]}$. Os benefícios e a complexidade advindos dessa capacidade têm levado à criação de novos protocolos de tratamento, fornecendo potencial para um controle maior das várias patologias tratadas.

As lâminas do MLC são controladas por computador e podem se movimentar até uma posição pré-definida, bloqueando a radiação em uma determinada região. Existem vários modelos de colimadores multi-lâminas, como os exemplos da 
Figura 5, com um maior ou menor número de lâminas e com larguras diferentes para se obter um grau de conformação maior ou menor.
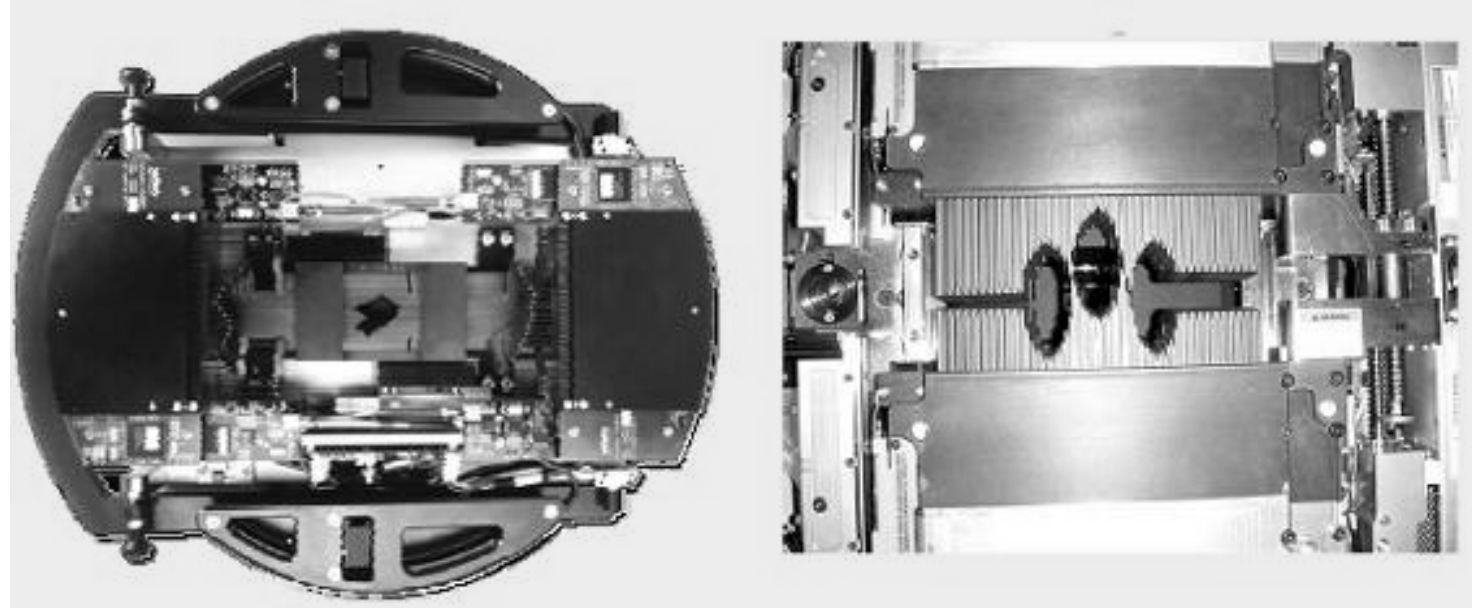

Figura 5: Vista inferior de sistemas de colimadores multi-lâminas: (a) micro-colimador m3 da BrainLab com 52 lâminas, à esquerda , e (b) colimador Millennium da Varian com 120 lâminas, à direita.

Pelo fato do MLC ser um sistema adicional ao acelerador, considerado assim como uma colimação terciária, e que modifica a geometria do feixe, ele requer um controle de qualidade rigoroso, para o qual devem ser elaborados testes rotineiros, e o conhecimento do impacto causado na dosimetria dos campos produzidos com esse sistema.

Na caracterização de um MLC, os seguintes parâmetros são importantes ${ }^{[7,25]}$ :

- número de pares de lâminas;

- largura das lâminas (geralmente referenciados ao valor projetado no isocentro);

- tamanho de campo máximo;

- distância máxima de ultrapassagem com relação ao eixo central.

Na Figura 6 encontra-se um diagrama de uma lâmina e a denominação das suas especificações. 


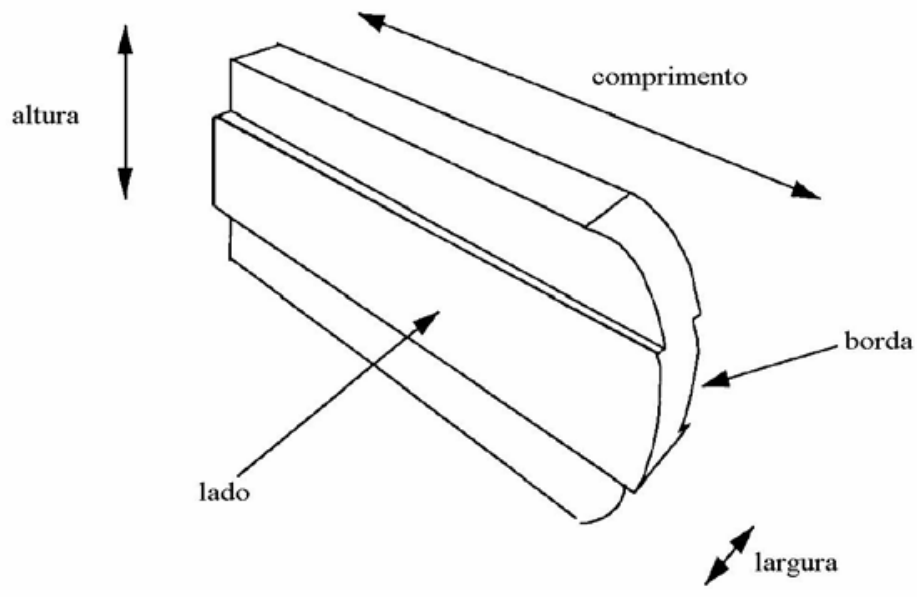

Figura 6. Esquema de uma lâmina que forma parte de um sistema MLC e a denominação das suas especificações ${ }^{[25]}$.

Os lados das lâminas, de todo sistema de MLC, são projetados para ter uma espécie de encaixe entre elas. Este projeto é conhecido como lingüeta - vão (do inglês tongue and groove), e é feito para minimizar a radiação transmitida entre lâminas adjacentes. Alguns exemplos de projeto lingüeta-vão estão ilustrados na Figura 7.

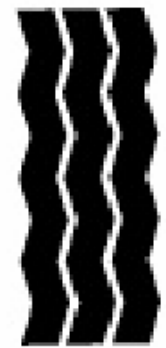

$\mathrm{GE}$

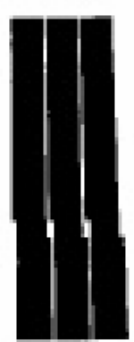

Scanditronix

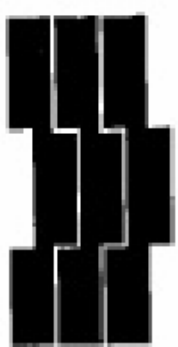

Varian

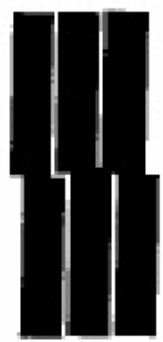

Philips

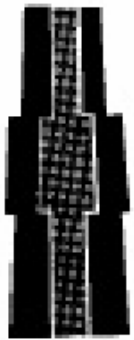

Siemens

Figura 7: Vista frontal de vários sistemas comerciais de MLC, com o respectivo projeto de encaixe lingüeta - vão (adaptado de Das e colaboradores ${ }^{[26]}$ ).

\subsubsection{Técnicas de Tratamento com MLC}

Os tratamentos em radioterapia tridimensional de grande exatidão são realizados por meio da utilização de diversos acessórios para posicionamento do paciente e sua localização no sistema de coordenadas conhecido ${ }^{[11]}$. Além dos procedimentos convencionais de simulação e planejamento, existem técnicas especiais 
de posicionamento e localização, nas quais são utilizados acessórios, como o arco estereotáxico $^{[1,9,10,11]}$, os sistemas de fixação por máscara termoplástica e os marcadores corporais $^{[11,17]}$, estes utilizados nos sistemas de detecção por vídeo ou infravermelho. Procedimentos mais recentes utilizam imagens de raios- $\mathrm{X}$, combinadas com marcadores externos, marcadores internos ou referências ósseas, em tempo real, para garantir o posicionamento e localização corretos.

Nas técnicas que utilizam o CLINAC equipado com um MLC e sistema de planejamento tridimensional, há a possibilidade de liberar doses por radiação altamente conformadas em uma ou múltiplas sessões de tratamento, através das metodologias $^{[1,5,11,17]}$ a serem descritas a seguir.

\section{Campos Conformados}

Os campos conformados utilizados na modalidade tridimensional são campos em que a configuração das lâminas segue a projeção do volume alvo considerando sua forma tridimensional. Essa configuração de lâminas do MLC é mantida fixa durante a irradiação de modo a bloquear as regiões fora do volume de tratamento, reduzindo a dose nos tecidos e órgãos sadios. Em cada campo de tratamento o cabeçote do acelerador e a mesa também permanecem fixos numa mesma posição, como representado na Figura 8. 


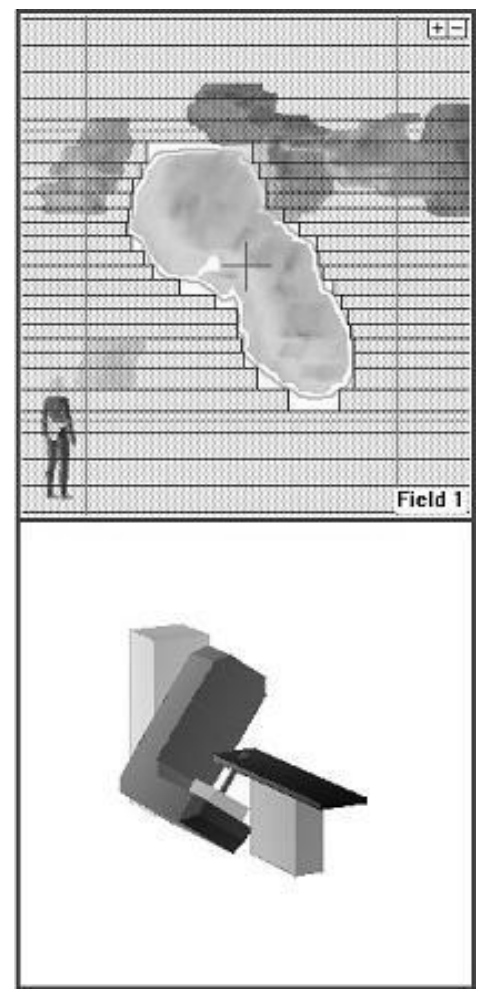

Figura 8: "Visão do feixe” de um campo conformado pelo MLC, acima, e posição da mesa de tratamento e cabeçote do acelerador, abaixo.

\section{- $\quad$ Arcos de conformação fixa}

Os arcos de conformação fixa são obtidos por meio da movimentação em arco do cabeçote do acelerador durante a irradiação. Para cada arco, no entanto, o MLC é mantido em uma mesma configuração fixa de colimação, que representa a média das projeções tridimensionais da lesão tratada. Na Figura 9 está representada a seqüência de tratamento de apenas um arco de conformação fixa: na parte superior são mostradas as projeções do volume alvo a ser tratado e o contorno do campo de tratamento gerado pela configuração das lâminas do MLC. Com a variação dos ângulos de cabeçote e mesa do acelerador, representados na parte inferior da Figura 9, a projeção tridimensional do volume alvo irregular também varia, não coincidindo exatamente com a configuração do MLC em todas as combinações de ângulos. No entanto, a utilização de uma configuração média fornece resultados de planejamento satisfatórios para muitos casos clínicos. 


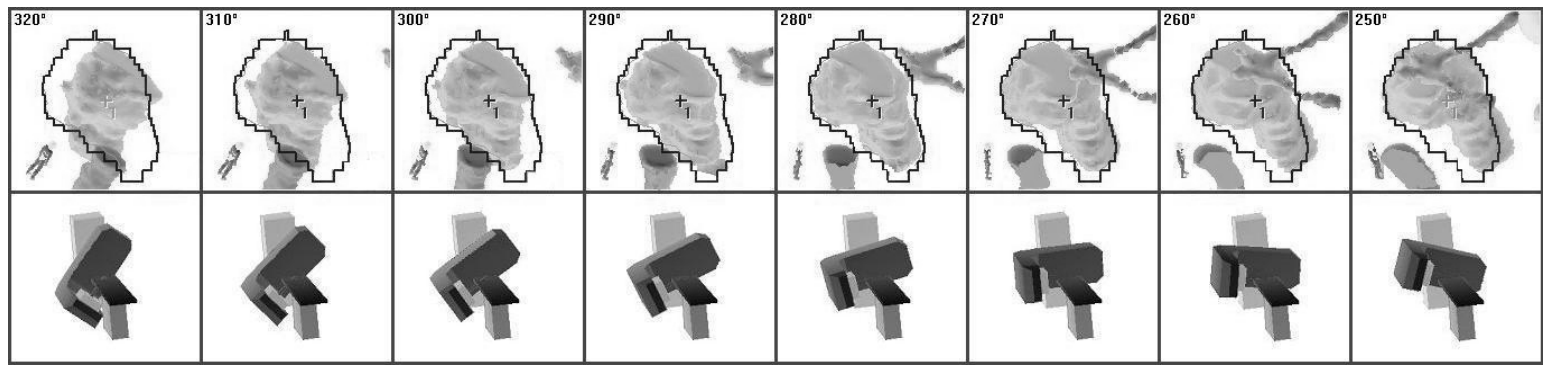

Figura 9: "Visões do feixe" das entradas de um arco conformado fixo, acima, e correspondentes posições de mesa de tratamento e do cabeçote do acelerador, abaixo.

Neste caso, a mesma configuração é mantida independente da movimentação do cabeçote do acelerador, e é escolhida como a média das projeções tridimensionais.

- Arcos de conformação dinâmica

Estes arcos, também referidos simplesmente como arcos dinâmicos, por meio do MLC (ou ainda terapia por arco de intensidade modulada - IMAT). No arco dinâmico, durante a movimentação em arco do cabeçote do acelerador ocorre uma adaptação da colimação por meio da movimentação das lâminas durante a irradiação, como pode ser visualizado no esquema da Figura 10.

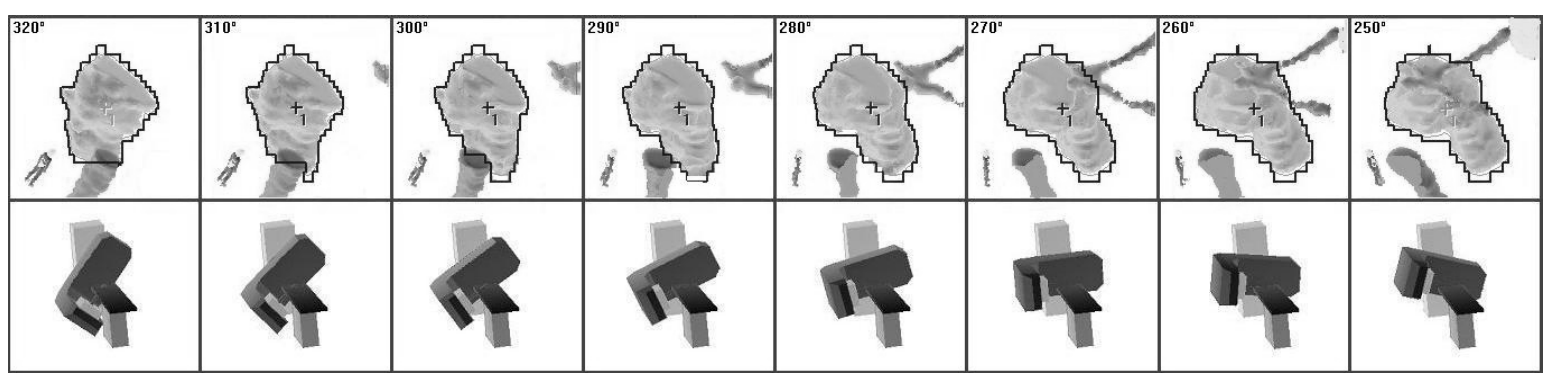

Figura 10: "Visões do feixe" das entradas de um arco dinâmico, acima, e correspondentes posições de mesa de tratamento e do cabeçote do acelerador, abaixo. A conformação pelas lâminas é adaptada de acordo com as projeções tridimensionais da lesão alvo.

Na Figura 10 está representada a seqüência de tratamento de apenas um arco de conformação dinâmica para o mesmo volume alvo e mesma combinação de ângulos de cabeçote e mesa de acelerador da Figura 9. Neste caso, porém, o contorno do campo de tratamento gerado pela configuração das lâminas do MLC coincide melhor com a projeção tridimensional do volume alvo em cada combinação de ângulos, resultando em uma conformação do volume alvo superior à obtida pela técnica anterior. 
- Campos de IMRT segmentados

Um campo com modulação de intensidade do feixe do tipo segmentada (“step and shoot” IMRT), consiste de uma sobreposição de pequenos segmentos de campo, ou sub-campos, de configuração fixa. Nas técnicas de IMRT descritas aqui, as configurações de mesa de tratamento e cabeçote do acelerador permanecem fixas durante a irradiação de cada campo.

Na Figura 11 mostra-se uma seqüência de nove segmentos de campo que formam um único campo de intensidade modulada para a mesma projeção do volume alvo do caso planejado com campo conformado fixo.

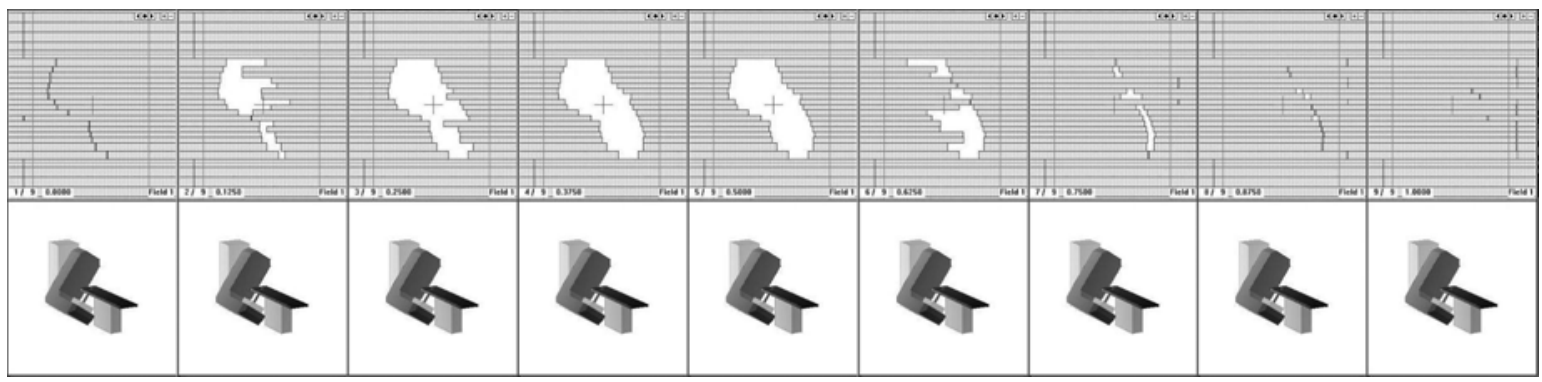

Figura 11: "Visões do feixe" de nove segmentos de um único campo de intensidade modulada para a mesma projeção do volume alvo do caso conformado (Figura 8). Na parte inferior estão representadas as configurações de mesa de tratamento e cabeçote do acelerador, que é sempre a mesma para um campo de intensidade modulada.

A segmentação do campo é realizada por cálculo computacional no sistema de planejamento com base em parâmetros iniciais definidos pelo usuário, tais como os ângulos de cabeçote e mesa de tratamento, o número de segmentos e os níveis de proteção a órgãos críticos e de cobertura da lesão alvo.

Como resultado da sobreposição dos diversos segmentos de campo gera-se um padrão de intensidades de radiação não uniforme, representado em escala de cinzas na Figura 12. Regiões da lesão menos irradiadas por um campo são compensadas em outro campo cuja cobertura não afeta órgãos críticos.

A irradiação ocorre em cada segmento do campo com as lâminas do MLC fixas em uma posição e é encerrada durante a movimentação das lâminas ao formar o próximo segmento, quando então se inicia um novo ciclo de irradiação. 


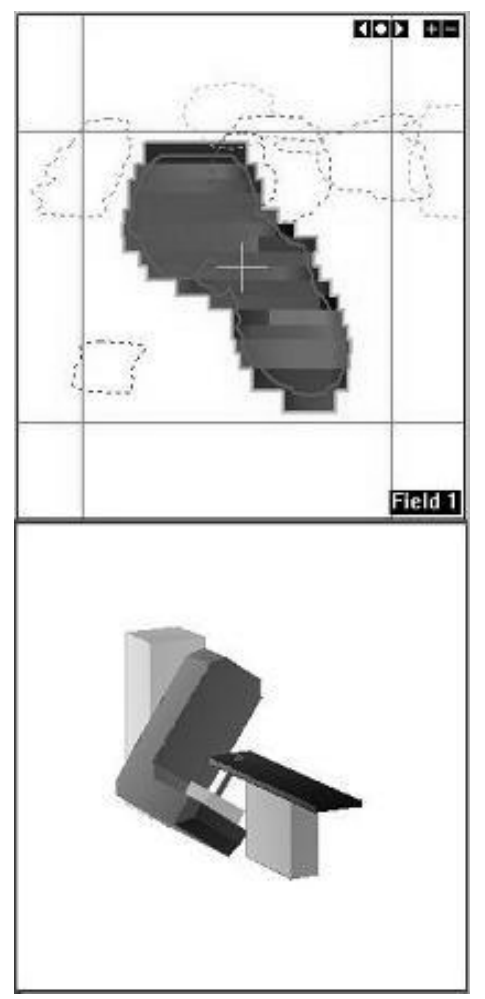

Figura 12: Na parte superior mostra-se um esquema com o padrão de intensidades resultante da composição dos diversos sub-campos. Abaixo está representado um esquema do acelerador com a posição relativa da mesa de tratamento com a disposição do cabeçote do acelerador para o campo definido acima.

- $\quad$ Campos de IMRT dinâmicos

Um campo com modulação de intensidade do feixe do tipo dinâmica (“dynamic IMRT” ou “sliding window”) consiste de uma sobreposição dinâmica de configurações de colimação para cada posição fixa do cabeçote do acelerador, durante a irradiação.

Como no caso dos campos de IMRT segmentados a movimentação das lâminas do MLC é calculada no sistema de planejamento com base nos parâmetros iniciais gerando um padrão de intensidades de radiação não uniforme. Neste caso, porém, não ocorre o efeito liga-desliga do feixe de radiação. A irradiação é contínua mesmo durante a movimentação das lâminas do MLC. Pode-se pensar como sendo o caso em que há infinitos segmentos de campo sobrepostos para formar um campo de intensidade modulada. Apesar das poucas diferenças para o caso dos campos segmentados, os diferentes parâmetros que devem ser levados em conta devido à movimentação das lâminas produzem implicações dosimétricas significativas, necessitando controles diferentes em cada uma das técnicas. 


\subsection{Avaliação de Incertezas}

A qualidade dos resultados experimentais seja em dosimetria como em diversas outras áreas da física, deve ter uma indicação de sua confiabilidade avaliada quantitativamente. Essa indicação permite que resultados de medições, entre eles mesmos ou com valores de referência, sejam comparados. Atualmente a indicação mais aceita internacionalmente é expressa pela incerteza da medição. É importante que a metodologia com que a incerteza é avaliada e expressa seja de caráter universal, e que a grandeza real usada para expressar a incerteza seja internamente consistente (derivável de seus componentes, independentemente de como estes estejam agrupados, ou de sua decomposição em sub-componentes) e transferível (permitindo usar a incerteza de cada componente na avaliação da incerteza do resultado final).

Neste trabalho, que se destina a conduzir uma pesquisa aplicada, é importante que se cumpram as características necessárias de universalidade, consistência e capacidade de transferência da qualidade dos resultados. Espera-se com isso que se faça uma ponte entre a comunidade acadêmica, os laboratórios de calibração de padrões e instrumentos, as leis e regulamentos nacionais e os usuários finais, permitindo que a execução dos ensaios e da prática clínica mantenha a rastreabilidade aos padrões nacionais e internacionais. Serão seguidas as recomendações do Guia para a Expressão da Incerteza de Medição ${ }^{[27]}$ aceito pelas principais associações técnicas de normas e metrologia nacionais (ABNT, INMETRO, SBM) e internacionais (IEC).

\subsubsection{Estimativa da Incerteza em Monte Carlo}

Assumindo que $x$ é a quantidade que se calcula por meio da simulação por Monte Carlo ${ }^{[22]}$, por exemplo, uma variável ou simplesmente um "tally”. O método convencional de estimar a incerteza ocorre como a seguir:

1. Assume-se que o cálculo foi feito a partir de $N$ histórias de partículas.

2. Armazena-se o valor computado para $x_{i}$ e para o seu quadrado $x_{i}^{2}$ para a $i$ ésima história, onde $1 \leq i \leq N$.

3. Calcula-se o valor médio de $x$ : 


$$
\bar{x}=\frac{1}{N} \sum_{i=1}^{N} x_{i}
$$

4. $\quad$ Estima-se a variância associada com a distribuição de $x_{i}$ :

$$
s_{x}^{2}=\frac{1}{N-1} \sum_{i=1}^{n}\left(x_{i}-\bar{x}\right)^{2}=\frac{1}{N-1} \sum_{i=1}^{n}\left(x_{i}^{2}-\bar{x}^{2}\right)
$$

5. A variância estimada de $\bar{x}$ é a variância padrão da média:

$$
s_{\bar{x}}^{2}=\frac{s_{x}^{2}}{N}
$$

que está relacionada ao erro que se busca e não a dispersão da distribuição de $x_{i}$.

6. Informa-se o resultado final como $x=\bar{x} \pm s_{\bar{x}}$.

A média e variância verdadeiras não estão disponíveis para quem está estimando a quantidade desejada, têm-se apenas as suas estimativas. O denominador ( $N$ 1) da equação 15 é apresentado freqüentemente como um argumento de "graus de liberdade”. No entanto, esse fator pode ser derivado considerando a relação entre a variância amostrada e a variância verdadeira.

\section{$\underline{\text { Combinação de erros de diferentes rodadas de cálculo }}^{[22]}$.}

Para $m$ rodadas independentes de Monte Carlo, pode-se derivar a seguinte relação:

$$
\bar{x}=\sum_{k=1}^{m}\left(\frac{N_{k}}{N}\right) \bar{x}_{k}
$$

em que $\bar{x}_{k}$ é o valor de $\bar{x}$ e $N_{k}$ é o número de histórias, para a $k$-ésima rodada.

O número total de histórias é dado por: 


$$
N=\sum_{k=1}^{m} N_{k}
$$

Assumindo uma propagação de $1^{\mathrm{a}}$ ordem dos erros independentes, também é possível demonstrar que:

$$
s_{\bar{x}}^{2}=\sum_{k=1}^{m}\left(\frac{N_{k}}{N}\right)^{2} s_{\bar{x}_{k}}^{2}
$$

em que $s_{\bar{x}_{k}}^{2}$ é a variância estimada de $\bar{x}_{k}$.

\subsubsection{Eficiência de Cálculo e Redução de Variâncias}

A eficiência de cálculo em Monte Carlo pode ser representada pela seguinte equação:

$$
\varepsilon=\frac{1}{s^{2} T}
$$

em que $s^{2}$ é a variância da amostra de dados obtidos e $T$ é o tempo de cálculo.

Por outro lado, o tempo de cálculo pode ser decomposto da seguinte forma:

$$
T_{M C}=N_{H}\left(T_{0}+\frac{\alpha+\beta}{\Delta}\right)
$$

em que $N_{H}$ é o número de histórias simuladas, $T_{0}$ é o tempo dependente unicamente da física do processo, $\alpha$ é um fator que descreve a complexidade geométrica, $\beta$ depende do número de fronteiras atravessadas pela partícula e $\Delta$ é a dimensão geométrica para a resolução desejada.

Alguns desses parâmetros podem ser controlados pelo usuário ao definir o modelo de cálculo. A escolha dos parâmetros deve ser cautelosa e adequada para permitir o aumento da eficiência de cálculo e a diminuição da variância associada à amostra de dados sem produzir distorções nos resultados físicos. 


\section{$\underline{\text { Redução de Variâncias }}$}

Nos processos estocásticos, como na física de radiações, as incertezas são avaliadas por métodos estatísticos (normalmente chamadas de Tipo A). Em Monte Carlo criaram-se técnicas que permitem reduzir essas incertezas. O uso de técnicas de redução de variâncias seja pela manipulação da natureza física dos processos envolvidos (como interações forçadas, roleta russa), como pela utilização de resultados prévios (como a amostragem correlacionada) permite diminuir a incerteza estatística relacionada aos cálculos provenientes de simulações. A teoria dessas técnicas mais comuns pode ser encontrada, por exemplo, no trabalho de Bielajew ${ }^{[22]}$, mas também de forma mais específica nos manuais de cada código de simulação. 


\section{REVISÃO BIBLIOGRÁFICA}

A radioterapia teve um grande salto tecnológico nos últimos anos com a introdução comercial dos colimadores multi-lâminas nos aceleradores lineares clínicos. Esse fato, combinado ao avanço nas técnicas de imagem tomográficas e na capacidade de processamento dos computadores, permitiu estabelecer a radioterapia tridimensional conformada. Na radioterapia tridimensional conformada ${ }^{[1]}$ toda a cadeia de tratamento é baseada na localização tridimensional do volume de tratamento e dos órgãos circundantes, no planejamento do tratamento com cálculo tridimensional e nas técnicas de liberação de radiação tridimensionais.

A radiocirurgia e a radioterapia esterotáxica ${ }^{[1,5,11]}$ com aceleradores lineares equipados com colimadores micro multi-lâminas se desenvolveu naturalmente nesse contexto, fazendo uso dos avanços mais recentes e combinando os procedimentos e técnicas de localização estereotáxicos utilizados na radiocirurgia. Nesses casos, com o uso de técnicas complexas de irradiação, como a do arco dinâmico, a radioterapia de intensidade modulada e a radioterapia conformada tridimensional, torna-se ainda mais importante o conhecimento dos campos estreitos de radiação provenientes desses equipamentos.

Paralelamente ao avanço das técnicas de tratamento ocorreu, e continua ocorrendo, o desenvolvimento de detectores e sistemas dosimétricos de qualidade superior que permitem avaliar o comportamento dos feixes de radiação e inferir as características dosimétricas relevantes em cada caso. Dentre os equipamentos adequados para a dosimetria dos feixes de radiocirurgia e radioterapia estereotáxica se encontram os sistemas que utilizam as câmaras de ionização de volume pequeno, os diodos dosimétricos, os detectores de diamante e os filmes dosimétricos.

No que diz respeito a este trabalho, os mesmos modelos de dosímetros haviam sido usados por outros pesquisadores, seja para avaliar a dosimetria dos aceleradores lineares, como também para realizar a comparação da resposta entre eles. Como exemplo, estão os trabalhos de Bucciolini e colaboradores $^{[28]}$ e Stasi e colaboradores $^{[29]}$.

Bucciolini e colaboradores ${ }^{[28]}$ compararam a resposta dosimétrica do detector de diamante com uma câmara de ionização $\mathrm{RK}^{\mathrm{TM}}$ e com diodo Scanditronix em condições de dosimetria de não-referência para feixes de fótons de energias diferentes 
(6 e $25 \mathrm{MV}$ ) e tamanhos de campo de $2,6 \mathrm{~cm} \times 2,6 \mathrm{~cm}$ a $10 \mathrm{~cm} \times 10 \mathrm{~cm}$. A não equivalência do tecido para o feixe de fótons de 6MV fizeram com que as medidas com diodo superestimaram levemente as doses na região mais profunda. Os valores das medidas de penumbra e tamanhos de campo, feitas com os diversos detectores, apresentaram boa concordância entre si, porém com uma super-estimativa sistemática das medidas com a câmara RK.

Stasi e colaboradores ${ }^{[29]}$ estudaram o comportamento de diversas microcâmaras de ionização em campos pequenos de radioterapia de intensidade modulada provenientes de um acelerador Varian $600 \mathrm{C} / \mathrm{D}^{\mathrm{TM}}$ equipado com colimador multi-lâminas de 120 lâminas. Os resultados indicaram que para campos muito pequenos como, por exemplo, o campo de $1 \mathrm{~cm} \mathrm{x} 1 \mathrm{~cm}$, apenas a microcâmara $\mathrm{A} 16^{\mathrm{TM}}$, com volume de $0,007 \mathrm{~cm}^{3}$, concordou bem com as medidas de Fatores Relativos de Dose feitas com o detector de diamante. No entanto as demais microcâmaras de volume maior forneceram resultados satisfatórios a partir do campo $2 \mathrm{~cm}$ x $2 \mathrm{~cm}$.

Devido ao caráter probabilístico da interação da radiação com a matéria o método de Monte Carlo ${ }^{[12]}$ é adequado para descrever os processos que envolvem radiações ionizantes. Em Física Médica, o método se aplica em todas as áreas nas quais se utiliza este tipo de radiação, seja nas técnicas de imagem, como o diagnóstico por raios-X e seus derivados (tomografia, mamografia, etc.), na Medicina Nuclear, ou na Radioterapia. Esta última em suas duas vertentes, a Braquiterapia, que utiliza fontes radioativas posicionadas próximas ou em contato com a região de tratamento, e a Teleterapia com feixes de fótons, elétrons, prótons e outros tipos de radiação. Outro importante campo de aplicação deste método é a proteção radiológica.

Andreo $^{[12]}$ reviu o papel das técnicas de Monte Carlo em física médica, podendo levar em conta o transporte das partículas secundárias e a falta de equilíbrio eletrônico presente em campos estreitos. Foram abordados alguns aspectos práticos, como a geração de números aleatórios, o transporte de fótons e elétrons, seguido da apresentação de alguns códigos de simulação existentes até então, e a aplicação na física médica. Na parte de radioterapia são mostradas as técnicas para simular os equipamentos de teleterapia, os dosímetros e as medidas em objeto simulador. Até então (1991), não havia a utilização comercial dos colimadores multilâminas e das possíveis técnicas de tratamento advindas dessa nova tecnologia. 
Durante os últimos anos, em particular em teleterapia, que é o objetivo deste trabalho, foram realizados diversos estudos utilizando o método de Monte Carlo para descrever as principais características dos feixes produzidos por aceleradores lineares e equipamentos de cobalto-terapia.

Lovelock e colaboradores $^{[30]}$ apresentaram um método modular para descrever os feixes de fótons de CLINACs. A informação das partículas cruzando um plano pré-definido podia ser armazenada em um arquivo de espaço de fases. O método foi explorado posteriormente por Libby e colaboradores ${ }^{[31]}$ para obter a informação detalhada e validar os modelos de CLINACs por Monte Carlo com um critério de aceitação de $\pm 1 \%$ de discrepância, se comparado a valores experimentais, para curvas de distribuição de dose em profundidade, e de $\pm 0,1 \mathrm{~cm}$ de diferença na posição dos pontos, para os perfis de dose em profundidade, a uma mesma dose. O método de Monte Carlo também foi utilizado por Siebers e colaboradores ${ }^{[32]}$ para modelar o MLC Millenium da Varian de 120 lâminas. Os MLCs da Varian também foram modelados

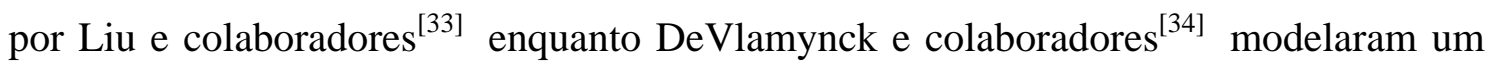
Linac Elekta SL25 com colimador multi-lâminas. Sánchez-Doblado e colaboradores ${ }^{[35]}$ avaliaram as relações de poderes de frenagem usadas na resposta das câmaras de ionização para dosimetria absoluta dos campos estreitos de radiocirurgia e IMRT, as simulações por Monte Carlo indicaram que as relações concordam dentro de $\pm 0,3 \%$ para os feixes estreitos de $6 \mathrm{MV}$, conformados por um colimador multi-lâminas.

Verhaegen e Seuntjens ${ }^{[13]}$ revisaram a modelagem por Monte Carlo dos feixes de fótons para radioterapia externa, reforçando o papel crescente das simulações por Monte Carlo como ferramenta adicional na radioterapia moderna. Um dos diversos temas indicados que merecem pesquisas adicionais é a utilização do método para o estudo dos colimadores multi-lâminas, especialmente para a liberação de tratamentos por campos pequenos, tais como os providos pela radiocirurgia conformada.

Uma descrição das características físicas detalhadas do colimador micro multi-lâminas $\mathrm{m} 3^{\mathrm{TM}}$ é dada por Cosgrove e colaboradores ${ }^{[36]}$ e Xia e colaboradores ${ }^{[37]}$, porém baseadas somente em medidas experimentais e sem investigar detalhadamente as implicações provocadas nos meios irradiados. O trabalho de simulação por Monte Carlo do colimador multi-lâminas $\mathrm{m}^{\mathrm{TM}}$, da BrainLab, realizado por Aaronson e colaboradores $^{[38]}$ utiliza uma modelagem simplificada desse colimador, sem descrever o 
projeto de encaixe do tipo lingüeta-vão entre lâminas. Com isso, não se investigaram as conseqüências dosimétricas desse projeto, como as diferentes componentes de transmissão e o efeito lingüeta-vão desse colimador, indicando assim, que faltam estudos adicionais. 


\section{OBJETIVOS}

O objetivo geral deste trabalho é contribuir para a segurança e o melhor conhecimento dosimétrico das técnicas de radioterapia e radiocirurgia estereotáxica tridimensionais com colimador micro multi-lâminas. O trabalho foi desenvolvido diretamente no Hospital Israelita Albert Einstein - HIAE, onde foram realizadas as medidas necessárias e a aplicação da metodologia abordada, contribuindo com o processo de garantia da qualidade dos tratamentos que utilizam esse tipo de colimador.

Os objetivos específicos podem ser divididos em três. O primeiro deles foi o de estabelecer dados dosimétricos experimentais de referência, e atualizados, de um CLINAC 600C (Varian) em configurações de campos regulares. Tais dados foram levantados por ocasião do comissionamento dos algoritmos para cálculo de dose em pacientes, utilizado no sistema de planejamento computadorizado Eclipse $^{\mathrm{TM}}$ (versão 6.5).

O segundo objetivo específico foi criar um modelo computacional do CLINAC, utilizando o Método de Monte Carlo, e com isso, determinar o seu espectro de fótons e permitir cálculos da dose absorvida na água por meio da simulação dos feixes de radiação.

O terceiro objetivo específico foi criar um modelo computacional do colimador micro multi-lâminas - mMLC $\mathrm{m}^{\mathrm{TM}}$ que é anexado como colimação adicional ao CLINAC 600C, também utilizando o Método de Monte Carlo. O modelo, além de caracterizar dosimetricamente o mMLC, possibilita a avaliação da dose produzida pelos campos estreitos de radiocirurgia e radioterapia estereotáxica conformadas. 


\section{MATERIAIS E MÉTODOS}

\subsection{Dosimetria do Acelerador Linear - Campos Abertos}

\subsubsection{Caracterização Dosimétrica do CLINAC}

O CLINAC 600C do Hospital Israelita Albert Einstein - HIAE, mostrado na Figura 13, produz feixes de fótons de 6MV para radioterapia externa.

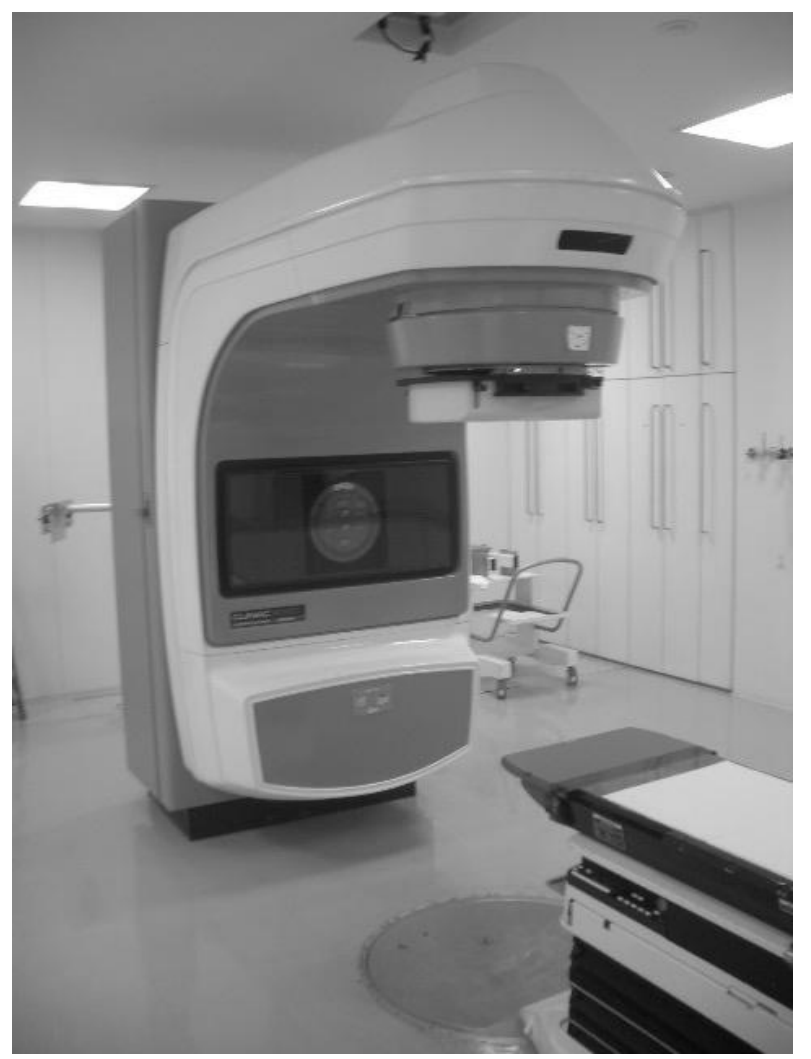

Figura 13: Acelerador Linear Clínico Varian 600C do Hospital Israelita Albert Einstein.

A caracterização dosimétrica do CLINAC foi feita por meio de medidas de distribuições de dose em água, realizadas em um tanque de varredura automática RFA300 $^{\mathrm{TM}}$ de $50 \mathrm{~cm}$ x $50 \mathrm{~cm}$ x $50 \mathrm{~cm}$ e seu eletrômetro RFA ${ }^{\mathrm{TM}}$ (Scanditronix). Para essas medidas foram utilizados uma câmara de ionização cilíndrica $\mathrm{RK}^{\mathrm{TM}}$ (Scanditronix), com volume sensível de $0,12 \mathrm{~cm}^{3}$ e raio da cavidade de $2 \mathrm{~mm}$, e um conjunto de diodos detectores de silício para fótons $\mathrm{PFD}^{3 \mathrm{G}}$ e $\mathrm{RFD}^{3 \mathrm{G}}$, com espessura efetiva de $60 \mu \mathrm{m}$ e diâmetro de área efetiva de 2,0 mm, todos da Scanditronix. As medidas seguem os novos padrões de calibração baseados na dose absorvida em água 
preconizados pelo protocolo de dosimetria da IAEA ${ }^{[16]}$. Foram obtidas as curvas de Porcentagem de Dose Profunda - PDP, os perfis laterais de dose em 5 profundidades (de $1,5 \mathrm{~cm}$ a $30 \mathrm{~cm}$ ) para campos de $2 \mathrm{~cm} \times 2 \mathrm{~cm}$ a $40 \mathrm{~cm}$ x $40 \mathrm{~cm}$ e os perfis diagonais do campo máximo. Também foram medidos os Fatores Relativos de Dose a $5 \mathrm{~cm}$ de profundidade (ou Fatores de Output - OF), de campos quadrados e retangulares. A conversão das curvas de PDP em curvas de Razão Tecido Máximo -TMR, bem descrita por Attix ${ }^{[2]}$, Johns e Cunningham ${ }^{[3]}$, Khan $^{[4]}$ e Podgorsak $^{[11]}$, foi realizada diretamente no programa RFW (Scanditronix) que utiliza valores de Fator de Espalhamento de Pico - PSF (do inglês Peak Scatter Factor) do BJR25 ${ }^{[39]}$ As medidas foram validadas por meio de comparações entre diferentes detectores e com valores de referência, como as curvas do comissionamento anterior (do ano 1999, após troca de tubo) e os valores do BJR25 $5^{[39]}$.

\subsection{Simulação do CLINAC}

Neste trabalho, a maior parte das simulações do CLINAC foi realizada utilizando o código de simulação PENELOPE versão de 2005. Uma simulação adicional foi feita com o código MCNP4C, permitindo confirmar e validar o espectro do feixe de fótons inicial do CLINAC. Ambos os códigos são adequados para a simulação do transporte acoplado de fótons e elétrons e têm sido usados freqüentemente nas pesquisas aplicadas em medicina ${ }^{[12,13]}$.

Devido às características individuais de cada equipamento, as simulações são personalizadas de acordo com os planos originais e recomendações do fabricante, de modo a reproduzir com a maior exatidão possível, a configuração original.

Os dados, como forma geométrica, disposição espacial e composição química, dos componentes do CLINAC 600C estão contidos no manual do fabricante ${ }^{[40]}$ , porém não são divulgados aqui por tratar-se de informação confidencial da empresa. Além disso, a informação é simplificada e limitada à finalidade exclusiva de simulação do acelerador, portanto não contém detalhes das peças originais. Entre os componentes simulados de acordo as recomendações se encontram: 
- $\quad$ Alvo para produção de raios X

- $\quad$ Colimador Primário,

- $\quad$ Filtro Aplainador,

- $\quad$ Câmara de Ionização,

- $\quad$ Disco de Blindagem Secundário,

- $\quad$ Espelho da Luz de Campo,

- $\quad$ Colimadores Convencionais X e Y,

Para fins de simulação, a geometria do acelerador foi dividida em três etapas. Na primeira etapa são descritos os componentes fixos do cabeçote e que são os principais responsáveis pela fluência e pelo espectro do feixe de radiação. Os componentes dominantes, com relação ao espectro de energia, são o alvo, para produção de raios-X, e o filtro aplainador. Os resultados dessa fase podem ser utilizados em diversas configurações de campo nas etapas subseqüentes. Na segunda etapa, são descritos os componentes móveis responsáveis pela colimação dos feixes de tratamento. Na terceira etapa, que poderia estar incluída na anterior, é descrita a região a irradiar, seja o paciente ou, mais comumente os objetos simuladores para estudos dosimétricos. Além dos componentes indicados foram criados dois planos virtuais para armazenamento da descrição por espaço de fases das "partículas” resultantes das simulações, um plano localizado abaixo dos componentes fixos do acelerador e outro localizado abaixo dos componentes móveis (fase de colimação).

Na primeira etapa de simulação o programa desenvolvido realizava o transporte da radiação pelos componentes fixos do acelerador (desde o alvo até o espelho para a luz de campo) resultando em uma descrição por espaço de fases a 25,0cm de distância do alvo, com a qual se extrai o espectro de fótons. Esses resultados, bem como a comparação por dois códigos computacionais ${ }^{[41]}$ podem ser considerados como aspectos inovadores do trabalho, já que não há informação publicada na literatura para este modelo de CLINAC. A segunda etapa de simulação, contendo a parte móvel composta pelos colimadores convencionais secundários (X e Y), foi realizada apenas com o código PENELOPE, podendo utilizar em um caso, a descrição por espaço de 
fases obtida da etapa anterior, e em outro um modelo de fonte única, com descrição espectral. Na terceira etapa, também realizada apenas com o código PENELOPE, o resultado obtido anteriormente, na forma de descrição por espaço de fases, foi simulado na região irradiada (objeto simulador de água) onde se avaliou a dose absorvida no meio. A validação de uma simulação por Monte Carlo, em geral, é feita por meio da comparação com medidas experimentais, neste caso as medidas de PDP e perfil do campo $10 \mathrm{~cm} \times 10 \mathrm{~cm}$, como sugerido e realizado por diversos autores ${ }^{[31] ~[32] ~[41]}$. Aqui se propõe um critério de aceitação da simulação por MC, na comparação com valores experimentais, de $\pm 1 \%$ de diferença entre as curvas de PDP e de $\pm 0,1 \mathrm{~cm}$ entre os perfis laterais em profundidade, para uma dada dose. Esse mesmo nível de discrepância foi estabelecido por Libby e colaboradores ${ }^{[31]}$ na simulação de um CLINAC 2100C utilizando o código EGS4.

As simulações foram realizadas em um computador pessoal, com processador Intel Celeron de $1 \mathrm{GHz}$, memória RAM de 256 Mbytes, com sistema operacional Windows XP da Microsoft. Como as simulações tiveram que ser realizadas nesse tipo de computador, relativamente comum e de velocidade de processamento baixa, os parâmetros de simulação foram escolhidos para resultar, após a primeira etapa, em uma descrição por espaço de fases do CLINAC contendo aproximadamente $10^{6}$ "partículas".

As recomendações de trabalhos anteriores ${ }^{[13,31,32,41]}$ indicam que uma descrição por espaço de fases de feixes clínicos utilizados em radioterapia necessita da ordem de $10^{8}$ “partículas” para fornecer resultados com incerteza estatística adequada. Devido a esse fato, deu-se preferência em utilizar na segunda etapa, que contém a fase de colimação do CLINAC, o modelo de fonte única com descrição espectral do feixe.

\subsubsection{PENELOPE}

O pacote de simulação PENELOPE ${ }^{[42]}$ contém um conjunto de rotinas escritas em Fortran, desenvolvido na Universidade de Barcelona, Espanha. O nome PENELOPE é um acrônimo para "Penetration and Energy Loss of Positrons and Electrons”. Como as rotinas estão escritas em Fortran, podem ser aplicadas em qualquer processador com um compilador adequado a esta linguagem de programação. A vantagem prática deste pacote é que permite ao usuário a construção do seu próprio 
programa de simulação (programa de usuário), assim como a construção dos arquivos de geometria e materiais, de uma forma simples e compreensiva, sem conhecer a fundo todos os aspectos da teoria do transporte e espalhamento de fótons e de elétrons.

Como acessórios, o pacote contém um simulador visual de trajetórias de partículas SHOWER, um conjunto de códigos para visualização gráfica dos resultados (sob o pacote GNU) e as rotinas para incluir campos eletromagnéticos (EMFIELDS). A Figura 14 mostra um exemplo de trajetórias simuladas com a base de dados do PENELOPE e visualizadas com o simulador SHOWER, de um conjunto de 50 elétrons com energia inicial de $6 \mathrm{MeV}$ incidente (da esquerda para a direita) em um volume de água com $7 \mathrm{~cm}$ de espessura.

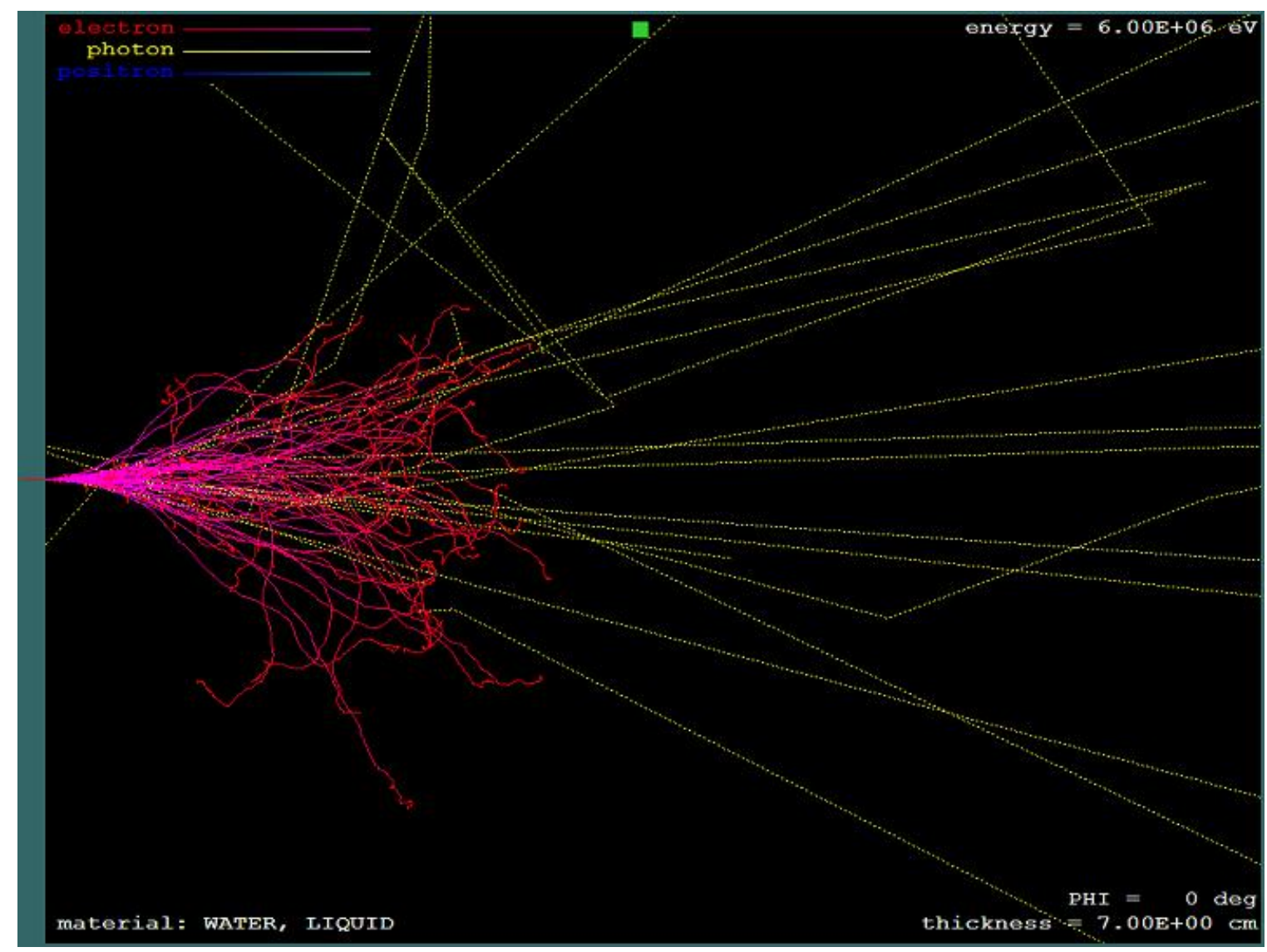

Figura 14: Exemplo de trajetórias em água das partículas geradas com o simulador SHOWER a partir de um feixe inicial de elétrons de $6 \mathrm{MeV}$. 
Desde o ponto de vista de programação interna, os elétrons, pósitrons e fótons são tratados como "partículas”, ainda que suas características devam ser definidas nas variáveis que definem o espaço de fases dessas “partículas”.

\section{Descrição Geométrica e Visualização}

O pacote de simulação PENELOPE utiliza as chamadas superfícies quadráticas $^{[42]}$ para descrever a geometria em 3D do problema físico real.

Neste tipo de descrição, as superfícies são definidas mediante uma equação quadrática. Os corpos são definidos como a parte interna ou externa a uma ou várias interseções de superfícies.

A equação geral de uma superfície quadrática é dada a seguir:

$$
F(x, y, z)=A_{x x} x^{2}+A_{x y} x y+A_{x z} x z+A_{y y} y^{2}+A_{y z} y z+A_{z z} z^{2}+A_{x} x+A_{y} y+A_{z} z+A_{0}=0
$$

Para facilitar a utilização e descrição da geometria se definem equações quadráticas reduzidas, reconhecidas pelo código original. As equações quadráticas reduzidas possuem simetria ao longo do eixo $z$, i.e. $\mathrm{F}_{\mathrm{r}}(-\mathrm{x},-\mathrm{y}, \mathrm{z})=\mathrm{F}_{\mathrm{r}}(\mathrm{x}, \mathrm{y}, \mathrm{z})$. No entanto, os corpos construídos com as equações quadráticas reduzidas podem sofrer transformações geométricas como rotações e translações em qualquer um dos eixos.

A equação geral de uma superfície quadrática na forma reduzida é dada como:

$$
F_{r}(x, y, z)=I_{1} x^{2}+I_{2} y^{2}+I_{3} z^{2}+I_{4} z+I_{5}=0
$$

em que os coeficientes $I_{1}$ a $I_{5}$ podem assumir somente os valores inteiros -1,0 e 1 .

As expansões, reduções ou distorções são realizadas por meio dos fatores de escala correspondentes X-SCALE = a, Y-SCALE $=\mathrm{b}$ e Z-SCALE $=\mathrm{c}$, contidos na equação reduzida modificada: 


$$
F_{r}(x, y, z)=I_{1}\left(\frac{x}{a}\right)^{2}+I_{2}\left(\frac{y}{b}\right)^{2}+I_{3}\left(\frac{z}{c}\right)^{2}+I_{4} \frac{z}{c}+I_{5}=0
$$

As rotações são realizadas através de transformações pelos ângulos de Euler OMEGA, THETA y PHI, enquanto as translações são feitas por transformações por um vetor de translação $t$, com componentes X-SHIFT $=t x$, Y-SHIFT $=$ ty e Z-SHIFT $=t z$.

Na Figura 15 apresentam-se alguns exemplos de superfícies descritas por equações quadráticas na forma reduzida. Os corpos que descrevem os objetos reais são construídos pela intersecção entre as superfícies e a seleção do lado de interesse (esquerda, direita, superior, inferior, externo ou interno a uma superfície dada). 


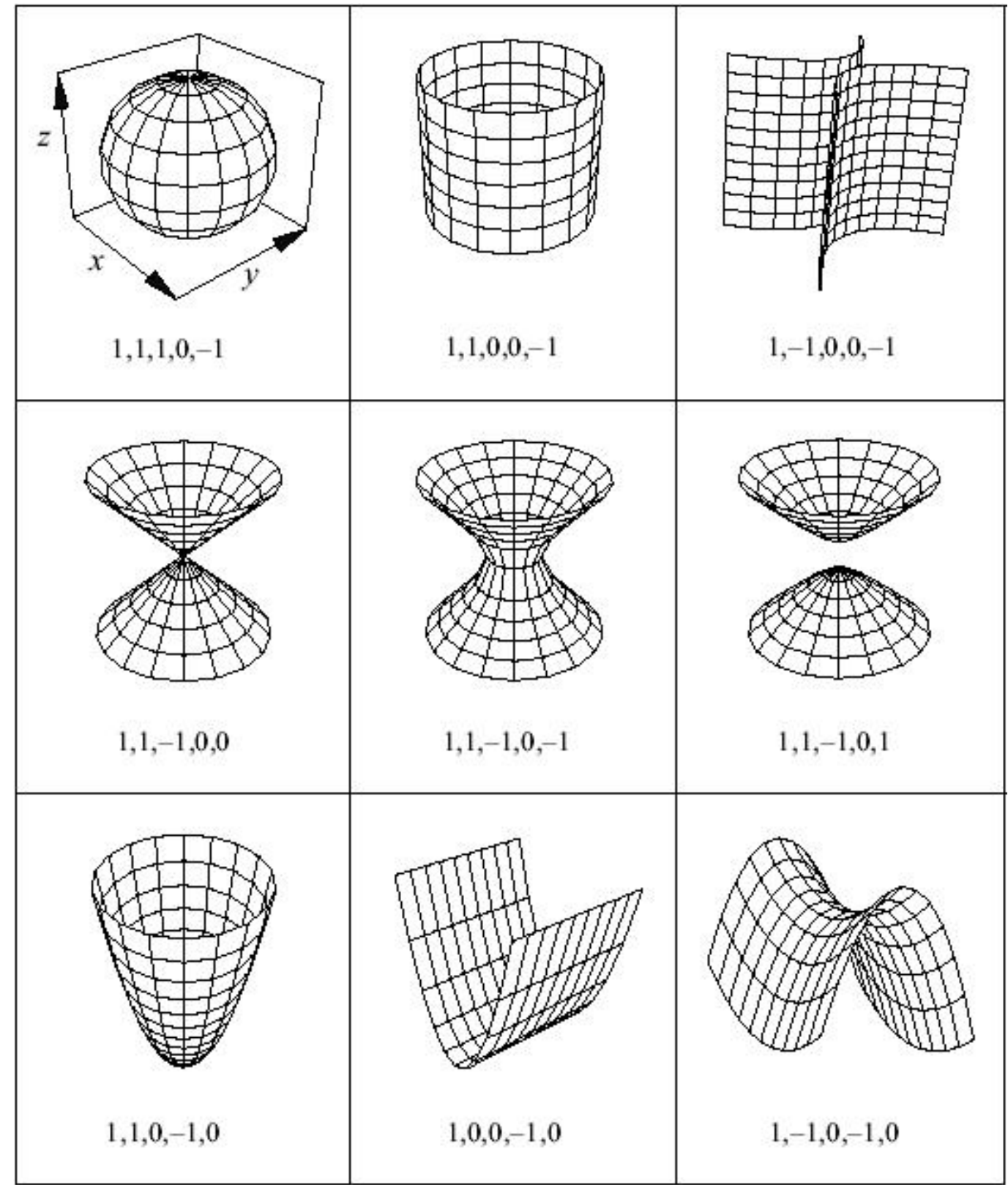

Figura 15: Superfícies quadráticas não planas definidas por equações quadráticas na forma reduzida e seus índices utilizados na equação 24 (adaptada de Salvat e colaboradores $^{[42]}$ ).

Estão incluídos, ainda, os programas visualizadores de geometria GVIEW em 2D e 3D, que permitem a rápida verificação e validação da descrição feita.

Um exemplo da capacidade de descrever e visualizar geometricamente estruturas tridimensionais está contido no objeto simulador antropomórfico da Figura 16, construído com geometria quadrática e incluído como exemplo no pacote PENELOPE. Este objeto simulador foi criado com a descrição de 173 superfícies e 108 volumes. A imagem da geometria descrita é gerada com o visualizador GVIEW3D. 


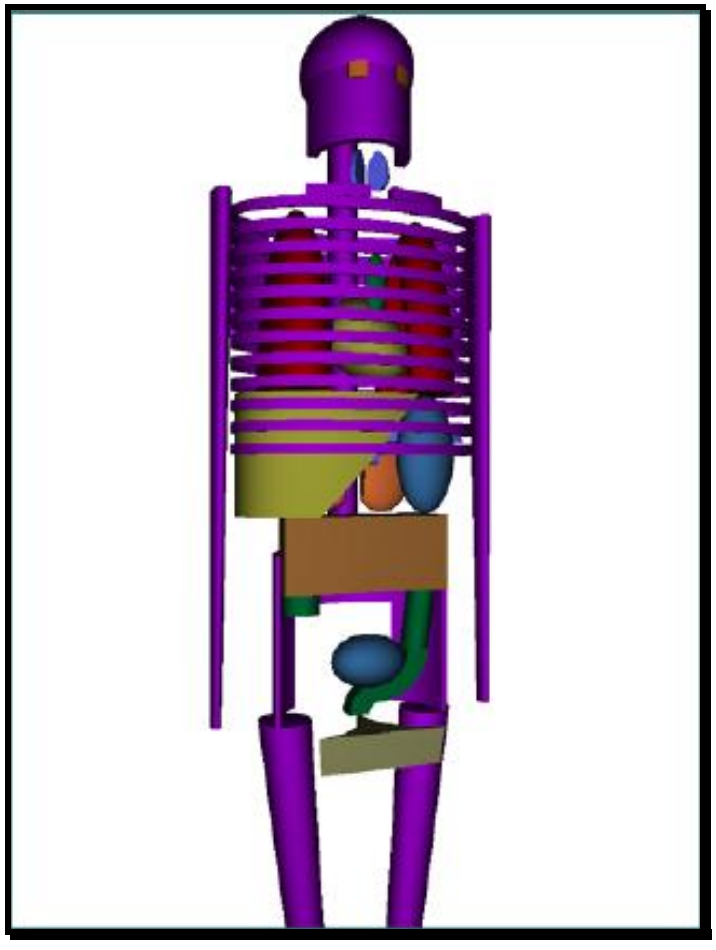

Figura 16: Objeto simulador antropomórfico construído através de superfícies quadráticas e visualizadas com o programa GVIEW3D.

\section{$\underline{\text { Base de dados }}$}

O pacote de simulação PENELOPE contém uma base de dados própria e ampla de seções de choque e coeficientes de interação para materiais e energias variando desde $1 \mathrm{keV}$ até $1 \mathrm{GeV}$, que coincide com os do ICRU-37 ${ }^{[43]}$.

\section{Transporte de Fótons}

Em termos da física do transporte de fótons, o pacote PENELOPE permite simular o espalhamento Compton com elétrons livres e ligados, o espalhamento Rayleigh com ou sem correções de ligações, o efeito foto-elétrico com amostragem angular e a produção de pares. 


\section{Transporte de Elétrons}

Com respeito ao transporte de elétrons, é um código de tipo Classe II para perda de energia e deflexão angular ${ }^{[12]}{ }^{[22]}$, ou seja, a perda de energia ocorre de modo contínuo ao longo de passos aleatórios para uma energia menor que um determinado valor de corte. Além disso, o espalhamento múltiplo ocorre ao longo desses passos aleatórios e para ângulos menores que um determinado valor de corte. As colisões que envolvem essas perdas pequenas podem ser agrupadas, ou condensadas, em uma descrição macroscópica, enquanto as colisões de perdas grandes, ou catastróficas, são selecionadas individualmente.

Já quanto à aniquilação de pósitrons, no PENELOPE este processo pode se dar tanto em repouso como em vôo.

\section{Estrutura de arquivos e Variáveis}

A partir do programa fonte MATERIAL.F constrói-se, no pacote PENELOPE, um programa para geração de seções de choque para os diversos materiais utilizando a base de dados PENDBASE. O programa fonte principal é o PENELOPE.F, que com o programa fonte geométrico PENGEOM.F, controla o transporte na geometria construída por superfícies quadráticas. Deve-se incluir um das rotinas de controle de tempo (TIMERG77.F; TIMERMS.F e TIMER1.F) e o programa de usuário. Como programa de usuário estão incluídos três exemplos (PENSLAB.F, PENCYL.F e PENDOSES.F), que podem ser editados ou servir como base para a criação de um programa personalizado USER.F. Acompanha o pacote um programa com rotinas de redução de variâncias (PENVARED.F) que podem ser implementadas facilmente. O programa de usuário deve conter as chamadas para as sub-rotinas do PENELOPE.F, do PENGEOM.F, de um dos TIMER_.F e, se for caso, do PENVARED.F. Além disso, é no programa de usuário que são estabelecidos os parâmetros de simulação e as informações que se deseja como saída. A compilação e vinculação desses programas permitem criar e construir o programa executável, chamado aqui genericamente de main.exe.

O programa main.exe deve ser executado em janela ou ambiente DOS (Sistema Operacional de Disco) em um diretório que contenha os arquivos de entrada 
user.in, geometry.geo e material.mat, que são editados em formato texto e descritos a seguir.

O arquivo user.in permite definir as variáveis e os valores da simulação, como no exemplo da Tabela 2, a seguir, que usa as variáveis originais do pacote de simulação:

Tabela 2: Exemplo de arquivo de entrada user.in, contendo as variáveis iniciais, contidas no pacote original ${ }^{[42]}$, e seus valores designados para simulação com o código PENELOPE.

KPAR 1

E0 6.00E6

SPOSIT 001

SDIREC 1800

SAPERT 0

NMAT 1

SIMPAR 1.0E5 1.0E4 1.0E5 0.05 0.05 1.0E4 1.0E3

DSMAX 1.0E-1

PFNAME 600C.mat

GFNAME 600C.geo

NSIMSH 100000

TIME 600

RSEED 1234554321 [tipo de partícula: 1=elétron, 2=fóton, 3=pósitron]

[Energia inicial, em eV] [Posição da fonte: X0, Y0, Z0 em cm] [Direção do feixe: THETA,PHI em deg] [Abertura do feixe, ALPHA em deg] [Número de materiais] [EABSs,C1,C2,Wcc,Wcr] [Comprimento máximo do passo, em $\mathrm{cm}$ ] [Nome do arquivo de material, 18 caracteres] [Nome do arquivo de geometria, 18 caracteres] [Número de histórias desejadas, máximo $=2 * * 31-1$ ] [Tempo reservado para simulação, em segundos] [Sementes para os números Aleatórios]

O arquivo user.in contém os dados da fonte de radiação, seu tipo (KPAR), energia (E0), posição (SPOSIT), direção(SDIREC) e abertura(SAPERT) do feixe, os dados sobre os materiais, como o número de materiais (NMAT) usados na simulação, sendo que para cada material adiciona-se uma linha com os parâmetros contidos na variável SIMPAR e outra linha para o comprimento de passo máximo permitido (DSMAX). Os parâmetros contidos na variável SIMPAR são as energias de absorção (EABS) para elétrons, fótons e pósitrons no material em questão, C1, que controla a deflexão angular média produzida pelo espalhamento múltiplo, e C2, que determina o valor máximo da perda de energia média dos elétrons, avaliados entre eventos consecutivos de colisão elástica catastrófica; Wcc que representa o corte para a perda de energia em colisões inelásticas catastróficas e Wcr que representa o corte para a perda 
de energia na emissão de raios $X$ por bremsstrahlung. Ainda devem ser inseridos os nomes dos arquivos de material (PFNAME) e geometria (GFNAME), o número de histórias de simulação desejada (NSIMSH), o tempo reservado para simulação (TIME) em caso de não haver atingido o valor definido em NSIMSH, e dois números inteiros que identificam as duas sementes iniciais de números aleatórios (RSEED). Outras variáveis também poderiam ser reconhecidas pelo programa de usuário, podendo substituir algumas dessas anteriores, por exemplo, uma distribuição espectral da fonte, ou um arquivo de espaço de fases que a descreva. Na versão do pacote PENELOPE do ano 2005 foram incorporadas as variáveis que permitem gravar e ler os arquivos de espaço de fases e a subdivisão da estrutura irradiada, para facilitar o armazenamento compartimentado ("tally") das grandezas de interesse, por exemplo, a energia depositada.

As energias de absorção (EABS) são determinadas de acordo com as características do experimento ou pela resolução espacial requerida. Os parâmetros C1 e C2 para espalhamento elástico devem ser limitados ao intervalo [0; 0,2]. Esses parâmetros têm uma influência pequena nos resultados da simulação, mas os criadores do pacote PENELOPE recomendam usar inicialmente na prática $\mathrm{C} 1=0,05$ e $\mathrm{C} 2=0,05$, que são valores conservadores. Se acaso o usuário optar por usar valores diferentes, deveria realizar testes de simulação para verificar que os resultados do seu problema permanecem inalterados, e obviamente que a simulação fique mais rápida, caso contrário seria melhor manter os valores conservadores. As energias de corte Wcc e Wcr têm uma influência nos resultados de distribuição de energias, por isso recomendase designar para ambas um valor de pelo menos um centésimo da energia das partículas primárias. A velocidade de simulação aumenta com o aumento de Wcc e Wcr, mas se os valores forem muito grandes as distribuições de energia podem tornar-se distorcidas.

O arquivo material.mat é construído com as seções de choque e poderes de frenagem do material indicado gerados na base de dados do PENELOPE. O usuário deve informar a composição dos materiais em que se dará a interação do feixe, seja por meio dos elementos químicos com números de 1 a 92, quanto por meio de um dos materiais de interesse dosimétrico pré-definidos, tais como osso, pulmão, água, e etc.

O arquivo geometry.geo deve ser construído pelo usuário num editor de texto, no formato específico que será reconhecido pelo programa PENGEOM.F. Nele 
são definidos todas as superfícies utilizadas na descrição geométrica, em seguida os corpos que são definidos pela interseção de superfícies e o material de preenchimento, segundo a ordem definida no arquivo material.mat.

Após a execução do programa main.exe com os arquivos de entrada user.in, geometry.geo e material.mat, realiza-se a simulação e gera-se um ou mais arquivos de saída saída.dat, nos quais são armazenados os resultados, por exemplo, o número de processos de atenuação em um dado objeto, dados de interação, um arquivo de espaço de fases, a distribuição da energia depositada num dado objeto, etc.

\subsubsection{MCNP4C}

$\mathrm{O} \mathrm{MCNP}^{[44]}$, foi desenvolvido em Los Alamos, EUA. As primeiras versões foram feitas originalmente para energias altas, da ordem de MeVs, podendo também simular nêutrons. Valores para energias mais baixas foram sendo incorporados à base de dados nas versões mais recentes. O MCNP ${ }^{[12] ~[13] ~[22] ~[44] ~ u s a ~ o ~ m o ́ d u l o ~ d a ~ f i ́ s i c a ~ d e ~}$ elétrons derivados do código anterior Integrated Tiger Series - ITS e a metodologia do código ETRAN, revisados por Rogers e Bielajew na comparação com o código EGS ${ }^{[45]}$. O pacote também possui rotinas escritas em Fortran, mas para esse trabalho foi utilizada a versão compilada mcnp4_lfw.exe $e^{1}$ do MCNP4C ${ }^{[44]}$. O formato do programa exige que se utilize um arquivo de entrada que contenha a descrição geométrica e os parâmetros de simulação, numa estrutura de cartões.

\footnotetext{
${ }^{1}$ Versão cedida pelo Prof. Dr. Helio Yoriyaz, do IPEN
} 
Descrição Geométrica e Visualização

No MCNP as descrições das superfícies geométricas são feitas por meio de mnemônicos nos cartões de superfície, que definem superfícies conhecidas e previamente estipuladas no programa. Esses mnemônicos, como os exemplificado na Tabela 3, em alguns casos também usam internamente uma equação quadrática, mas podem usar equações de ordem 1, para planos e em outros casos até a ordem 5 . Outra possibilidade é descrever uma superfície através de pontos localizados espacialmente. Os corpos são definidos como a parte interna ou externa a uma ou várias interseções de superfícies.

Tabela 3: Exemplos de definições de superfícies no MCNP.

\begin{tabular}{|c|c|c|c|}
\hline Mnemônico & Tipo & Descrição & Equação \\
\hline $\mathrm{P}$ & Plano & Geral & $A x+B y+C z-D=0$ \\
\hline $\mathrm{PX}$ & Plano & $\begin{array}{c}\text { Normal ao eixo } \\
\mathrm{X}\end{array}$ & $x-D=0$ \\
\hline $\mathrm{SO}$ & Esfera & $\begin{array}{c}\text { Centrada na } \\
\text { origem }\end{array}$ & $x^{2}+y^{2}+z^{2}-R^{2}=0$ \\
\hline $\mathrm{SX}$ & Esfera & $\begin{array}{c}\text { Centrada no } \\
\text { eixo X }\end{array}$ & $(x-\bar{x})^{2}+y^{2}+z^{2}-R^{2}=0$ \\
\hline $\mathrm{SZ}$ & Esfera & $\begin{array}{c}\text { Centrada no } \\
\text { eixo Z }\end{array}$ & $x^{2}+y^{2}+(z-\bar{z})^{2}-R^{2}=0$ \\
\hline $\mathrm{CZ}$ & Cilindro & No eixo Z & $x^{2}+y^{2}-R^{2}=0$ \\
\hline $\mathrm{KZ}$ & Cone & No eixo Z & $\sqrt{x^{2}+y^{2}}-t(z-\bar{z})=0$ \\
\hline
\end{tabular}

A visualização das estruturas geométricas definidas no arquivo de entrada é feita diretamente com o uso do programa compilado, com a inclusão do comando "ip" para abrir a interface gráfica em 2D-mcnplot, que permite a verificação e validação da descrição feita.

\section{$\underline{\text { Base de dados }}$}

O MCNP usa uma base de dados contendo seções de choque do código ITS e os poderes de frenagem que a princípio eram equivalentes aos do ICRU-37 ${ }^{[43]}$, mas como mostrado por Siebers e colaboradores ${ }^{[41]}$ podiam diferir significativamente, por exemplo, para um alvo de tungstênio. No pacote do MCNP está contido o gerador XGEN para produzir os dados dos diversos materiais e energias. 


\section{$\underline{\text { Transporte de Fótons }}$}

Em termos da física do transporte de fótons, o MCNP permite simular o espalhamento Compton apenas com elétrons ligados, o espalhamento Rayleigh utilizando correções de ligações, o efeito foto-elétrico com amostragem angular e a produção de pares.

\section{$\underline{\text { Transporte de Elétrons }}$}

Com respeito ao transporte de elétrons, o MCNP é um código de tipo Classe I para perda de energia e deflexão angular ${ }^{[12,22]}$, ou seja, todas as interações são agrupadas, ou condensadas, utilizando um conjunto predeterminado de passos. Ao fim desses passos as colisões são amostradas individualmente e de forma aleatória.

Já quanto à aniquilação de pósitrons, o MCNP permite apenas esse tipo de efeito com a partícula em repouso, ou seja, após perder toda sua energia cinética em colisões.

\section{Estrutura de arquivos e Variáveis}

O programa mcnp4_lfw.exe deve ser executado em ambiente, ou janela, DOS (Sistema Operacional de Disco) dentro de um diretório que contenha o arquivo de entrada user2, editado em formato texto e descrito a seguir.

O arquivo user2 contém as variáveis e valores da simulação, como o exemplo da Tabela 4, contendo os dados da fonte de radiação, seu tipo (PAR), energia (ERG), posição (POS), direção(DIR) para a direção do feixe, os dados sobre os materiais, sendo que para cada material adiciona-se uma linha que especifica sua composição. Também no MCNP há outras variáveis que podem substituir algumas dessas anteriores, por exemplo, uma distribuição espectral da fonte, ou um arquivo de espaço de fases que a descreva. Possui ainda, um conjunto de tipos de armazenamento de resultados pré-definidos (“tallies”), como por exemplo, fluência numa superfície, fluência num detector, energia depositada e energia depositada por fissão. 
Tabela 4: Exemplo de arquivo de entrada user2, contendo as variáveis iniciais e seus valores designados para simulação com o código MCNP.

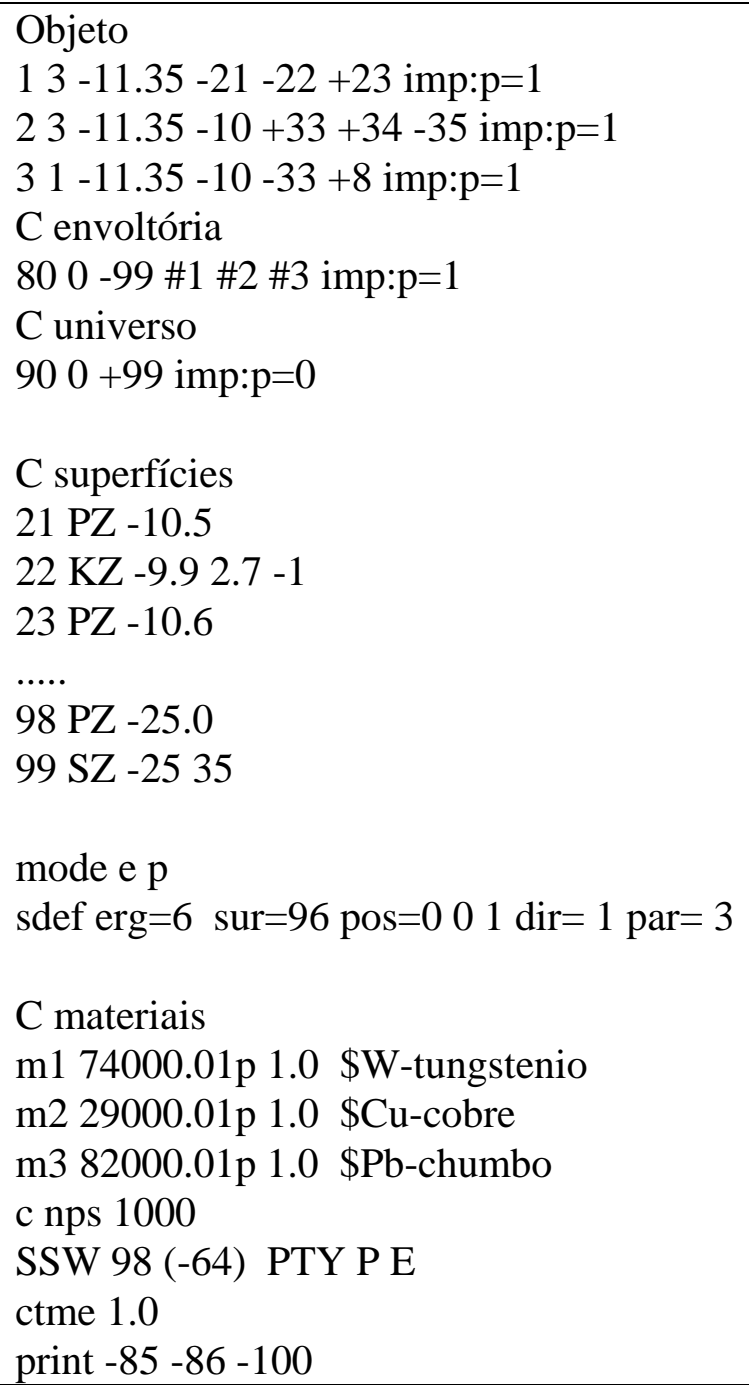

Após a execução do programa mcnp4_lfw.exe com os arquivos de entrada user2 e de base de dados, realiza-se a simulação e geram-se os arquivos de saída out e runtp, e, se for o caso, os arquivos de espaço de fases wss.

\subsection{Dosimetria do Acelerador Linear equipado com o mMLC}

O mMLC, modelo m3 ${ }^{\mathrm{TM}}$ (BrainLAB), utilizado nesse trabalho é acoplável ao CLINAC 600C como uma colimação terciária. O mMLC é composto de 52 lâminas de tungstênio com movimento independente, sendo que os 14 pares de lâminas centrais possuem uma largura de 3,0 mm, os 6 pares intermediários possuem 4,5 mm e os 6 pares externos possuem 5,5 mm (valores referentes à largura projetada no isocentro de 
tratamento a 1 metro da fonte de radiação). O movimento das lâminas se dá na direção perpendicular ao eixo central do feixe de radiação. Para minimizar a fuga de radiação entre lâminas adjacentes o projeto utiliza um projeto específico de encaixe lingüeta-vão ("tongue and groove").

Para avaliar o impacto do mMLC na dosimetria do feixe do CLINAC 600C foram realizadas medidas experimentais com filme radiográfico X-OMAT-V (Kodak) da transmissão e do efeito lingüeta-vão em um objeto simulador de material equivalente a água ("Solid Water” ${ }^{\circledR}$ - SW). Todos os filmes foram processados e escaneados em um digitalizador VXR-12 Plus (VIDAR). Outras medidas dosimétricas relevantes do mesmo mMLC do HIAE foram realizadas por Delgado ${ }^{[25]}$ e incluem dados para comissionamento e controle de qualidade do mMLC, como a penumbra em função do tamanho de campo e da profundidade em água, a penumbra em diferentes angulações de conformação, a estabilidade e reprodutibilidade do posicionamento das lâminas em movimento e o impacto da tolerância mecânica nessa movimentação.

Para os cálculos de simulação do m3, cada lâmina foi descrita por meio de 32 superfícies no formato adequado ao PENELOPE. Foram criados os arquivos de usuário, de geometria e de materiais para serem usados no pacote de simulação PENELOPE que permitissem simular o feixe do CLINAC, utilizando o modelo de fonte, incidindo nos colimadores convencionais X e Y, no mMLC e em um objeto simulador de água. O modelo, mais completo e detalhado, do m3 descrito nesse trabalho também é de caráter inédito, permitindo, por exemplo, a avaliação da transmissão do mMLC e do efeito lingüeta-vão, devidos ao projeto das lâminas.

\subsection{Cálculo de Dose Devido aos Campos Conformados pelo mMLC}

Para a simulação dos campos conformados, também foram criados os arquivos de usuário, de geometria e de materiais para serem usados no pacote de simulação PENELOPE. O programa permite simular o feixe do CLINAC, utilizando o modelo de fonte, incidindo nos colimadores convencionais X e Y, no mMLC e em um objeto simulador de água. Inicialmente foram avaliados as distribuições de dose na água devidas aos campos circulares de 1,8cm e 6,0 cm de diâmetro conformados pelo mMLC, validados por comparações com valores experimentais, medidos com a câmara de 
ionização RK. Esses campos, de certa forma, aproximam-se e representam campos reais de tratamento, mas são também utilizados no processo de comissionamento do mMLC.

Os fatores relativos de dose de campos conformados pelo mMLC foram calculados a partir de simulações por Monte Carlo e comparados aos valores de medidas experimentais, realizadas com a micro câmara de ionização A16 (Exradin), com um volume sensível de $0,007 \mathrm{~cm}^{3}$. Também nesse caso foram escolhidos campos de conformação circular de diversos diâmetros e que se aproximam da situação clínica de tratamento e são, portanto, de fundamental importância para o melhor entendimento dosimétrico da radiocirurgia com mMLC bem como de seu programa de garantia de qualidade. 


\section{RESULTADOS E DISCUSSÃO}

\subsection{Avaliação Dosimétrica do Acelerador Linear}

O coeficiente de calibração do CLINAC 600C, igual a 1cGy por UM nas condições de referência, e o seu índice de qualidade do feixe $\mathrm{TPR}_{20,10}=0,669$, definido como a razão entre os TPRs (razões tecido - objeto simulador) medidos a $20 \mathrm{~cm}$ e a 10 cm em água, são avaliados mensalmente segundo o procedimento de controle de qualidade do Departamento de Radioterapia do HIAE e se mantém dentro da faixa de $1 \%$ de variação. As medidas são realizadas de acordo com a calibração de dose absorvida na água seguindo o protocolo de calibração TRS398 ${ }^{[16]}$ da IAEA.

Com isso, no que diz respeito a este trabalho, todas as medidas foram realizadas apenas para determinar doses relativas em água. Entre as medidas realizadas se incluem as curvas de PDP, os perfis laterais de dose em profundidade e os fatores relativos de dose.

\subsubsection{Validação de Medidas Experimentais}

As comparações pontuais das curvas de Porcentagem de Dose Profunda PDP e Razão Tecido Máximo - TMR atualizadas (realizadas em dezembro de 2006), com as curvas antigas de referência (realizadas em 1999) foram feitas para cada campo disponível, porém são difíceis de avaliar diretamente nos gráficos das curvas completas, como o ilustrado na Figura 17, a partir de 1,5cm de profundidade e para uma escala de 0 a $100 \%$, nos quais as diferenças são da ordem de $1 \%$. 


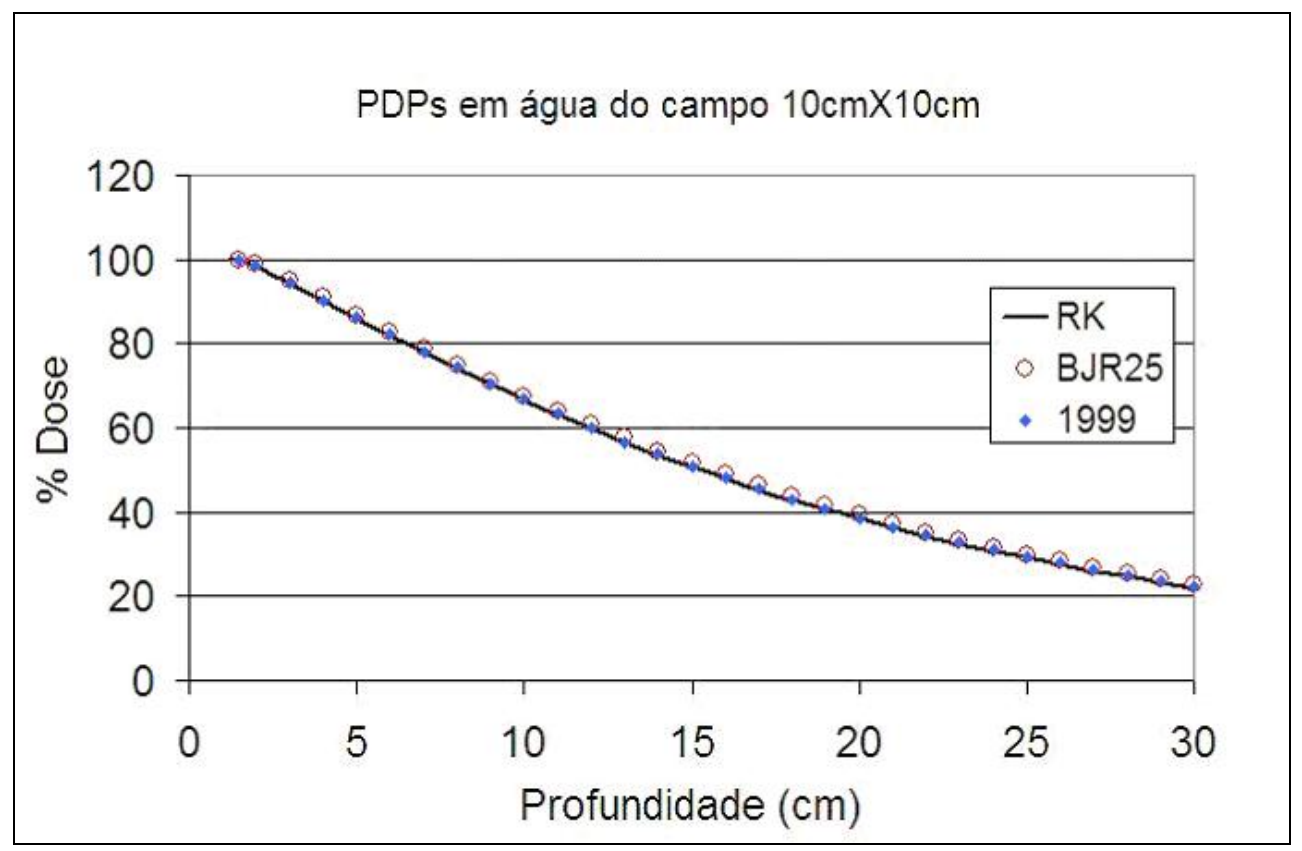

Figura 17: Gráfico das curvas de PDP em água do campo $10 \mathrm{~cm}$ x $10 \mathrm{~cm}$ medidas com a câmara RK, do BJR25 e da dosimetria antiga (1999), também com a câmara RK.

Os gráficos de diferenças entre as curvas de PDP, ou TMR, representam melhor os desvios, que podem ser amplificados graficamente com o reajuste da escala. No entanto, para esses gráficos não se tornarem excessivos, são aqui agrupados os resultados dos vários campos medidos em um mesmo gráfico, como o da Figura 18, para as curvas de PDP, e o da Figura 19, para as curvas de TMR. 


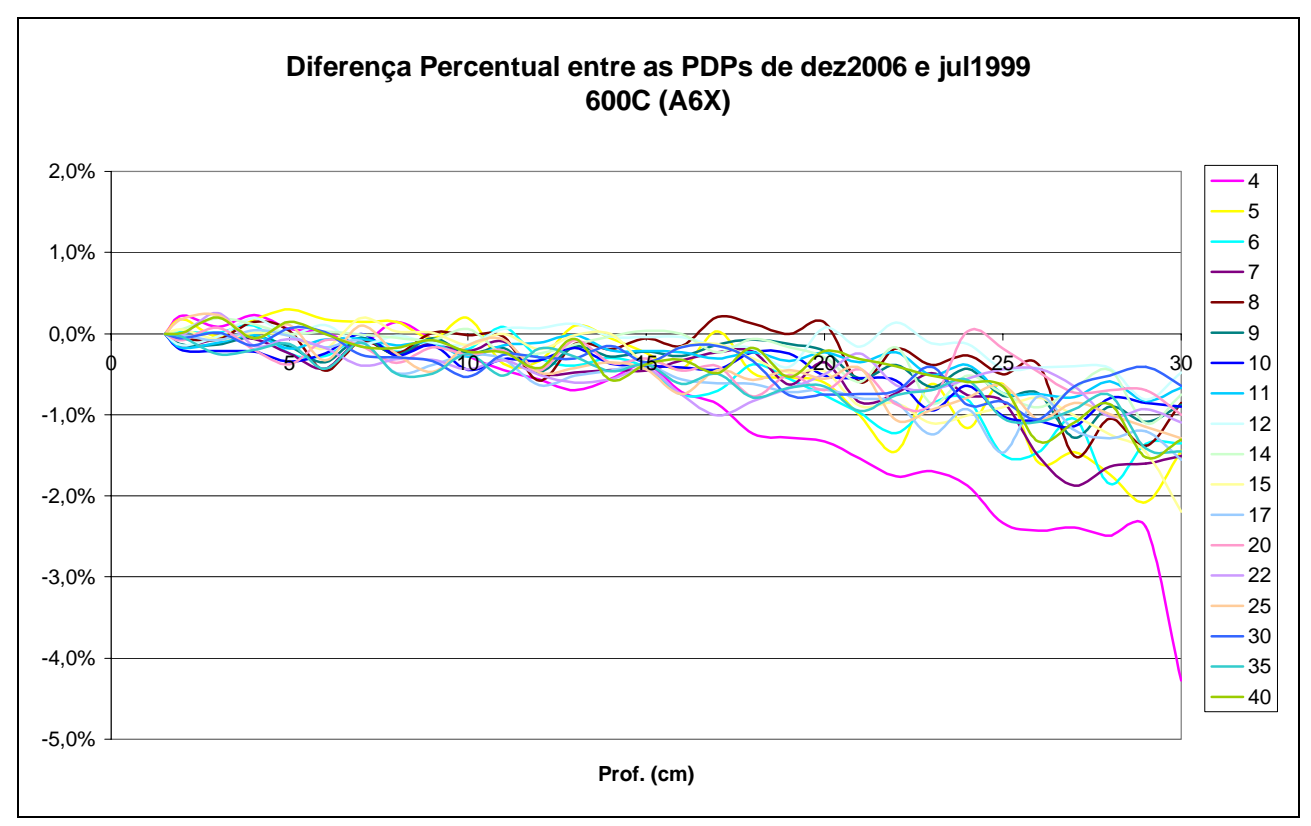

Figura 18: Gráfico das diferenças das curvas de PDP entre dados das medidas novas (dezembro de 2006) e antigas (julho de 1999), de campos quadrados de $4 \mathrm{~cm} \mathrm{x} \mathrm{4cm} \mathrm{a}$ $40 \mathrm{~cm}$ x $40 \mathrm{~cm}$.

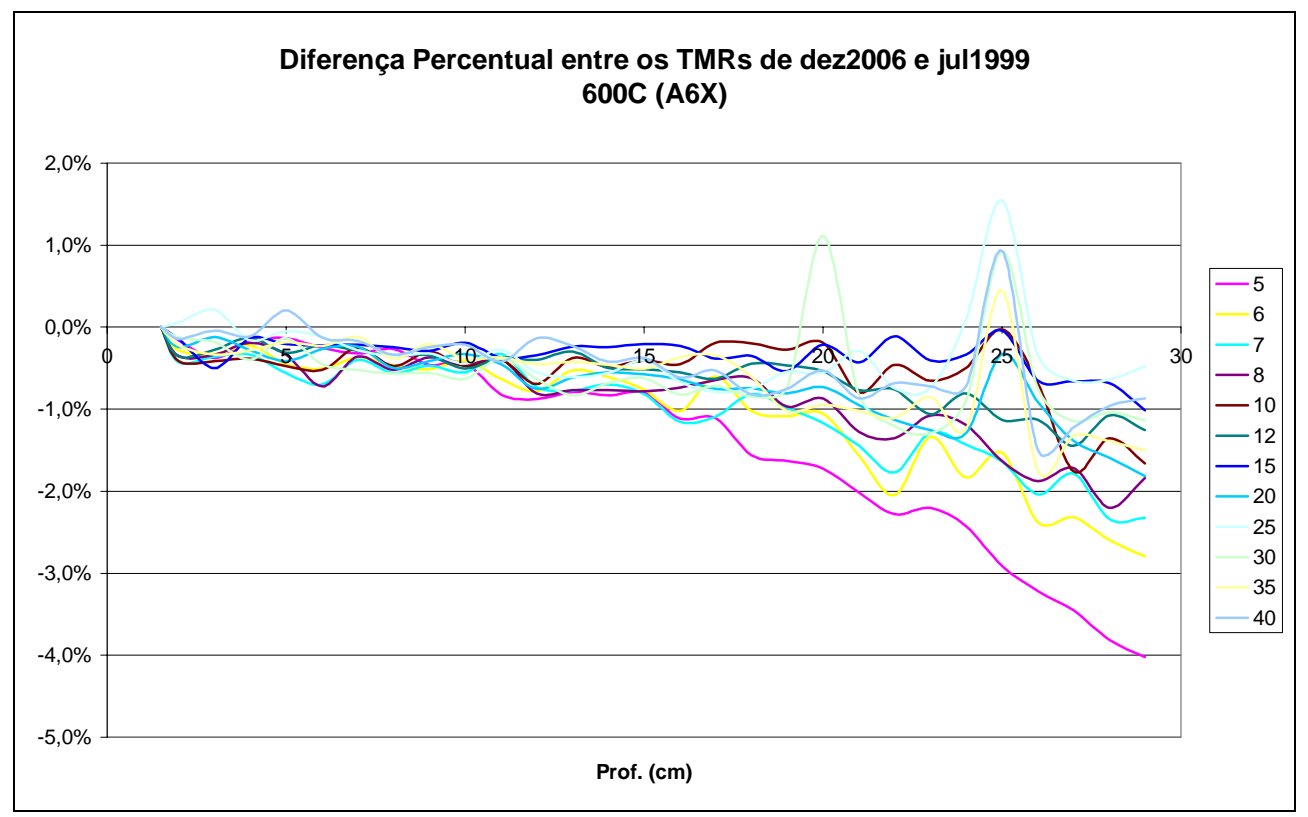

Figura 19: Gráfico das diferenças das curvas de TMR entre dados das medidas novas (dezembro de 2006) e antigas (julho de 1999), de campos quadrados de $5 \mathrm{~cm} \times 5 \mathrm{~cm}$ a $40 \mathrm{~cm} \times 40 \mathrm{~cm}$.

As diferenças são avaliadas após a região de "build up” (considerada a partir de $1,5 \mathrm{~cm}$ de profundidade para o feixe deste CLINAC), onde se esperam diferenças menores que $5 \%$ pontualmente e menores que $1,0 \%$ na média para cada campo 
avaliado. Na comparação das curvas medidas com as antigas (julho de 1999), tomadas como referência aparecem diferenças, na média, menores que 1\%, mas com um valor pontual de até $4,3 \%$, correspondente ao campo $4 \mathrm{~cm}$ x $4 \mathrm{~cm}$ e profundidade $30 \mathrm{~cm}$. Esse comportamento consistentemente decrescente das curvas, apesar de sutil, já que a escala está expandida, poderia indicar tanto uma dependência leve na resposta da câmara de ionização, quanto uma mudança na energia do feixe do acelerador. Assume-se que essa última hipótese é a mais provável e ocorre devido ao desgaste das peças do acelerador durante os anos. Como será visto mais adiante o mesmo tipo de comportamento (excetuando-se a dependência maior para campos pequenos) ocorre na comparação das medidas com diodo, mas nesse caso é devido a uma superestimativa das medidas feitas com diodo. Ainda assim, a questão abre tema para pesquisas futuras.

Os gráficos de diferenças entre as curvas de PDP, ou TMR, correspondentes às comparações das medidas novas com os valores de referência do BJR25 são apresentados na Figura 20, para as curvas de PDP, e na Figura 21, para as curvas de TMR.

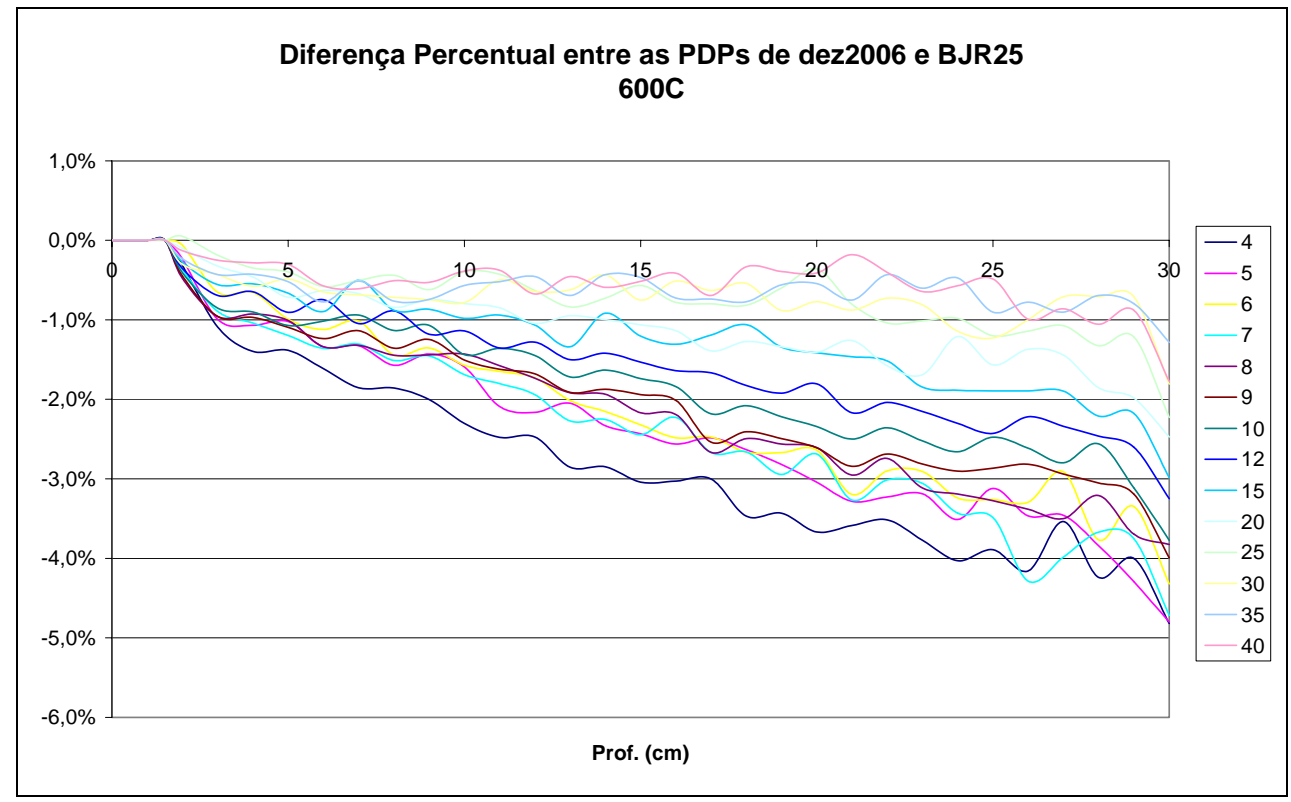

Figura 20: Gráfico das diferenças das curvas de PDP entre dados das medidas novas (dezembro de 2006) e valores do BJR25, de campos quadrados de $4 \mathrm{~cm} \mathrm{x} \mathrm{4cm} \mathrm{a} 40 \mathrm{~cm} \mathrm{x}$ $40 \mathrm{~cm}$. 


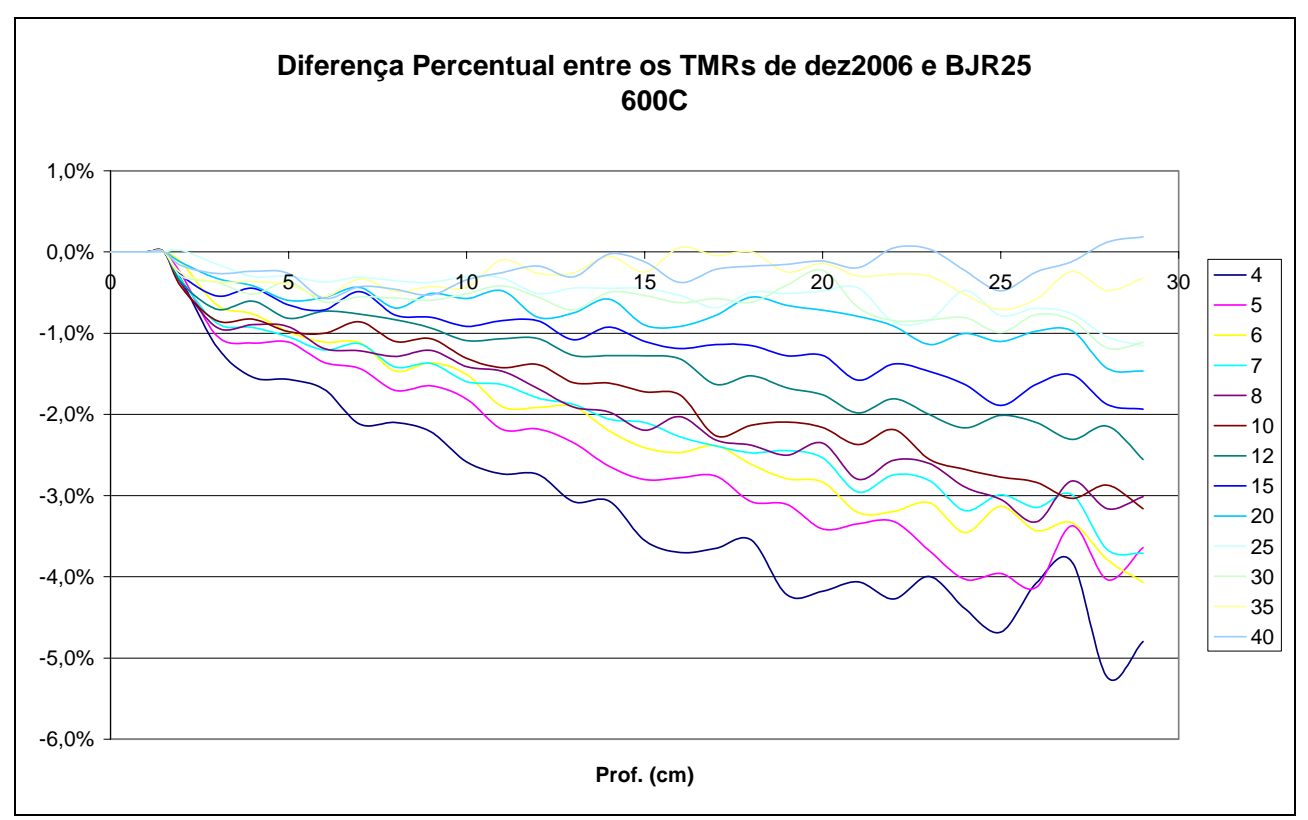

Figura 21: Gráfico das diferenças das curvas de TMR entre dados das medidas novas (dezembro de 2006) e valores do BJR25, de campos quadrados de $4 \mathrm{~cm}$ x $4 \mathrm{~cm}$ a $40 \mathrm{~cm} \mathrm{x}$ $40 \mathrm{~cm}$.

Com relação aos valores de referência do BJR25, as diferenças foram um pouco maiores, mas na média dentro de $1,5 \%$, e com um valor pontual de $4,7 \%$, para PDP, e 5,2\%, para TMR, que em ambos os casos correspondem ao campo de $4 \mathrm{~cm} \mathrm{x}$ $4 \mathrm{~cm}$ em grandes profundidades.

A comparação das curvas dosimétricas de PDP e TMR com os valores de referência do BJR25 também serve como um controle de qualidade, possibilitando a detecção de erros grosseiros. No entanto, podem aparecer discrepâncias grandes, já que esses valores publicados representam uma média de aceleradores distintos com feixes de fótons de potencial de aceleração nominal de 6MV, e não necessariamente se aplicam ao modelo utilizado neste trabalho.

Uma seqüência de medidas novas das curvas de PDP foi feita com o diodo $\mathrm{PFD}^{3 \mathrm{G}}$ para avaliar principalmente os campos menores (campos quadrados de $2 \mathrm{~cm} \mathrm{x}$ $2 \mathrm{~cm}$ a $25 \mathrm{~cm} \times 25 \mathrm{~cm}$ ). As maiores discrepâncias pontuais, nas comparações tanto com os dados antigos (4,3\%) quanto com os dados do BJR25 (4,7\%), ocorreram para o menor campo de 4cm x 4cm, comparado anteriormente. As comparações dessas medidas novas das PDPs, feitas com a câmara de ionização RK e com o diodo PFD $^{3 G}$, e que agora 
também incluem os campos quadrados de $2 \mathrm{~cm}$ x $2 \mathrm{~cm}$ e $3 \mathrm{~cm}$ x 3cm, estão representadas na Figura 22.

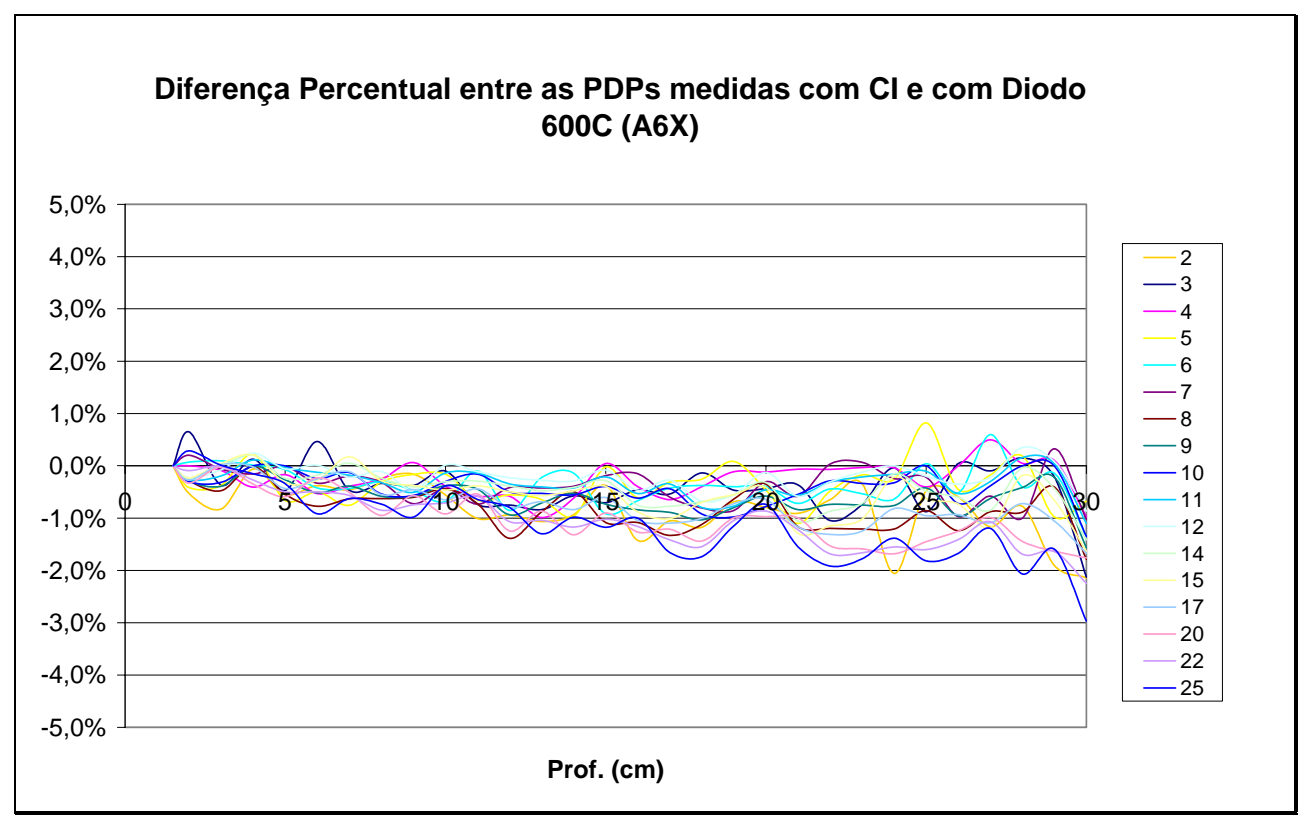

Figura 22: Gráfico das diferenças das curvas de PDP medidas com a RK e com diodo, de campos quadrados de $2 \mathrm{~cm}$ x $2 \mathrm{~cm}$ a $25 \mathrm{~cm}$ x $25 \mathrm{~cm}$.

Nesta comparação de medidas de câmara de ionização com diodo, a média das diferenças pontuais das curvas de PDP foi de $-0,6 \%$, mas variando gradualmente de $0 \%$ (a 1,5cm de profundidade) a aproximadamente $-2 \%$ (a $30 \mathrm{~cm}$ de profundidade), consistentemente para os diversos tamanhos de campo medidos, permitindo validar as curvas de PDP nesses termos.

Medidas com diodo podem superestimar ligeiramente a dose em regiões de profundidade grande para feixes de 6MV devido a não equivalência do silício com a água, como havia sido mostrado por Bucciolini e colaboradores ${ }^{[28]}$ para o mesmo tipo e modelo de detector. Assim, a diferença encontrada de 2\% possibilita a validação nesses termos, inclusive para os campos menores. Admite-se, com isso, que as medidas atuais, feitas com a câmara de ionização RK, estejam corretas, pois esta apresenta boa sensibilidade para medidas em profundidade.

Os perfis laterais de dose em profundidade foram medidos com diodo, devido a melhor resolução espacial ${ }^{[28][29]}$, e comparados a algumas amostras feitas com a câmara RK. Na Figura 23 mostram-se apenas os perfis do campo $10 \mathrm{~cm} \mathrm{x} 10 \mathrm{~cm}$ a 1,5cm em água. A comparação mostra boa concordância (diferenças menores que 1\%) 
na região central plana e, como esperado, são discordantes na região de alto gradiente de dose (diferenças de até 30\%) e na região fora do campo.

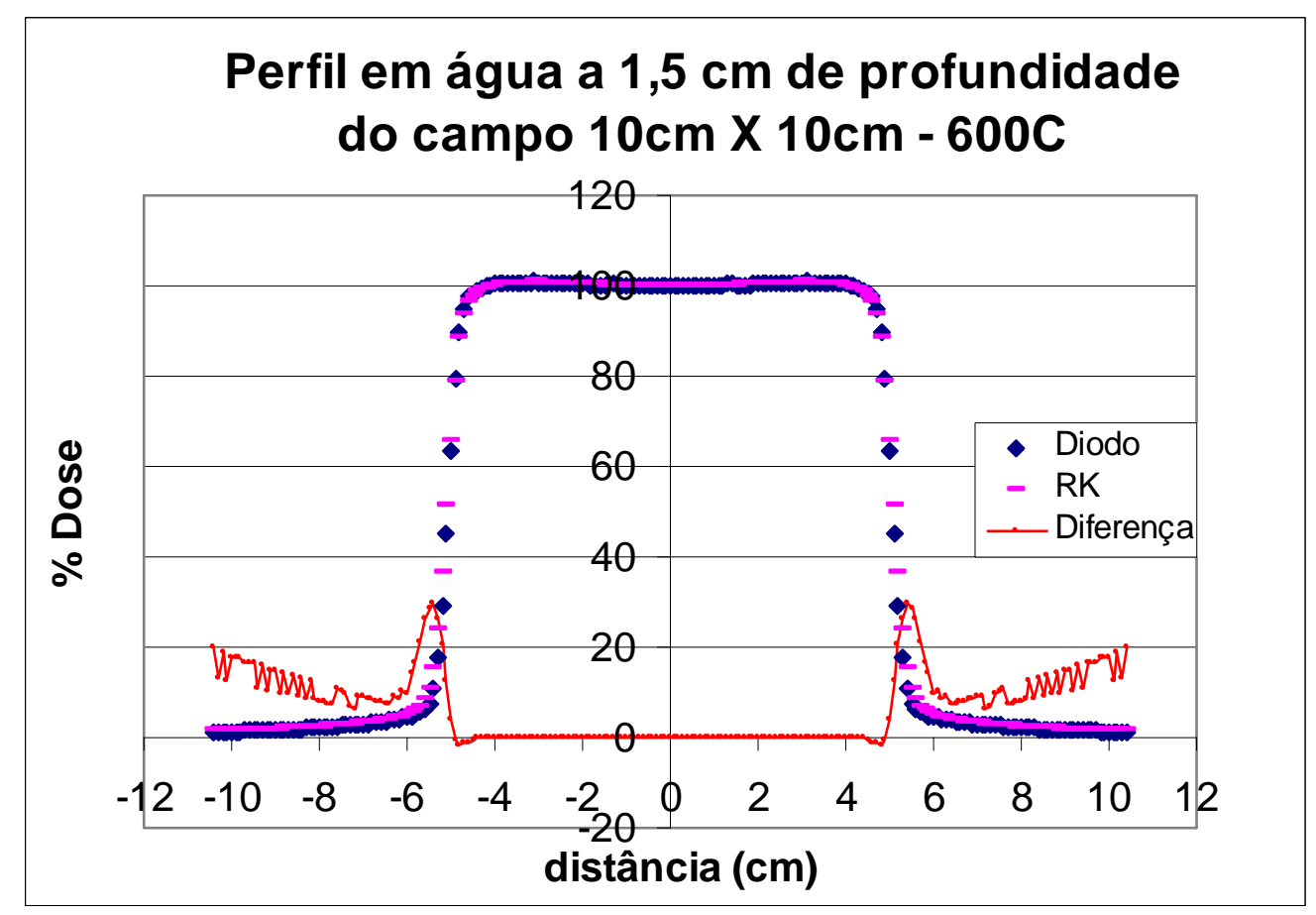

Figura 23: Gráfico dos perfis laterais de dose em água do campo $10 \mathrm{~cm}$ x $10 \mathrm{~cm}$ medidos a 1,5 cm de profundidade com a câmara RK e com o diodo.

As penumbras (definidas na região 80\%-20\% da dose) dos campos medidos com a câmara RK em geral superestimam de 10\% a 40\% o valor das penumbras obtidas com o diodo, por exemplo, a penumbra do campo mostrado na Figura 23 foi de 0,38cm quando medido com o diodo e 0,46 cm quando medida com a câmara RK. Os resultados mostram que mesmo uma câmara de ionização de volume pequeno como a RK não é o detector mais adequado para medidas com alta resolução espacial confirmando resultados publicados ${ }^{[28]}$, mas ainda assim podem ser utilizadas para validação de medidas ou mesmo medidas de comissionamento, desde que suas limitações sejam conhecidas.

Os Fatores Relativos de Dose foram medidos com a câmara RK a 5cm de profundidade em água (no eixo central, à distância fonte superfície SSD $=100 \mathrm{~cm}$ ) e convertidos à profundidade de dose máxima (considerada como sendo de $1,5 \mathrm{~cm}$ para este feixe de 6MV). Apenas os valores de campos quadrados puderam ser comparados 
com os valores antigos e apresentaram diferenças que resultam em uma diferença média de $0,25 \%$. Os valores dos Fatores Relativos de Dose e a comparação entre eles são mostrados na Tabela 5, a seguir:

Tabela 5: Fatores Relativos de Dose - OF de campos quadrados, atualizados e medidos com a câmara RK, valores anteriores de referência e diferença percentual entre eles.

Todos os valores de OF têm uma incerteza estimada de 0,003.

\begin{tabular}{|c|c|c|c|c|c|c|c|c|c|c|}
\hline $\mathbf{6 0 0 C}$ & $\mathbf{2}$ & $\mathbf{4}$ & $\mathbf{5}$ & $\mathbf{6}$ & $\mathbf{7}$ & $\mathbf{1 0}$ & $\mathbf{1 5}$ & $\mathbf{2 0}$ & $\mathbf{3 0}$ & $\mathbf{4 0}$ \\
\hline OF_RK & 0,883 & 0,944 & 0,955 & 0,969 & 0,980 & 1,000 & 1,027 & 1,042 & 1,067 & 1,081 \\
\hline OF_Ref & - & 0,942 & 0,958 & 0,969 & 0,977 & 1,000 & 1,023 & 1,040 & 1,062 & 1,070 \\
\hline diferença & - & $0,21 \%$ & $-0,31 \%$ & $0,00 \%$ & $0,31 \%$ & $0,00 \%$ & $0,39 \%$ & $0,19 \%$ & $0,47 \%$ & $1,03 \%$ \\
\hline
\end{tabular}

Os OFs medidos com a câmara RK mostraram-se adequados para os feixes e tamanhos de campo medidos.

\subsubsection{Simulação do Acelerador Linear Clínico}

A descrição geométrica completa do CLINAC é mostrada a seguir na Figura 24, numa reconstrução tridimensional gerada com o programa GVIEW3D. Além dos componentes indicados pelo fabricante foram criados dois planos virtuais para armazenamento da descrição por espaço de fases das "partículas” resultantes das simulações

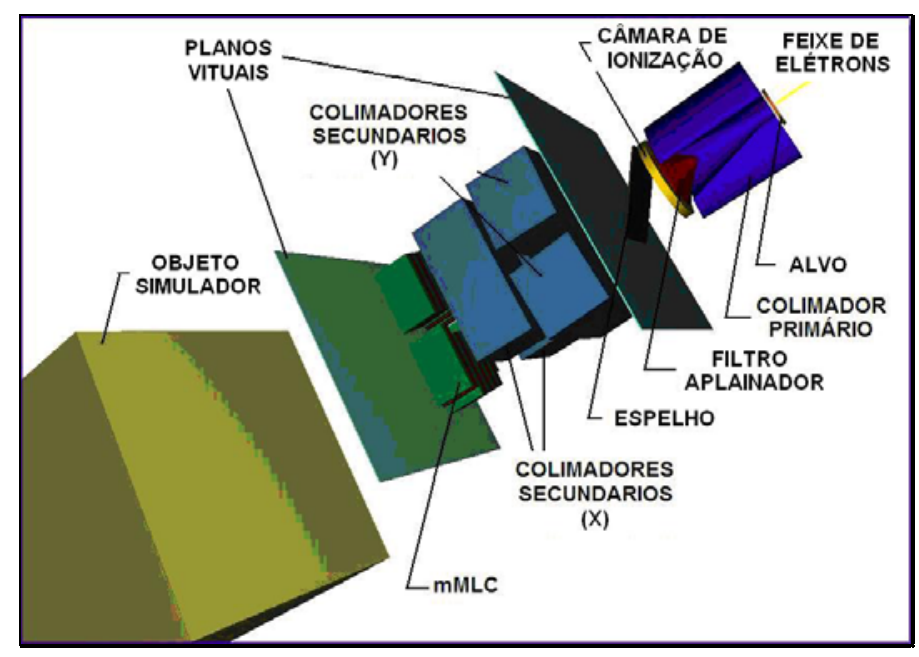

Figura 24: Principais componentes do CLINAC 600C para fins de simulação em Monte Carlo. Figura gerada com o programa GVIEW3D do PENELOPE. 
Na primeira etapa de simulação, o CLINAC 600C possui uma colimação primária cônica de raio $\mathrm{R}=24,93 \mathrm{~cm}$ (projetado no isocentro). Os componentes são posicionados em um sistema de coordenadas com a direção do eixo $Z$ na vertical em ordem decrescente, a partir de $\mathrm{Z}=0 \mathrm{~cm}$ (alvo) e até $\mathrm{Z}=-25 \mathrm{~cm}$ (abaixo da blindagem secundária e do espelho para a luz de campo) e foram modelados seguindo-se as recomendações e medidas fornecidas pelo fabricante. Considera-se que abaixo do alvo, o ar na pressão padrão de 1013 mbar seja o meio onde se encontram imersos os componentes. As descrições geométricas e os resultados das simulações dessa primeira etapa são discutidos a seguir, nos itens 6.1.2.1, 6.1.2.2 e 6.1.2.3.

\subsubsection{Simulação com PENELOPE}

A descrição geométrica do acelerador foi feita por meio de superfícies quadráticas, tal como requerida pela rotina PENGEOM do PENELOPE. Com essa descrição se obtém uma representação tridimensional do equipamento, no qual se dá o transporte individual das partículas produzidas.

O programa de usuário criado em linguagem de programação Fortran é baseado no exemplo "PENDOSES.F” contido no pacote de programas do PENELOPE. Para a entrada de dados é necessário criar um arquivo que contém a descrição do feixe inicial de elétrons de $6 \mathrm{MV}$, como fonte de radiação e o número de materiais. As energias de absorção escolhidas foram EABS $=100 \mathrm{keV}$, para elétrons e pósitrons, e EABS = $10 \mathrm{keV}$ para fótons, os parâmetros de simulação C1 e C2 foram igualados a 0,10, após testes inicias, e os parâmetros Wcc e Wcr foram escolhidos como sendo 10 keV e $1 \mathrm{keV}$, respectivamente. Também é necessário indicar o plano virtual (em $\mathrm{Z}=$ $25,0 \mathrm{~cm})$ no qual se armazenam as informações do espaço de fases das partículas resultantes, os parâmetros para utilização de interações forçadas como técnica de redução de variâncias, o número de histórias a simular, o tempo de simulação e as sementes para a geração da seqüência de números aleatórios.

Foi observado que nessa etapa inicial, grande parte do tempo de simulação é gasta com o transporte dos elétrons energéticos no alvo. Foram introduzidas, aos poucos, técnicas de redução de variâncias para permitir o aumento de velocidade de 
simulação. Na versão final realizada com o PENELOPE foram utilizadas técnicas de redução de variâncias do tipo “rejeição por alcance” para elétrons secundários e “interações forçadas” para produção de raios-X, com um fator 40. Ainda assim, o tempo de simulação para obter um arquivo com espaço de fases adequado ( $10^{8}$ "partículas”) levaria mais de 1 ano de simulação contínua e ininterrupta com esse processador. A velocidade final atingida ficou em torno de 8200 partículas por hora. No entanto, devido a simetria cilíndrica contida nessa primeira etapa de simulação do acelerador é possível obter uma descrição do espectro de fótons do feixe, mesmo utilizando-se um arquivo de espaço de fase reduzido (com aproximadamente $10^{6}$ “partículas”).

\subsubsection{Simulação com MCNP4C}

A simulação realizada com o código MCNP utiliza a mesma fonte inicial de elétrons de $6 \mathrm{MeV}$, monoenergética e monodirecional, incidindo nos componentes do acelerador representados na Figura 25, gerada com o vizualizador mcnplot.

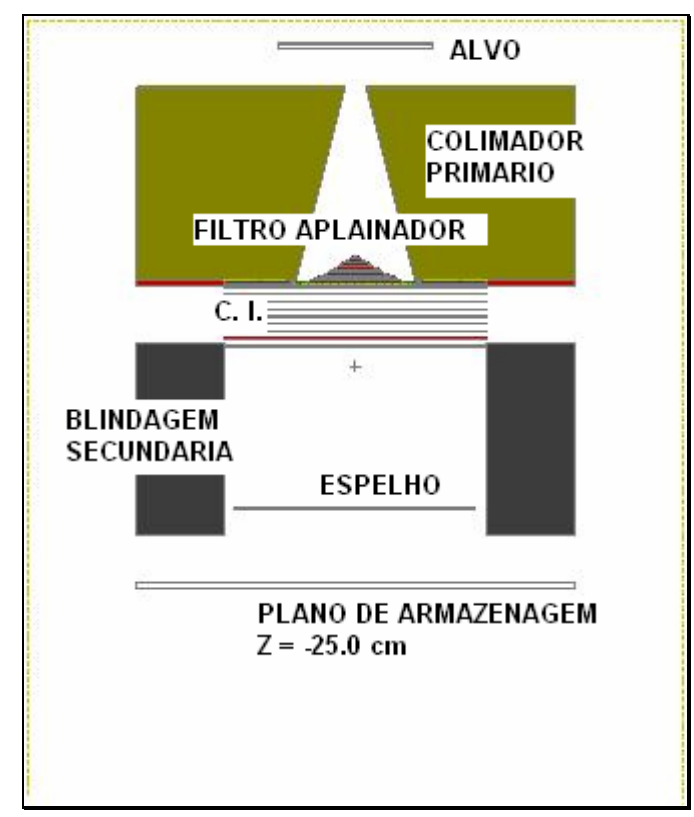

Figura 25: Visualização no mcnplot da geometria descrita.

Foram feitas simulações de teste sem energias de corte e, então, com energias de corte para os elétrons de $100 \mathrm{keV}$ e $500 \mathrm{keV}$, porém somente para as células que contém o alvo e o colimador primário, onde ocorre um número muito grande de 
colisões eletrônicas, retardando assim o processo de simulação. O programa de entrada ainda solicitava,, a obtenção da fluência de fótons e o armazenamento da descrição por espaço de fase das “partículas” resultantes nos planos $Z=0,3 \mathrm{~cm}$ (abaixo do alvo), 11,4 cm (abaixo do filtro aplainador) e 25,0 cm (abaixo do espelho e da blindagem secundária), cujos resultados são apresentados na Tabela 6.

Tabela 6: Sumário dos resultados obtidos para as três simulações com o MCNP (considerando três energias de corte para elétrons) e estimativa do tempo de simulação para obter o arquivo com espaço de fases adequado ( $10^{8}$ "partículas") no plano $\mathrm{Z}=$ $25 \mathrm{~cm}$.

\begin{tabular}{|c|c|c|c|c|c|}
\hline \multirow{2}{*}{$\begin{array}{c}E_{\text {corte }} \mathbf{p} / \mathbf{e}_{\mathrm{s}}^{-} \\
(\mathrm{MeV})\end{array}$} & \multirow{2}{*}{$\begin{array}{l}\text { histórias } \\
\text { por min. }\end{array}$} & \multicolumn{3}{|c|}{ partic. armaz./min (plano Z) } & \multirow{2}{*}{$\begin{array}{l}\mathbf{T}_{\text {estim }} \\
\text { (dias) }\end{array}$} \\
\hline & & $\mathrm{Z}=0,3 \mathrm{~cm}$ & $\mathrm{Z}=11,4 \mathrm{~cm}$ & $\mathrm{Z}=25 \mathrm{~cm}$ & \\
\hline - & 213 & 164 & 15 & 15 & 4630 \\
\hline 0,1 & 9806 & 6939 & 545 & 449 & 155 \\
\hline 0,5 & 15257 & 10678 & 800 & 624 & 111 \\
\hline
\end{tabular}

Os resultados preliminares dessas simulações permitem estimar o tempo de simulação para obter o arquivo com espaço de fase adequado ( $10^{8}$ "partículas" armazenadas no plano $Z=25 \mathrm{~cm})$. Com base nesses resultados, optou-se por utilizar o caso mais rápido e, ao mesmo tempo mais cauteloso, em que as energias de corte são de $100 \mathrm{keV}$. Isto permite aumentar a velocidade de simulação de 213 para 9806 histórias por minuto e diminuir o tempo de simulação por um fator 30 para chegar ao conjunto de $10^{8}$ "partículas”. A escolha de energias de corte maiores também seria possível, mas deve ser cautelosa para não interferir no processo físico.

A fluência média de fótons produzida pelo acelerador, ilustrada na Figura 26, bem como a dependência radial da energia média dos fótons do feixe, mostrada na Figura 27, também puderam ser inferidas por meio de uma saída de dados do MCNP. Para este estudo, o plano $Z=25 \mathrm{~cm}$ foi segmentado em anéis cilíndricos de raio 2, 4, 6, 8 e $10 \mathrm{~cm}$ onde se armazenou a fluência resultante. 


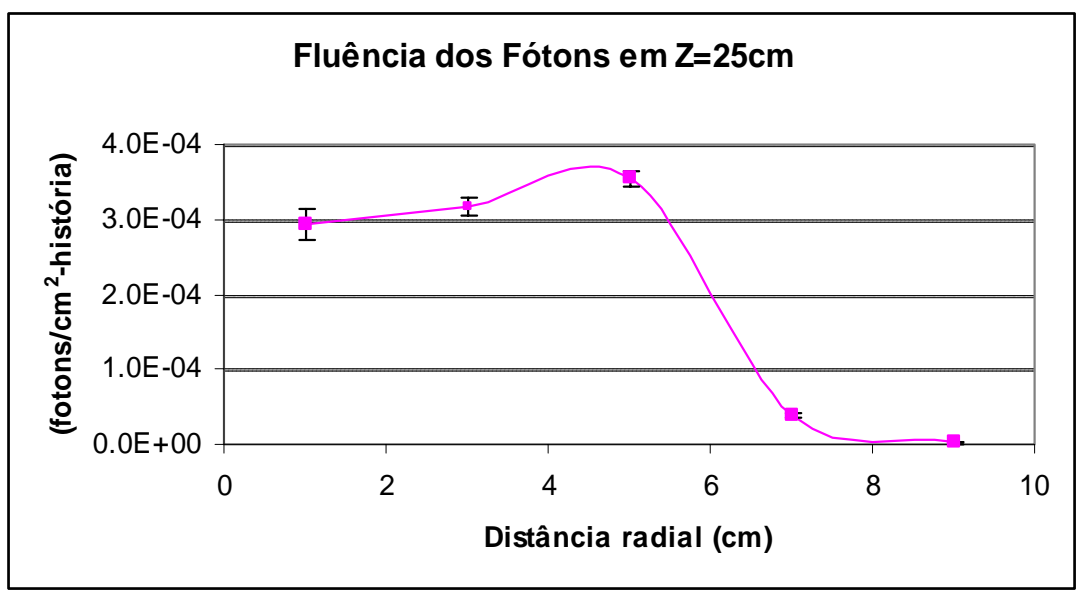

Figura 26: Fluência dos fótons no plano $Z=25 \mathrm{~cm}$, segmentado por superfícies cilíndricas, após simulação através da parte fixa do acelerador.

Como esperado, a fluência média de fótons tem um valor central que aumenta em direção às bordas, devido ao formato do filtro aplainador (mais espesso no centro e menos espesso em direção às bordas). A fluência deve ser próxima a zero na região mais externa, blindada pelo colimador primário.

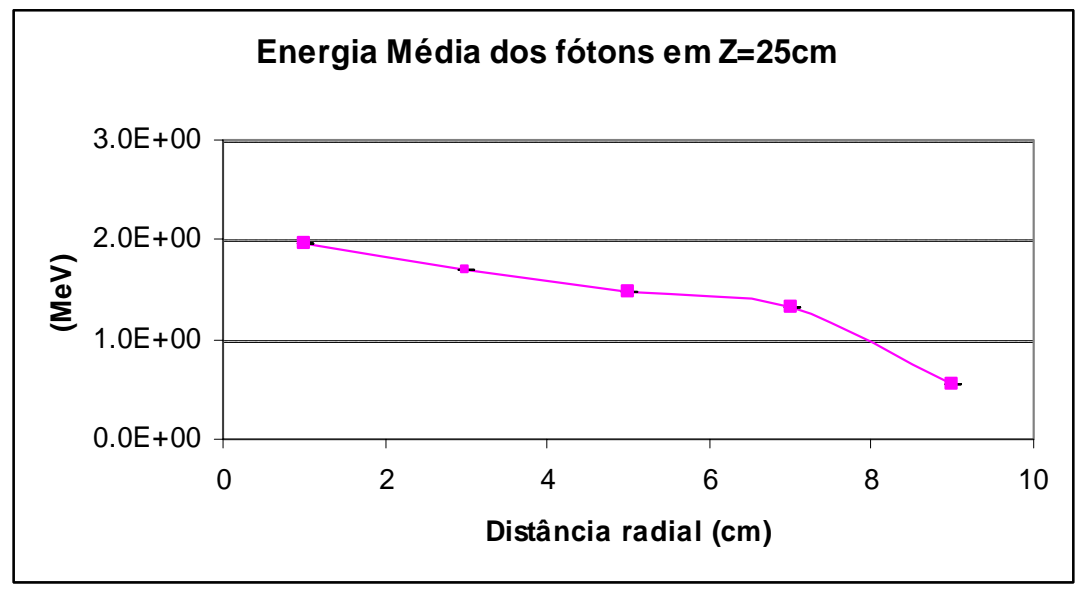

Figura 27: Energia média dos fótons no plano $Z=25 \mathrm{~cm}$, segmentado por superfícies cilíndricas e por energia, após simulação através da parte fixa do acelerador.

A energia média dos fótons, ao contrário da fluência, tem um valor central que diminui em direção às bordas, mas isso também é devido ao formato do filtro aplainador. Na região central, onde o filtro é mais espesso, há um maior endurecimento do feixe. 


\subsubsection{Espectro de Fótons de 6MV}

A partir dos dados dos arquivos de espaço de fases é possível observar a distribuição das partículas do feixe no plano de armazenamento, como o exemplo mostrado na Figura 28. Nesse exemplo, o arquivo, gerado em uma simulação de teste com o MCNP, contém aproximadamente 2200 fótons e 11 elétrons no plano $Z=25 \mathrm{~cm}$.



Figura 28: Exemplo de amostragem espacial de partículas (fótons em azul e elétrons em vermelho) no plano $\mathrm{Z}=25 \mathrm{~cm}$, após simulação através da parte fixa do acelerador, gerada com o MCNP.

O espectro de energia do feixe de fótons pode ser inferido pela distribuição de energias em cada caso, representados na Figura 29. Para permitir a comparação, o espectro calculado com o MCNP foi renormalizado para a mesma área do espectro obtido com o PENELOPE. Apesar da pouca estatística de dados da simulação com o MCNP, o espectro apresentado concorda em aproximadamente $80 \%$ dos pontos, considerando as barras de incerteza, com o espectro obtido da simulação com o PENELOPE, no qual as incertezas estão próximas a 0,5\%. A energia média foi de $(1,6 \pm$ $0,3) \mathrm{MeV}$ com o MCNP e de $(1,72 \pm 0,08) \mathrm{MeV}$ com o PENELOPE. 


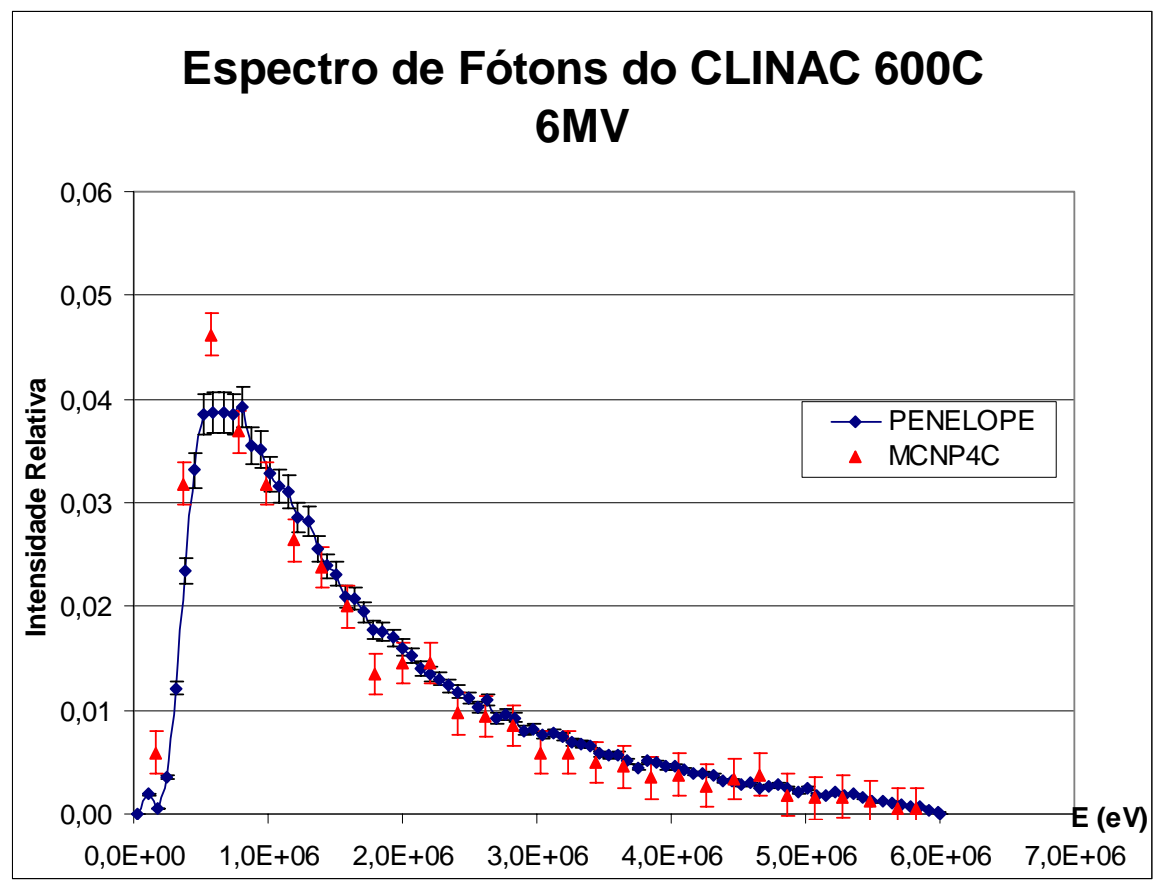

Figura 29: Espectro de Energia dos fótons no plano $Z=25 \mathrm{~cm}$, após simulação através da parte fixa do acelerador.

Os espectros simulados com o PENELOPE e o MCNP também são mostrados de forma um pouco mais simplificada na tabela a seguir.

Tabela 7: Intensidades relativas das energias do feixe de 6 MV do CLINAC 600C simuladas por Monte Carlo com PENELOPE e MCNP.

\begin{tabular}{|c|c|c|}
\hline $\mathbf{E}(\mathrm{eV})$ & PENELOPE & MCNP4C \\
\hline $1,00 \mathrm{E}+05$ & 0,002 & 0,003 \\
\hline $2,00 \mathrm{E}+05$ & 0,001 & 0,003 \\
\hline $4,00 \mathrm{E}+05$ & 0,039 & 0,074 \\
\hline $6,00 \mathrm{E}+05$ & 0,107 & 0,133 \\
\hline $8,00 \mathrm{E}+05$ & 0,113 & 0,106 \\
\hline $1,00 \mathrm{E}+06$ & 0,102 & 0,094 \\
\hline $1,20 \mathrm{E}+06$ & 0,087 & 0,084 \\
\hline $1,40 \mathrm{E}+06$ & 0,075 & 0,075 \\
\hline $1,60 \mathrm{E}+06$ & 0,065 & 0,063 \\
\hline $1,80 \mathrm{E}+06$ & 0,056 & 0,047 \\
\hline $2,00 \mathrm{E}+06$ & 0,047 & 0,038 \\
\hline $2,20 \mathrm{E}+06$ & 0,042 & 0,047 \\
\hline $2,40 \mathrm{E}+06$ & 0,035 & 0,029 \\
\hline $2,60 \mathrm{E}+06$ & 0,030 & 0,031 \\
\hline $2,80 \mathrm{E}+06$ & 0,027 & 0,026 \\
\hline $3,00 \mathrm{E}+06$ & 0,023 & 0,020 \\
\hline
\end{tabular}

\begin{tabular}{|c|c|c|}
\hline $\mathbf{E ~ ( e V )}$ & PENELOPE & MCNP4C \\
\hline $3,20 \mathrm{E}+06$ & 0,021 & 0,015 \\
\hline $3,40 \mathrm{E}+06$ & 0,020 & 0,015 \\
\hline $3,60 \mathrm{E}+06$ & 0,017 & 0,017 \\
\hline $3,80 \mathrm{E}+06$ & 0,015 & 0,012 \\
\hline $4,00 \mathrm{E}+06$ & 0,012 & 0,010 \\
\hline $4,20 \mathrm{E}+06$ & 0,011 & 0,010 \\
\hline $4,40 \mathrm{E}+06$ & 0,011 & 0,009 \\
\hline $4,60 \mathrm{E}+06$ & 0,009 & 0,011 \\
\hline $4,80 \mathrm{E}+06$ & 0,008 & 0,009 \\
\hline $5,00 \mathrm{E}+06$ & 0,006 & 0,006 \\
\hline $5,20 \mathrm{E}+06$ & 0,006 & 0,004 \\
\hline $5,40 \mathrm{E}+06$ & 0,005 & 0,004 \\
\hline $5,60 \mathrm{E}+06$ & 0,004 & 0,004 \\
\hline $5,80 \mathrm{E}+06$ & 0,003 & 0,001 \\
\hline $6,00 \mathrm{E}+06$ & 0,001 & 0,001 \\
\hline
\end{tabular}


É provável que ambos os espectros obtidos das simulações sejam um pouco mais endurecidos que o espectro real, pois a utilização de energias de corte faz com que diminua a contribuição de partículas com energias mais baixas. Além disso, as próprias bases de dados de coeficientes de interação contidas nesses $\operatorname{códigos~}^{[12,22,42,44]}$ não contemplam valores para energias muito baixas. Por isso, para que o feixe calculado possa ser utilizado com fins dosimétricos é necessário que o modelo de fonte espectral seja validado por meio de comparações com valores de dose determinados a partir de medidas experimentas.

\subsubsection{Validação do Código de Simulação}

A validação do espectro obtido anteriormente, na primeira etapa de simulação, foi feita com a continuidade da segunda e terceira etapas, para um campo de referência de 10cm x 10cm utilizando o código PENELOPE.

Na segunda etapa de simulação foi utilizado o modelo de fonte simples, contendo o espectro do feixe de fótons, incidindo sobre a fase de componentes móveis do CLINAC. Os resultados foram armazenados no plano virtual abaixo dos colimadores, e a descrição por espaço de fases foi utilizada na terceira etapa da simulação incidindo em um objeto simulador de água. A distribuição de dose em profundidade - PDP foi calculada em volumes de $0,5 \mathrm{~cm}$ x 0,5 $\mathrm{cm} \mathrm{x} \mathrm{0,5} \mathrm{cm}$ ao longo do eixo central e, então, comparada com as medidas realizadas com a câmara de ionização RK, apresentadas na Figura 30. 


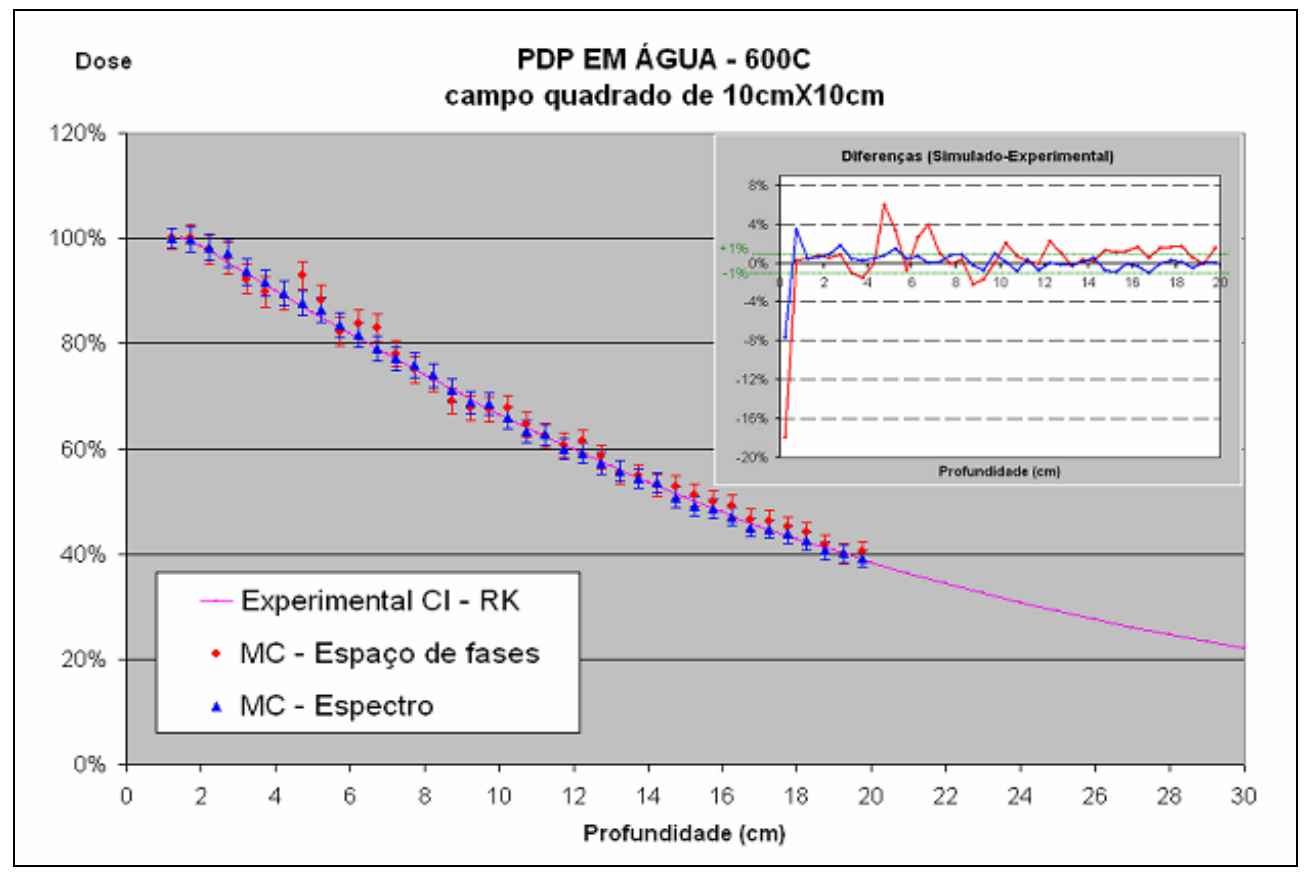

Figura 30: PDP em água do campo $10 \mathrm{cmx} 10 \mathrm{~cm}$ utilizando as duas técnicas de simulação com o código PENELOPE, (a) Em vermelho, obtida com a descrição por espaço de fases; (b) em azul, obtida com o modelo de fonte espectral.

Para efeitos de comparação, foi incluído o resultado de uma simulação de teste contendo a descrição por espaço de fases do acelerador obtida na primeira etapa de simulação do CLINAC. Como esperado, a descrição por espaço de fases não é completa (contém aproximadamente $10^{6}$ "partículas", sendo que a quantidade mais adequada seria da ordem de $10^{8}$ ) e ocupa uma grande quantidade de memória e espaço em disco, tornando a simulação mais lenta. Essa descrição de espaço de fases limitada se vê refletida no ruído estatístico da curva de PDP simulada, como visto na Figura 30. As alternativas para melhorar a estatística dos resultados seriam re-utilizar o conjunto de dados, contido no arquivo de espaço de fases, com novas seqüências de simulação (utilizando diferentes sementes de números aleatórios no programa de simulação), ou, em outro caso, aproveitar-se da simetria rotacional do CLINAC na primeira etapa de simulação e produzir rotações das partículas contidas no arquivo de espaço de fases. No entanto, a distribuição de dose ao longo do eixo central ainda sofreria com as distribuições de partículas e energias “viciadas”. O mais correto para obter-se uma descrição adequada por espaço de fases é utilizar computadores com maior poder computacional, ou mesmo os conjuntos (os chamados "clusters") de 
computadores $^{[13,31,41]}$, nos quais diversos processadores são interligados para dividir a tarefa de simulação.

Os resultados da simulação que utiliza o modelo de fonte, com espectro inicial, mostram que além da região de "build up", apenas dois pontos diferem mais de $1 \%(1,8 \%$ e $1,5 \%)$, enquanto mais de $90 \%$ dos pontos se encontram dentro da faixa de diferença de $\pm 1 \%$ atingindo os critérios de seleção para validar o código de simulação ${ }^{[13,31]}$. O mesmo não ocorre para o resultado obtido da descrição reduzida por espaço de fases que apresenta diferenças até maiores que 4\%, mesmo após a região de "build up”.

A distribuição lateral de dose, ou perfil de dose, foi calculada em volumes de 0,2 cm x 0,2 cm x 0,5 cm ao longo de um dos eixos transversais (eixo Y), a uma mesma profundidade em água. Para estas simulações apenas o modelo de fonte, criado com o código PENELOPE e usando o espectro de fótons, foi utilizado. Os resultados das simulações por MC foram comparados às medidas realizadas com o diodo $\mathrm{PFD}^{3 \mathrm{G}} \mathrm{e}$ são apresentados na Figura 31 ( a 1,5 cm de profundidade) e Figura 32 ( a $10 \mathrm{~cm}$ de profundidade) a seguir.

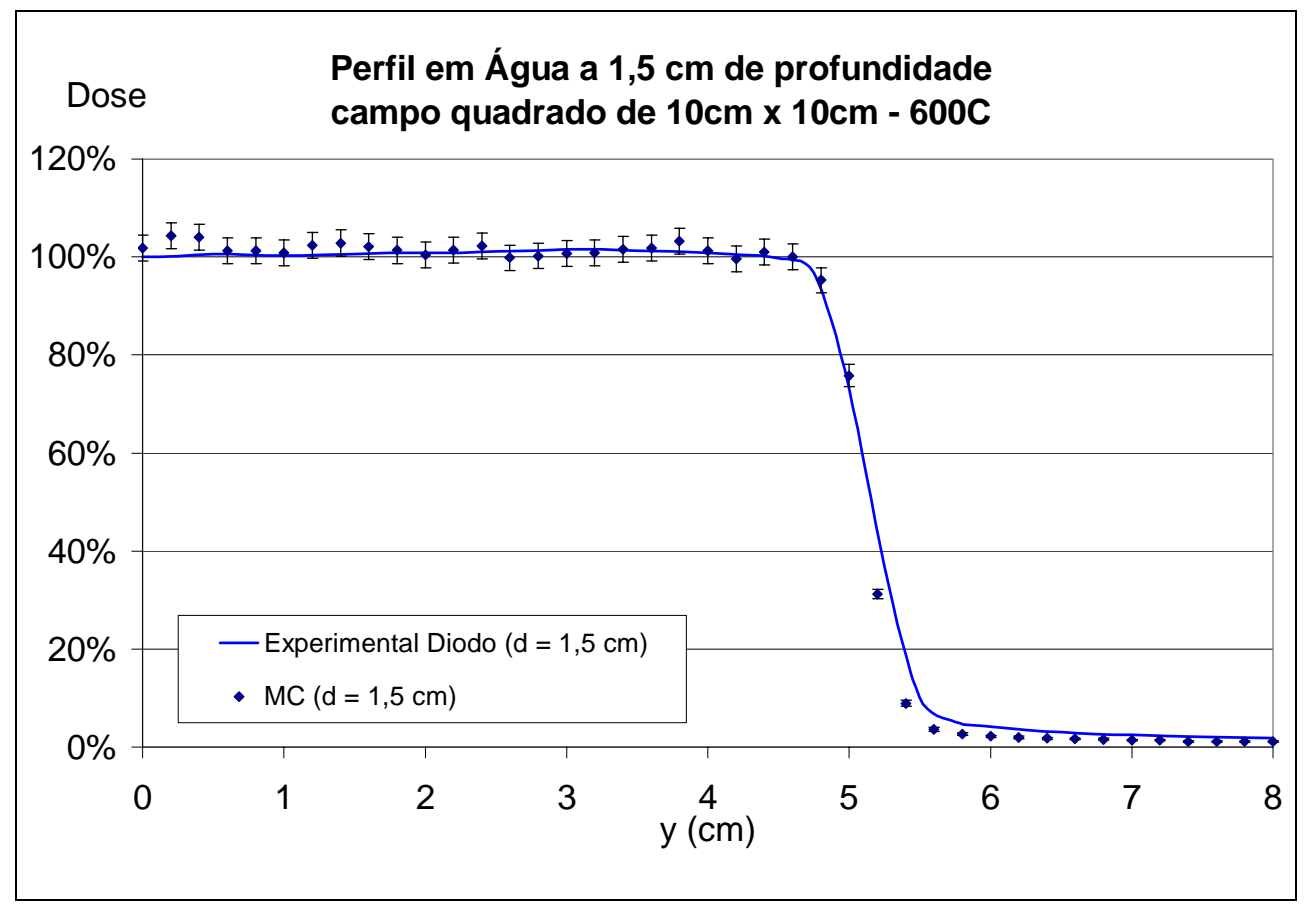

Figura 31: Perfil em água a $1,5 \mathrm{~cm}$ de profundidade do campo $10 \mathrm{~cm} \times 10 \mathrm{~cm}$ utilizando o modelo de fonte espectral na simulação com o código PENELOPE e valores experimentais medidos com diodo. 


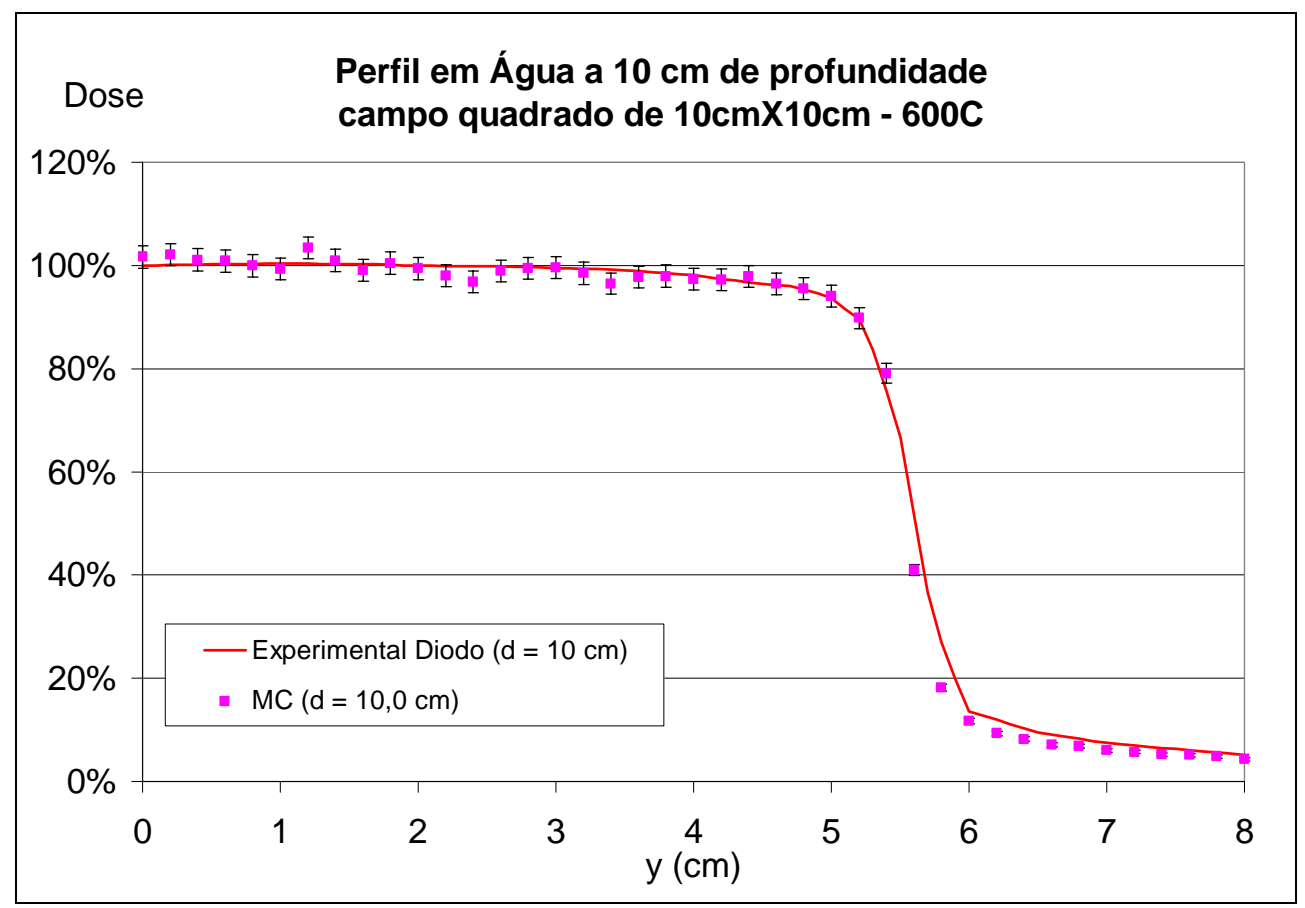

Figura 32: Perfil em água a $10 \mathrm{~cm}$ de profundidade do campo $10 \mathrm{~cm}$ x10 $\mathrm{cm}$ utilizando o modelo de fonte espectral na simulação com o código PENELOPE e valores experimentais medidos com diodo.

Os resultados das simulações dos perfis laterais de dose mostram que há concordância com os valores experimentais, em ambos os casos, de mais de $90 \%$ dos pontos na região plana do perfil. Para avaliar a região de alto gradiente de dose, correspondente à borda do campo, mede-se as diferenças entre a posição calculada e a posição medida para uma mesma dose. O gráfico dessas diferenças é apresentado na Figura 33. 


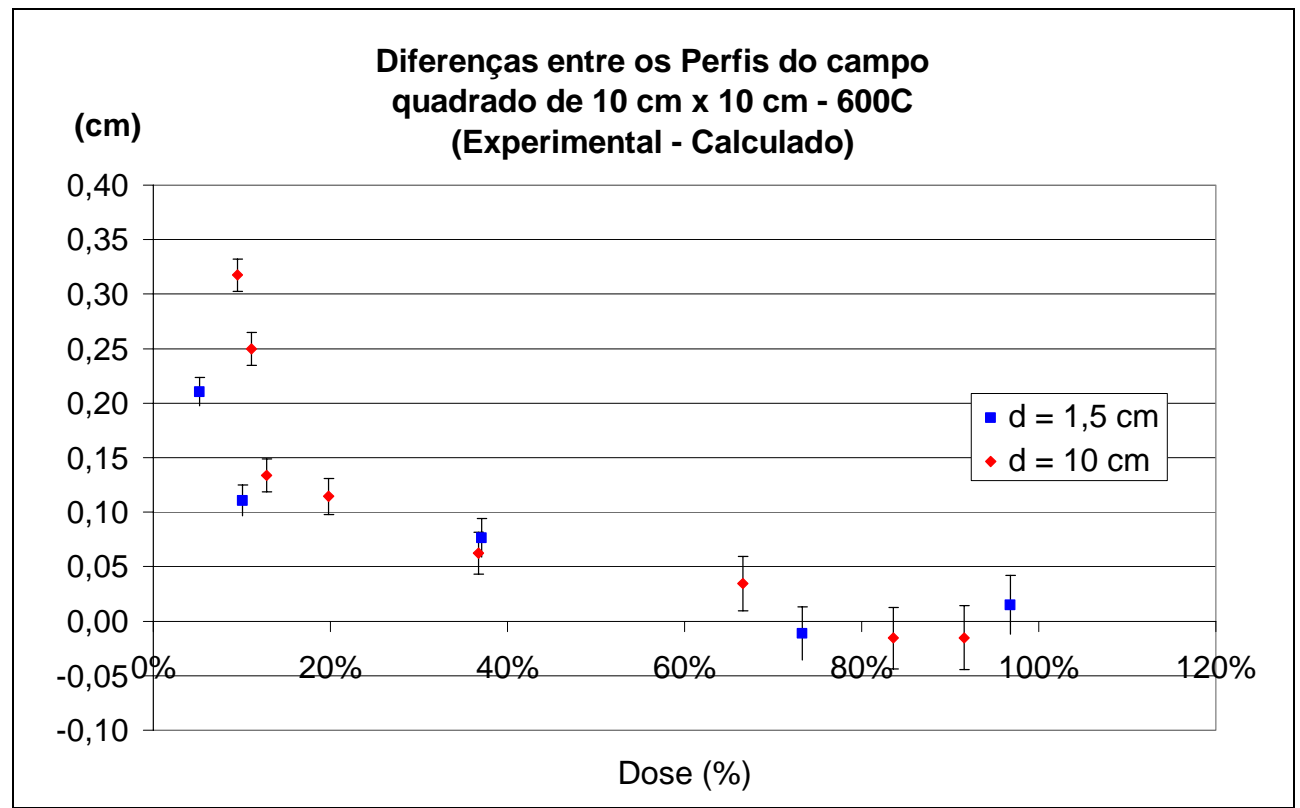

Figura 33: Diferença entre os perfis do campo $10 \mathrm{~cm} \times 10 \mathrm{~cm}$, medidos experimentalmente e calculados por MC, correspondente aos perfis da Figura 31 ( a 1,5 cm de profundidade) e da Figura 32 ( a $10 \mathrm{~cm}$ de profundidade), avaliados na região de alto gradiente de dose.

$\mathrm{Na}$ região de alto gradiente de dose (80\%-20\%) as diferenças entre a posição calculada e a posição medida para uma mesma dose se encontram dentro da faixa de $\pm 0,1 \mathrm{~cm}$, atingindo os critérios de seleção para validar o código de simulação ${ }^{[13]}$ [31] . Assim, mesmo utilizando o modelo de fonte simples criado com o código PENELOPE, é possível calcular as distribuições de dose em água com discrepâncias da ordem de $\pm 1,0 \%$ na dose e de $\pm 0,1 \mathrm{~cm}$ na posição, que são perfeitamente aceitáveis em Radioterapia.

\subsection{Avaliação Dosimétrica do Acelerador Linear equipado com o mMLC}

A descrição geométrica do mMLC, visualizada na Figura 34 por meio dos programas GVIEW2D e GVIEW3D, contidos no pacote PENELOPE, concorda com os planos contidos no manual do fabricante. A modelagem detalhada das lâminas inclui as bordas das extremidades, a espessura divergente e os encaixes do tipo lingüeta-vão (“tongue and groove”) entre lâminas adjacentes. 


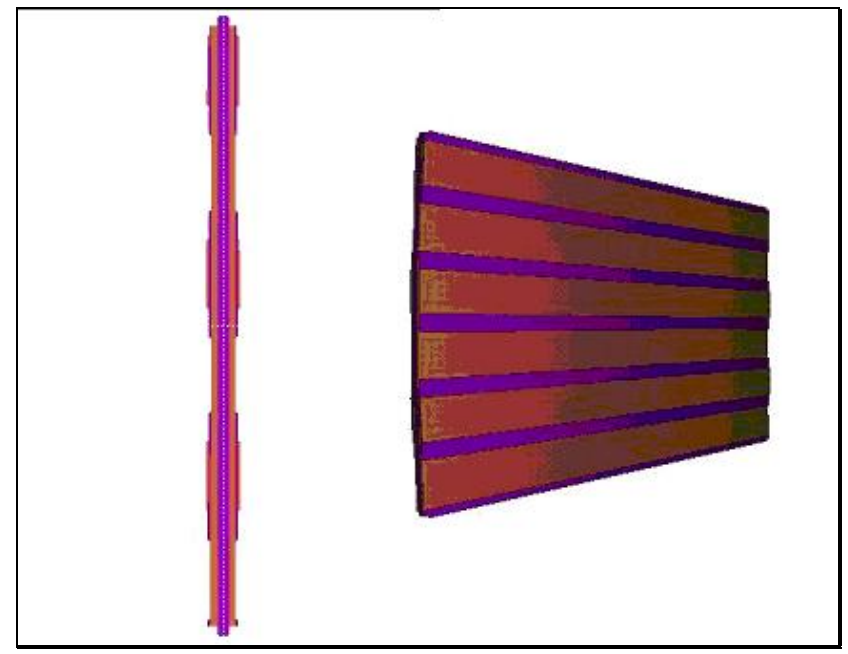

Figura 34: Visualização de uma das lâminas do mMLC, em um corte transversal em 2D, à esquerda; e numa visualização em 3D, à direita.

\subsubsection{Transmissão e Efeito Lingüeta-Vão (Tongue and Groove) do m3}

A transmissão do mMLC pode ser dividida em duas componentes, a transmissão intra-lâminas que ocorre através da lâmina inteira, e a transmissão entrelâminas, através da junção entre lâminas adjacentes, representadas na Figura 35.

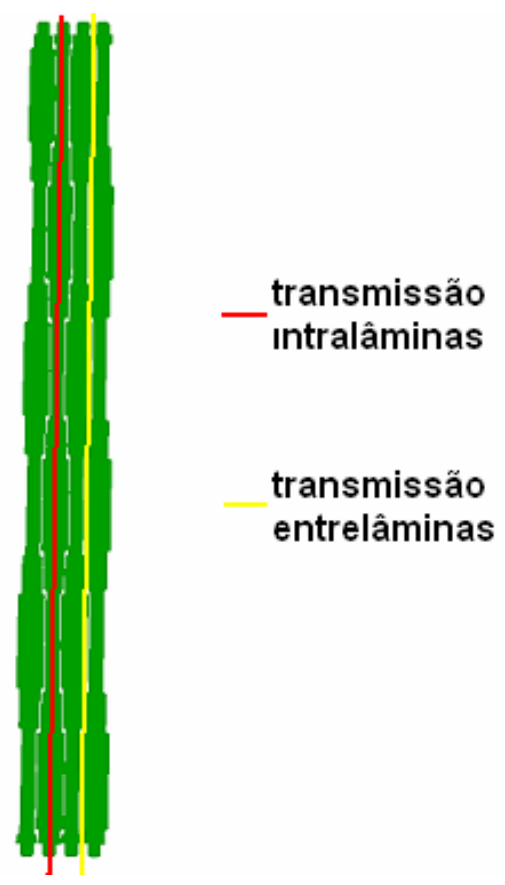

Figura 35: Esquema com quatro das lâminas do mMLC m3 e as trajetórias típicas da radiação transmitida intra-lâminas e entre-lâminas. 
A transmissão é medida com todas as lâminas de um lado do mMLC bloqueando o campo de radiação. A distribuição de fótons obtida da simulação através desse campo fechado foi obtida de um arquivo de espaço de fases em um plano logo abaixo do mMLC, e que está representada na Figura 36. Para o cálculo da dose simulada as energias de corte foram $100 \mathrm{keV}$ para elétrons e pósitrons, e $10 \mathrm{keV}$ para os fótons. A validação experimental da transmissão simulada foi feita na mesma geometria utilizando o filme dosimetrico X Omat-V (Kodak) e um objeto simulador de "Solid Water”, a 5cm de profundidade. Os filmes para medir a transmissão foram irradiados com 2500 UM, campo fechado, e 100 UM para o campo aberto de referência.
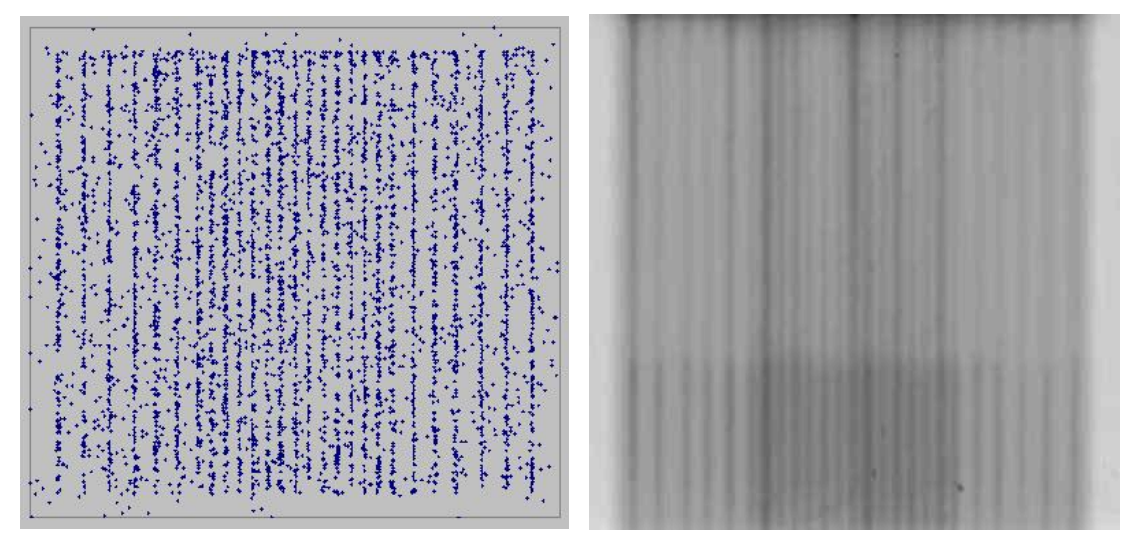

Figura 36: Distribuição de fótons obtida da simulação do mMLC fechado (à esquerda); Filme radiográfico irradiado para avaliar a transmissão do mMLC (à direita).

De acordo com as simulações, o endurecimento do feixe causado pela atenuação no mMLC resultou em um aumento da energia média dos fótons de aproximadamente $0,8 \mathrm{MeV}$, quando comparado ao espectro do campo aberto, indicando e confirmando que a medida deve ser feita idealmente em profundidades maiores que a profundidade de dose máxima do campo aberto $(1,5 \mathrm{~cm})$.

A transmissão total média obtida da simulação por MC foi de $(1,1 \pm 0,2) \%$, enquanto que o valor medido com filme variou entre 1,03\% (corresponde à transmissão intra-lâminas) ao valor máximo de 1,62\% (corresponde à transmissão entre-lâminas). Na mesma figura mostra-se o filme dosimétrico irradiado para avaliar a transmissão do mMLC, no qual as linhas mais escuras correspondem à transmissão entre lâminas. 
Observa-se o mesmo padrão de linhas tanto na simulação quanto na medida experimental com filme.

Devido à baixa estatística de dados após a simulação através do mMLC bloqueado, as componentes da transmissão não foram calculadas separadamente, porém o valor médio obtido do cálculo em um volume de $5 \mathrm{~cm}$ x $5 \mathrm{~cm}$ x 0,5cm concorda, dentro da incerteza de $0,2 \%$, com a transmissão intra-lâminas determinada por medida experimental. A transmissão intra-lâminas é a componente majoritária da transmissão do m3, uma vez que a maior parte da radiação cruza a espessura completa das lâminas e apenas uma pequena porção cruza a região entre elas. Assim, em termos de valor médio, a transmissão obtida de uma simulação deve estar próximo ao valor da transmissão intra-lâminas, como foi o caso.

O efeito lingüeta-vão foi avaliado a 1,5 cm de profundidade usando um par de campos complementares com um padrão de tiras, resultando em 13 linhas de junção ao longo do comprimento de lâminas adjacentes, que podem ser visualizadas no filme mostrado na Figura 37. Essas linhas de junção não deveriam existir se as bordas laterais das lâminas fossem idealmente retas e estivessem perfeitamente alinhadas, situação que geralmente é considerada nos cálculos de sistemas de planejamento computadorizados. Nesse caso idealizado cada um dos campos contribuiria, na junção, exatamente com $50 \%$ da dose da região aberta e o campo composto seria totalmente uniforme. Para lâminas reais há uma subdosagem que, como mostrado, pode ser significativa.

As energias de corte para o cálculo de dose por meio da simulação com PENELOPE foram $100 \mathrm{keV}$ para elétrons e pósitrons, e $10 \mathrm{keV}$ para os fótons. $\mathrm{O}$ cálculo da dose foi realizado ao longo de volumes de $0,25 \mathrm{~cm} \times 2 \mathrm{~cm} \times 0,5 \mathrm{~cm}$, resultando em um perfil de dose transversal ao comprimento das lâminas, visto na Figura 37. 

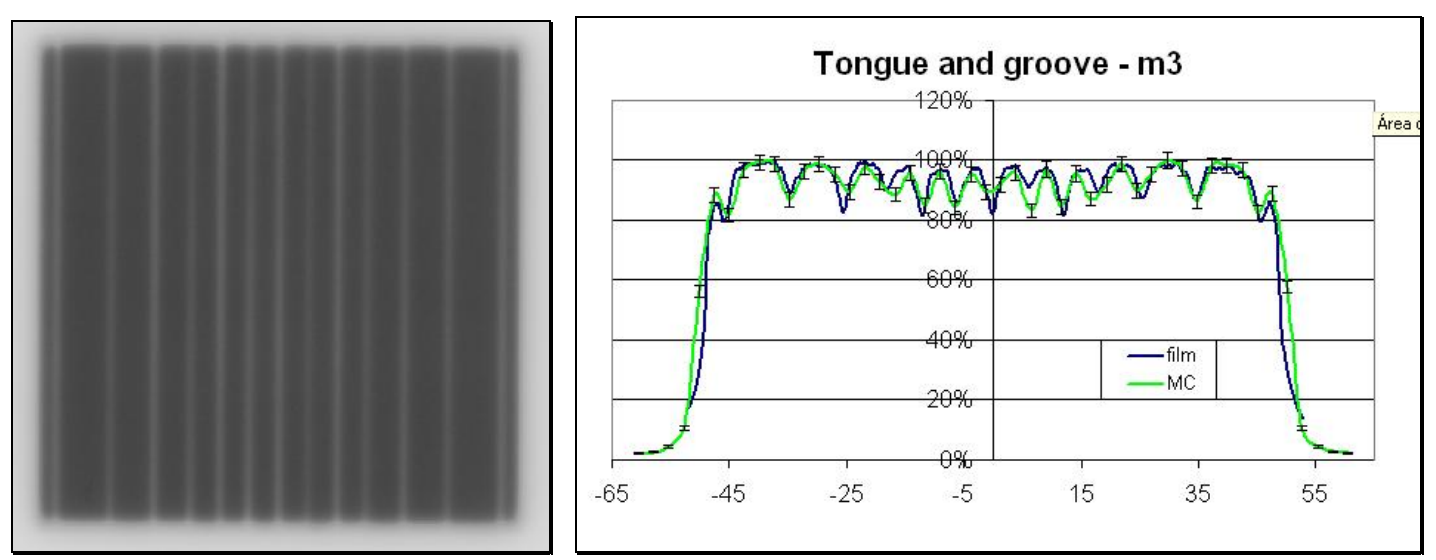

Figura 37: Filme radiográfico do efeito lingüeta-vão (“togue and groove”) (à esquerda) e gráfico dos perfis de dose para avaliar esse efeito, medido com filme e simulado por Monte Carlo (à direita).

A validação experimental do efeito lingüeta-vão foi feita na mesma geometria utilizando filme dosimetric X Omat-V (Kodak) e um objeto simulador de “Solid Water”. O filme para medir o efeito “tongue and groove” foi irradiado com 45 MU por campo, Figura 37.

Os resultados indicam que houve uma concordância maior que $90 \%$ entre os pontos calculados e medidos, apesar de ocorrerem pequenas discrepâncias devido ao alinhamento mecânico real das lâminas. As treze linhas de junção do perfil de dose determinaram que ocorreu uma subdosagem média de $(11,4 \pm 2,0) \%$, utilizando o método de Monte Carlo, e de $(12,5 \pm 2,7) \%$ medida com filme. A simulação por MC do efeito lingüeta-vão permitiu calcular valores pontuais dentro de uma incerteza estimada de $\pm 2 \%$.

O modelo do mMLC e o programa de MC criados são, desta forma, validados para o cálculo de dose absorvida devida aos campos conformados.

\subsubsection{Campos Conformados pelo mMLC m3}

Para a aplicação dos programas e geometrias de simulação aplicados à avaliação de campos conformados pelo mMLC foram escolhidos inicialmente dois campos circulares de diâmetro 1,8cm e 6,0cm, sempre utilizando o código PENELOPE. Esses dois campos são normalmente utilizados no processo de comissionamento do m3 e, ao mesmo tempo, representam campos próximos aos utilizados em situação de 
tratamento real. Como no caso dos campos abertos, os resultados simulados da distribuição de dose em água são comparados aos valores obtidos de medidas experimentais.

\section{1) campo circular de diâmetro $1,8 \mathrm{~cm}$}

A curva de dose em profundidade foi obtida da simulação por Monte Carlo e comparada com as medidas experimentais realizadas com a câmara de ionização RK em água. Os resultados apresentados na Figura 38 mostram que, excetuando-se os dados na região de "build-up”, houve excelente concordância entre os valores calculados por simulação e os dados experimentais.

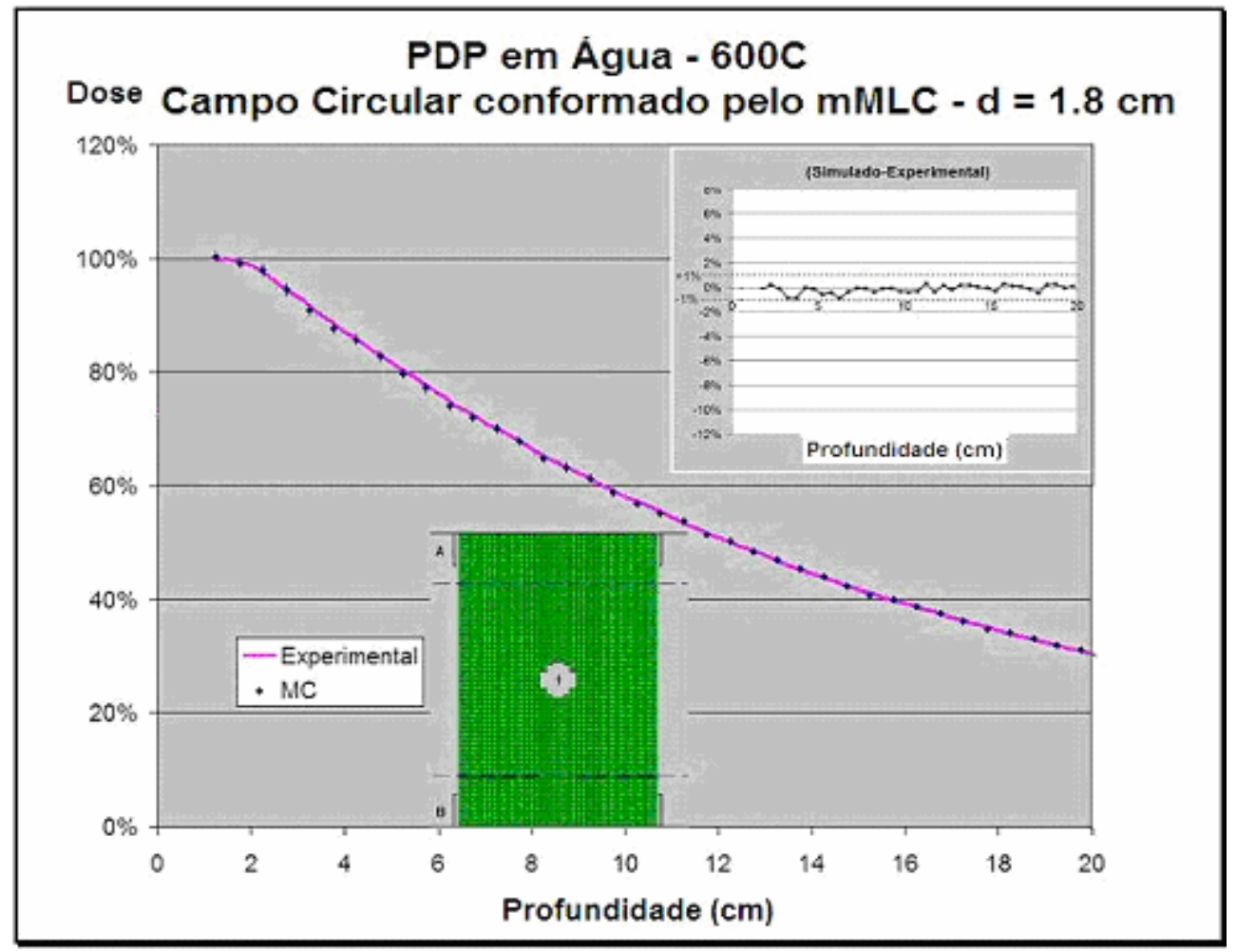

Figura 38: Comparação das PDPs, experimental e simulada por MC, em água, do campo circular de diâmetro 1,8 cm (representado no detalhe em verde).

Essa concordância está dentro das linhas que delimitam a diferença $\pm 1 \%$ (vide detalhe da Figura 38), obtendo-se os critérios de aceitação do código de simulação. As pequenas discrepâncias na região de "build-up" são devidas provavelmente à dificuldade em realizar medidas experimentais exatas nessas regiões. 


\section{2) campo circular de diâmetro $6,0 \mathrm{~cm}$}

A curva de dose em profundidade foi obtida da simulação por Monte Carlo e comparada com as medidas experimentais com câmara de ionização RK em água. Os resultados, como no caso do campo de 1,8 cm de diâmetro, mostram o mesmo tipo de discrepância na região de "build-up" e uma excelente concordância nos demais pontos da curva (diferenças dentro do intervalo $\pm 1 \%$ ), como visto na Figura 39.

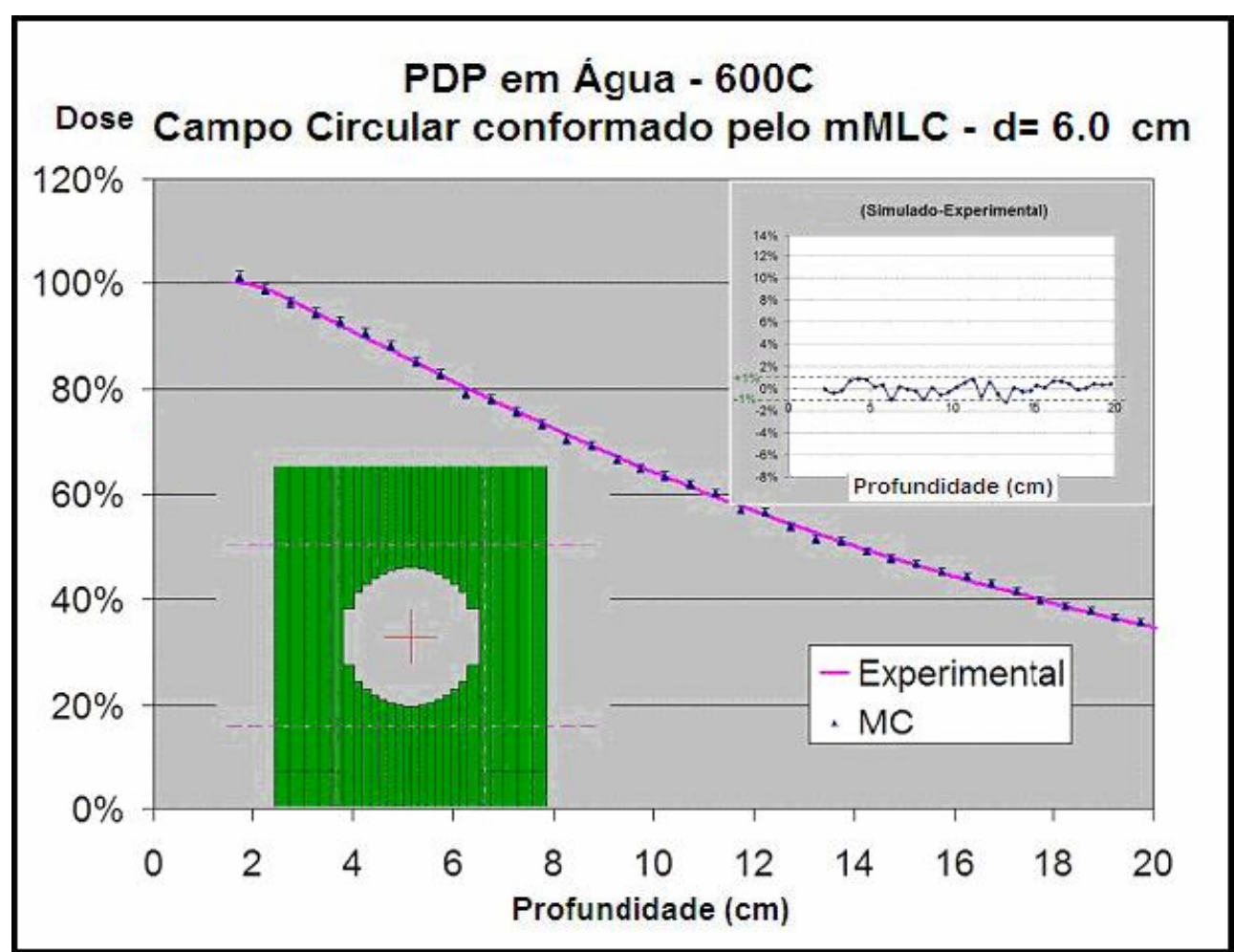

Figura 39: Comparação das PDPs, experimental e simulada por MC, em água, do campo circular de diâmetro 6,0 cm (representado no detalhe em verde).

\section{3) Fatores relativos de dose de campos conformados}

Os fatores relativos de dose de campos conformados pelo mMLC m3 foram calculados pela simulação por Monte Carlo e comparados aos valores de medidas experimentais com a micro câmara de ionização A16. Os campos calculados simulam campos circulares de diâmetros 1,8cm; 4,2cm; 6,0cm; 8,0cm e 9,8cm. Os resultados das medidas e simulações são mostrados na Figura 40. 




Figura 40: Fatores Relativos de Dose a $5 \mathrm{~cm}$ de profundidade em água, obtidos de medidas experimentais com câmara de ionização A16 e simulados por MC, de campos circulares conformados pelo mMLC m3.

Na comparação desses fatores relativos de dose, a $5 \mathrm{~cm}$ de profundidade em água, de campos conformados pelo mMLC m3, houve concordância entre todos os pontos medidos e calculados, vistos por meio das barras de incerteza da Figura 40. Porém, deve ser considerado que as incertezas dos valores calculados ficaram dentro do intervalo de 1 a 3\%, enquanto que os valores medidos têm aproximadamente 1\% de incerteza.

Ainda assim, o programa de simulação criado com o código PENELOPE fornece dados dosimétricos satisfatórios que poderiam, por exemplo, confirmar dados de comissionamento, avaliar modelos de cálculos dos SPTCs, bem como realizar cálculos de verificação independente dos tratamentos. Essa última finalidade poderia complementar as verificações feitas com cálculos convencionais a partir de dados retirados dos SPTCs, como o programa de cálculo independente para arco dinâmico de Delgado e colaboradores ${ }^{[46]}$ criado durante a realização deste trabalho e incluído no apêndice. A utilização da simulação por Monte Carlo, no entanto, permitiria realizar cálculos de campos mais complexos, sejam irregulares ou bloqueados, e ainda campos de IMRT. 


\section{CONCLUSÕES}

As medidas experimentais recentes do CLINAC 600C foram validadas por meio de comparações com valores de referência e por meio de medidas com diferentes detectores. Foram assumidos como valores corretos as curvas de PDP e os Fatores Relativos de Dose, realizados com a câmara de ionização RK, e os perfis de dose em profundidade, determinados de medidas com o diodo. Observou-se que o diodo superestima a dose em profundidade em até aproximadamente $2 \%$ para grandes profundidades, mas oferece uma resolução espacial maior para medidas de perfil de dose. Essas curvas de distribuição de dose absorvida em água são, agora, consideradas de referência e permitem caracterizar o feixe deste CLINAC para o cálculo de dose em pacientes.

A descrição geométrica do CLINAC 600C e a construção de programas de simulação pelo Método de Monte Carlo, utilizando os códigos PENELOPE e MCNP, mostraram-se adequadas para descrever o feixe de fótons de $6 \mathrm{MV}$. Os espectros de fótons resultantes de ambas as simulações concordam em aproximadamente $80 \%$ dos pontos amostrados, sendo que as energias médias de $(1,6 \pm 0,3) \mathrm{MeV}$, com o MCNP, e de $(1,72 \pm 0,08) \mathrm{MeV}$, com o PENELOPE, são coincidentes. O modelo de fonte simples do CLINAC 600C, criado com o código PENELOPE, permite calcular as distribuições de dose em água, de campos abertos, com discrepâncias da ordem de $\pm 1,0 \%$ na dose e de $\pm 0,1 \mathrm{~cm}$ na posição, se comparados a medidas experimentais. Com isso, se atingem os critérios de aceitação propostos inicialmente para validar o modelo de simulação.

A descrição geométrica do mMLC m3 para fins de simulação pelo Método de Monte Carlo, utilizando o código PENELOPE, também foi considerada satisfatória, permitindo a sua utilização para a caracterização dosimétrica desse sistema de colimador. A transmissão desse colimador foi calculada com uma incerteza estimada de $\pm 0,2 \%$. Além disso, foi calculada a sub-dosagem média de $(11,4 \pm 2,0) \%$, devida ao efeito lingüeta-vão, que coincide com o valor determinado experimentalmente de $(12,5 \pm 2,7) \%$, específicos para esse projeto de colimador.

Os programas de simulação por Monte Carlo, que fazem o uso de um modelo de fonte simples do CLINAC 600C, combinado com o modelo completo do mMLC m3, permitiram calcular distribuições de dose em água, de campos 
conformados, dentro do intervalo de $\pm 1 \%$ de discrepância, após a região de "build-up”, enquanto que os fatores relativos de dose de campos conformados pelo mMLC puderam ser calculados com incertezas que variam de 1 a $3 \%$ concordando com os valores experimentais. Com isso, o modelo contribui para o melhor entendimento dosimétrico da radiocirurgia e radioterapia de campos conformados com o mMLC e seu programa de garantia de qualidade. Esse modelo pode, ainda, ser usado como parâmetro de comparação em tarefas de comissionamento do m3, na avaliação dos algoritmos de cálculos dos sistemas de planejamento de tratamentos computadorizados, bem como numa possível verificação independente de tratamentos planejados nos STPCs, o que garante uma boa prática clínica. No entanto, os programas não trabalham diretamente com a representação geométrica tridimensional do paciente sendo mais apropriados para o cálculo de dose em objetos simuladores que possam ser definidos nos arquivos de entrada do PENELOPE. 


\section{APÊNDICE}

\section{CÁLCULO INDEPENDENTE DE DOSE PARA TRATAMENTOS DE ARCO} DINÂMICO COM COLIMADOR MICROMULTI-LÂMINAS*

Juan Fernando Delgado ${ }^{1}$, André Mozart Miranda Vieira² ${ }^{2}$ José Carlos Cruz ${ }^{3}$, Laura Natal Rodrigues $^{2}$

Radiol Bras 2006;39(5):355-359

Recebido para publicação em 16/10/2005. Aceito, após revisão, em 8/11/2005.

* Trabalho realizado no Departamento de Radioterapia do Hospital Israelita Albert Einstein, São Paulo, SP.

1. Instituto de Pesquisas Energéticas e Nucleares - Universidade de São Paulo, Hospital Oncológico "Solón Espinosa Ayala” - Núcleo de Quito, Equador.

2. Instituto de Pesquisas Energéticas e Nucleares - Universidade de São Paulo.

3. Departamento de Radioterapia do Hospital Israelita Albert Einstein.

\section{RESUMO}

OBJETIVO: Em técnicas de tratamento como o arco dinâmico, a verificação de forma manual dos cálculos do sistema de planejamento é muito difícil. Nestes casos, a utilização de ferramentas computacionais é de utilidade e torna-se um componente essencial do programa de controle de qualidade.

MATERIAIS E MÉTODOS: Foi criado um programa computacional de tipo planilha eletrônica para realizar um cálculo independente da dose, ou equivalentemente das unidades monitoras, nos tratamentos realizados pela técnica de arco dinâmico com micro multi-lâminas. Os valores de dose calculados, por arco e por tratamento completo, foram comparados aos valores obtidos do sistema de planejamento BrainScan v5.3. O programa desenvolvido foi testado com 229 campos de arco dinâmico que representam 42 tratamentos de crânio. Desses, 109 campos foram calculados em reconstrução tridimensional feita a partir das imagens de tomografia dos pacientes, 109 na reconstrução de um objeto simulador de polimetilmetacrilato e 21 na de um objeto simulador sólido equivalente à água.

RESULTADOS: A diferença média de doses totais encontrada nos 42 tratamentos (compostos de um ou mais arcos dinâmicos), entre o programa de verificação e o sistema de planejamento, foi de $+1,73 \%$, com desvio-padrão de $0,76 \%$. A diferença máxima encontrada foi de 3,32\% e a mínima, de $-0,20 \%$. No caso dos 229 arcos testados um a um, a diferença média encontrada foi de 1,61\%, com desvio-padrão de 1,04\%. Os valores máximos e mínimos das diferenças foram de $4,01 \%$ e $-2,04 \%$, respectivamente. Em $80,35 \%$ dos arcos testados, as doses calculadas encontram-se na faixa de $\pm 2,5 \%$ de diferença com relação às doses geradas pelo sistema de planejamento. 
CONCLUSÃO: O programa apresentado é recomendado para a verificação da dose pontual dos planos de tratamento, como parte do procedimento de garantia de qualidade em radioterapia e radiocirurgia estereotáxica quando se utiliza a técnica de arco dinâmico por meio de um colimador micromulti-lâminas, nos quais um cálculo manual é muito difícil ou inviável devido à complexidade da técnica.

Unitermos: Radioterapia; Radiocirurgia estereotáxica; Acelerador linear; Controle de qualidade em radioterapia; Cálculo de unidades monitoras; Colimador micromulti-lâminas.

\section{INTRODUÇÃO}

Um programa de controle de qualidade em radioterapia externa deve realizar a verificação de unidades monitoras em forma independente do cálculo do sistema de planejamento.

Em técnicas de tratamento convencionais esta constatação pode ser feita manualmente e de modo muito simples.

Com o uso de novas técnicas de tratamento, como a radioterapia por intensidade modulada de feixe (IMRT) e o arco dinâmico, o cálculo da dose pontual e as distribuições de dose dos planejamentos são mais complexos e a verificação de forma manual chega a ser muito difícil ou mesmo inviável. Nesses casos, a utilização de ferramentas computacionais ajuda nessa verificação e, junto com a medição da dose absoluta, torna-se um componente essencial do programa de controle de qualidade para as técnicas mencionadas. Cada tratamento de arco dinâmico possui um número significativo de segmentos a ser verificado, já que a cada $10^{\circ}$ de arco, o sistema de planejamento gera um segmento. Um tratamento geralmente é constituído por vários arcos.

Uma das técnicas de tratamento para radiocirugia estereotáxica é o arco dinâmico. O principio é a conformação do volume-alvo para liberar nele uma dose alta, poupando os tecidos sadios circundantes. Ao mesmo tempo em que o sistema de suporte funcional (gantry) do acelerador gira, formando um arco, as lâminas do colimador micromulti-lâminas (mMLC) conformam o alvo em forma dinâmica, adaptando-se ao volume-alvo em cada projeção. Esta técnica apresenta vantagens com relação às outras técnicas na conformação da dose, desde que a implementação, o diagnóstico, o planejamento, o controle de qualidade e o tratamento sejam realizados de forma rigorosa.

Apresentam-se, neste trabalho, os resultados obtidos por meio de um programa computacional de tipo planilha eletrônica que foi desenvolvido como ferramenta de verificação 
e controle de qualidade no Departamento de Radioterapia do Hospital Israelita Albert Einstein. O algoritmo usado na elaboração do programa permite o cálculo de unidades monitoras, ou dose absorvida, em tratamentos de arco dinâmico.

\section{MATERIAIS E MÉTODOS}

O equipamento utilizado nos tratamentos de radioterapia e radiocirurgia com arco dinâmico do Hospital Israelita Albert Einstein é um acelerador monomodal Clinac 600C (Varian Medical Systems; Palo Alto, Califórnia, EUA) com sistema de mMLC modelo $\mathrm{m}^{\mathrm{TM}}$ (BrainLAB, AG; Heimstetten, Alemanha) acoplado nele. O sistema tem a capacidade de produzir campos conformados, campos de intensidade modulada, em modo dinâmico e estático, e terapia rotatória dinâmica, mais conhecida como arco dinâmico ${ }^{(1)}$.

O sistema de planejamento utilizado para gerar os tratamentos é o Brainscan v.5.3 (BrainLAB, AG; Heimstetten, Alemanha). O cálculo é realizado em etapas: a definição geométrica das projeções do arco, a otimização considerando as características físicas das lâminas, e, por último, a contribuição da transmissão através do mMLC. O cálculo direto da distribuição de dose é baseado no algoritmo de feixe estreitamente colimado (pencil beam) ${ }^{(2,3)} \mathrm{e}$ utiliza correção para heterogeneidades.

Terminado o planejamento de um tratamento por arco dinâmico, este é revisado e discutido conjuntamente entre radioterapeuta e físico para sua aprovação. Uma vez aceito, os dados do plano de tratamento são enviados pela rede de registro e verificação para o controle do acelerador linear.

Nesse momento devem ser desenvolvidas tarefas de controle de qualidade do plano de tratamento escolhido. O sistema de planejamento permite exportar o plano a um objeto simulador, no qual é possível realizar medidas de dose absoluta, com câmara de ionização, e de distribuição de dose, com filme de verificação dosimétrica. Os dados de tratamento para cada arco, como ângulo inicial e final do sistema de suporte funcional, ângulo de mesa, pontos de localização do isocentro, configuração do mMLC, dose e unidades monitoras, são, então, verificados. Deve-se determinar a dose absoluta a partir do plano gerado no objeto simulador seguindo os protocolos de determinação de dose absorvida ${ }^{(4,5)}$.

Outra etapa muito importante, como parte do programa de controle da qualidade, é a verificação das unidades monitoras calculadas pelo sistema de planejamento ${ }^{(6-9)}$. Para isso, foi desenvolvido um programa computacional de verificação do tipo planilha eletrônica, com o objetivo de facilitar o cálculo de unidades monitoras, que, diferentemente das técnicas 
convencionais de radioterapia, não pode ser feito de forma direta e intuitiva. A idéia inicial é verificar o cálculo com poucos dados de entrada ${ }^{(10)}$.

Para verificar as unidades monitoras, o programa desenvolvido precisa de alguns parâmetros para calcular a dose prevista pelo sistema de planejamento no ponto de normalização. São utilizados os seguintes parâmetros:

- os arquivos com as posições das lâminas do mMLC de cada arco, divididas em segmentos separados por um ângulo de gantry de $10^{\circ}$, exportados pelo sistema de planejamento;

- as profundidades médias, equivalentes à água, do ponto de normalização para cada arco;

- as unidades monitoras (ou dose) no relatório final do plano escolhido.

Na Figura a1 encontra-se um exemplo da tela com o arquivo em formato texto (.txt), exportado pelo sistema de planejamento, contendo a informação do número de segmentos e as posições das lâminas de cada segmento de campo de tratamento. 


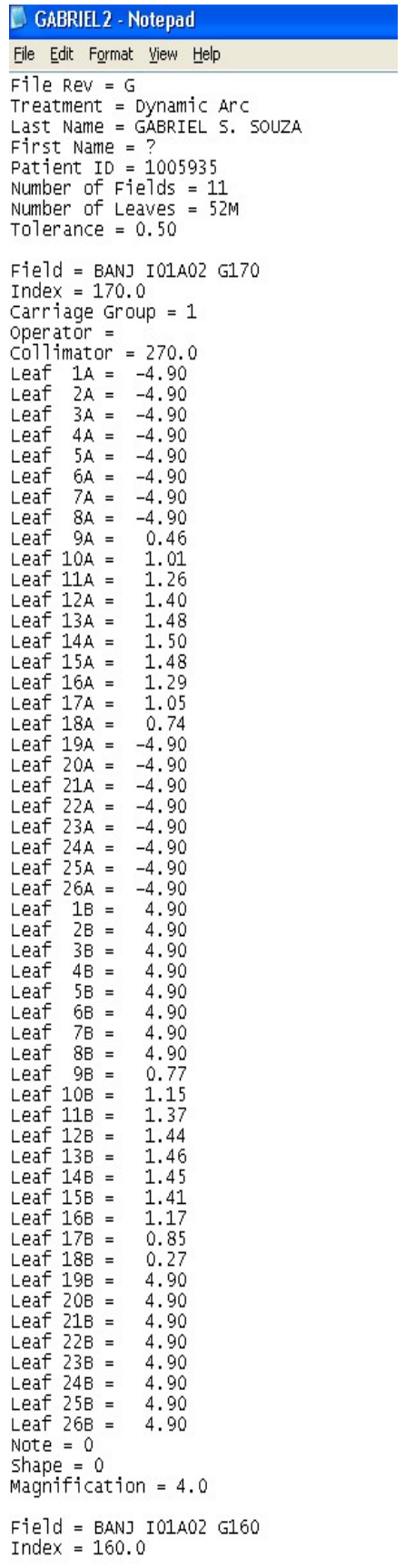

Figura a1. Tela do arquivo em formato de texto exportado pelo sistema de planejamento com as posições das lâminas para um segmento de arco.

Com esses três conjuntos de dados, o programa calcula o quadrado equivalente de cada segmento dos arcos de tratamento usando a relação de Sterling ${ }^{(11)}$. Com a profundidade equivalente de cada arco, o programa determina os valores da razão tecido máxima, dos fatores de espalhamento e das razões fora do eixo central, a partir dos valores obtidos no comissionamento do equipamento ${ }^{(12,13)}$. 
Para determinar as razões fora do eixo central de cada segmento, as coordenadas gravitacionais devem ser calculadas por meio das seguintes relações:

$$
\begin{gathered}
x_{g}=\frac{\int_{x_{1}}^{x_{2}} x y d x}{\int_{x_{1}}^{x_{2}} y d x} \\
y_{g}=\frac{\frac{1}{2} \int_{x_{1}}^{x_{2}} y^{2} d x}{\int_{x_{1}}^{x_{2}} y d x}
\end{gathered}
$$

O número total de unidades monitoras de cada arco dinâmico é distribuído igualmente entre os segmentos que o compõem. A contribuição de cada segmento do arco $\left(c o n_{i}\right)$, para a dose prescrita no ponto de normalização (no eixo central), é definida de acordo com o grau de cobertura do ponto de normalização pelas lâminas. Se a distância do ponto de normalização até a borda mais próxima das lâminas é maior que $0,5 \mathrm{~cm}$, a contribuição do campo descoberto é máxima $\left(\operatorname{con}_{i}=1,0\right)$. Para os pontos cobertos pelas lâminas em pelo menos $0,5 \mathrm{~cm}$, a contribuição é aquela determinada pela transmissão do sistema de multi-lâminas, obtida no comissionamento do sistema ${ }^{(13)}$.

Quando o ponto de normalização está entre os pontos descritos anteriormente, localizados a $0,5 \mathrm{~cm}$ da borda das lâminas e cobertos até $0,5 \mathrm{~cm}$, o algoritmo determina a contribuição interpolando-a linearmente, dependendo da posição do ponto de normalização com relação à posição das lâminas.

Assim, as unidades monitoras de cada segmento são determinadas a partir da seguinte relação:

$$
U M_{i}=U M_{S P} \times w_{i} \times \operatorname{con}_{i}
$$

em que $U M_{S P}$ são as unidades monitoras calculadas pelo sistema de planejamento e $U M_{i}$ são as unidades monitoras de cada segmento.

A dose com a qual cada segmento contribui para o ponto de normalização é calculada pela seguinte expressão: 


$$
D_{i}=U M_{i} \times T M R_{i} \times S_{c p_{i}} \times O A R_{i}
$$

Na última equação $D_{i}$ é a dose de cada segmento, $U M_{i}$ são as unidades monitoras de cada um dos segmentos, $T M R_{i}$ é a razão tecido máximo na profundidade equivalente para cada segmento, $S_{c p, i}$ é o fator total de espalhamento para o campo equivalente do segmento que esta sendo calculado. O $O A R_{i}$ é a razão fora do eixo obtido a partir da posição do ponto de gravitação do segmento. A dose total do arco é obtida pela soma das contribuições dos segmentos:

$$
D_{A D-V E R}=\sum_{i} D_{i}
$$

As doses calculadas pelo software desenvolvido $\left(D_{A D-V E R}\right)$ foram comparadas com as doses calculadas pelo sistema de planejamento $\left(D_{A D-S P}\right)$ :

$$
\% \text { dif }=\frac{D_{A D-V E R}-D_{A D-S P}}{D_{A D-S P}} \times 100
$$

Também foram comparados os resultados a partir das doses totais em diferentes tratamentos. Nesses casos, as diferenças entre a dose de tratamento gerada pelo programa de verificação desenvolvido $\left(D_{T O T A L-V E R}\right)$ e a dose total calculada pelo sistema de planejamento $\left(D_{\text {TOTAL-SP }}\right)$ foram encontradas da seguinte forma:

$$
\% \text { dif }=\frac{D_{\text {TOTAL-VER }}-D_{\text {TOTAL-SP }}}{D_{\text {TOTAL }-S P}} \times 100
$$

Todos os campos testados foram comparados com os respectivos cálculos no sistema de planejamento. Alguns casos foram calculados a partir das imagens do paciente $\left(D_{A D-}\right.$ VER-PAC), outros a partir das imagens de tomografia de um objeto simulador sólido equivalente à água (Solid Water ${ }^{\circledR}$ - SW), sendo as doses calculadas pelo sistema $\left(D_{A D-V E R-S W}\right)$, e por fim, os casos usando um objeto simulador de polimetilmetacrilato (PMMA) $\left(D_{A D-V E R-P M M A}\right)$, este último desenvolvido justamente para testar campos de arco dinâmico e de intensidade modulada, simulando um crânio. Para todos os casos utilizou-se a correção por densidade de material que é própria do sistema de planejamento. 
Como foi descrito, cada arco de tratamento está constituído por certo número de segmentos que depende da amplitude do arco. Neste trabalho, o número maior de segmentos por arco usado nos cálculos foi 13, e o menor número foi de sete segmentos, correspondendo a arcos de $120^{\circ}$ e $60^{\circ}$, respectivamente. A tela de resultados da planilha desenvolvida, para um exemplo de cálculo de um arco com nove segmentos, é apresentada na Figura a2.

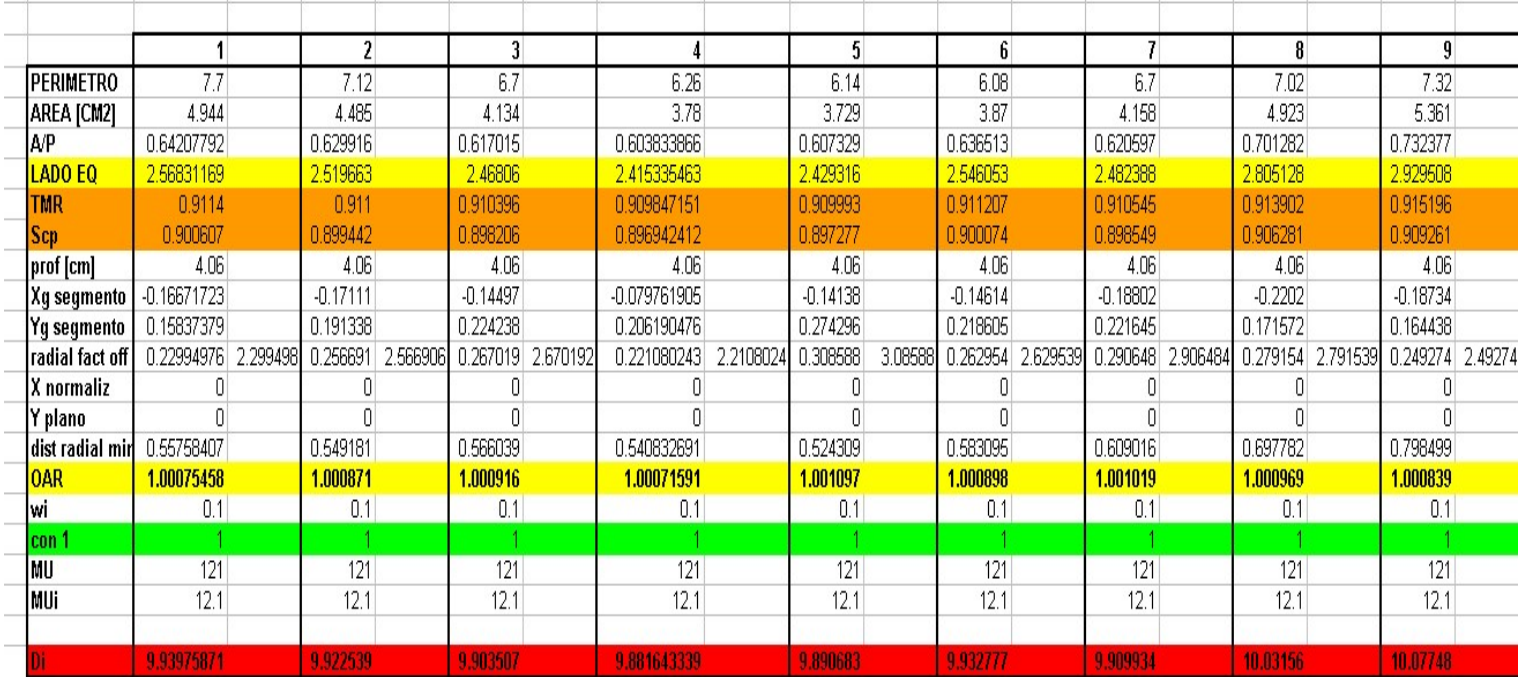

Figura a2. Tela com os resultados do cálculo para oito segmentos que formam um campo de tratamento.

\section{RESULTADOS}

O programa desenvolvido foi testado com 229 feixes de arco dinâmico com o algoritmo apresentado no item anterior. Esses 229 feixes representam 42 tratamentos de crânio. Desse total, 109 campos foram calculados no sistema de planejamento nas imagens do paciente, 109 foram calculados no objeto simulador de PMMA e 21 no objeto simulador de SW.

A diferença encontrada para as doses totais nos 42 tratamentos de arco dinâmico entre o programa de verificação e a dose calculada pelo sistema de planejamento foi de $+1,73 \%$, com desvio-padrão de $0,76 \%$. A diferença máxima encontrada foi de 3,32\% e a mínima, de 020\%. Os resultados são mostrados na Figura a3. 


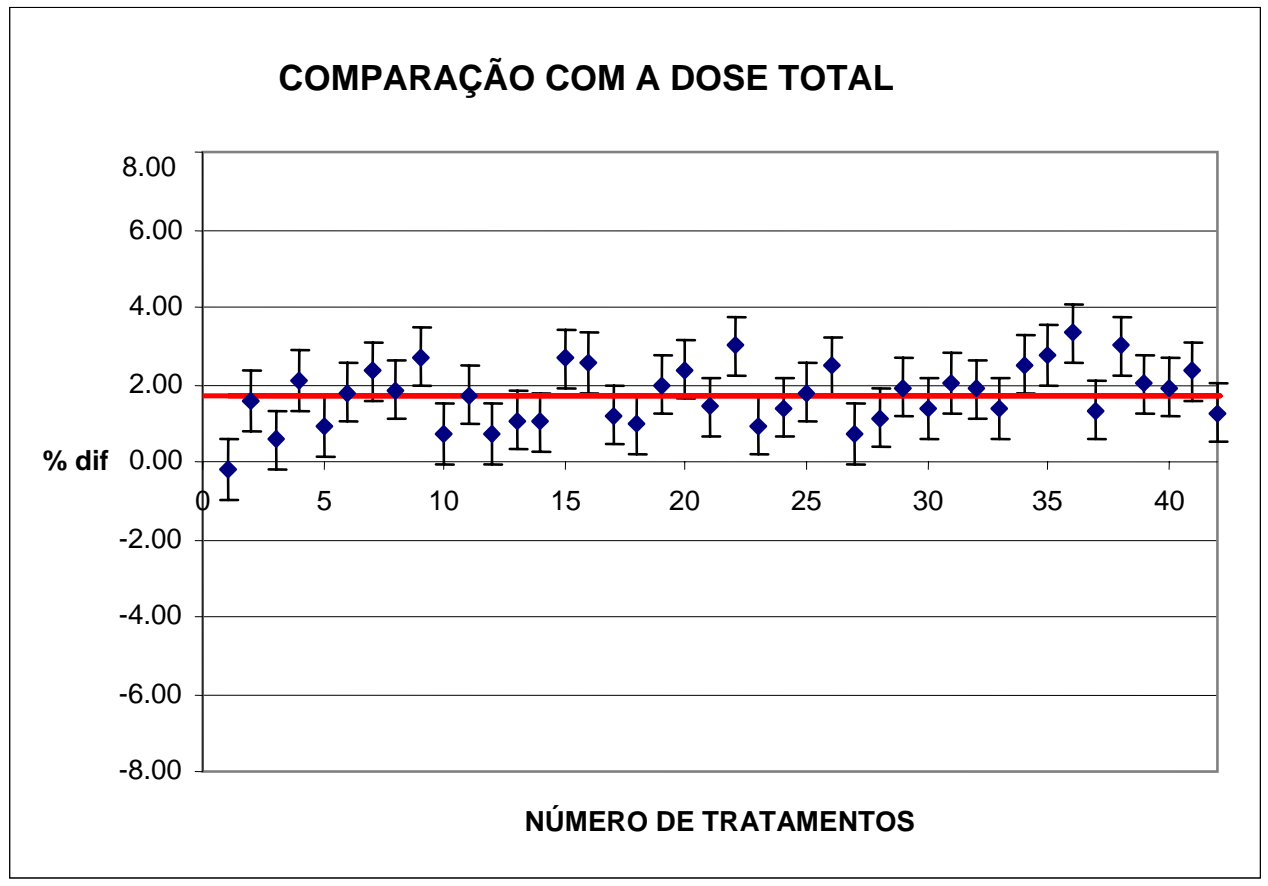

Figura a3. Comparação da dose total entre os valores calculados pelo programa de verificação e os valores calculados pelo sistema de planejamento para os 42 tratamentos de crânio.

Para os 229 arcos testados, a diferença média encontrada foi de 1,61\%, com desvio-padrão de 1,04\%. Estes resultados encontram-se na Figura a4. Os valores máximos e mínimos das diferenças obtidos foram 4,01\% e -2,04\%, respectivamente.

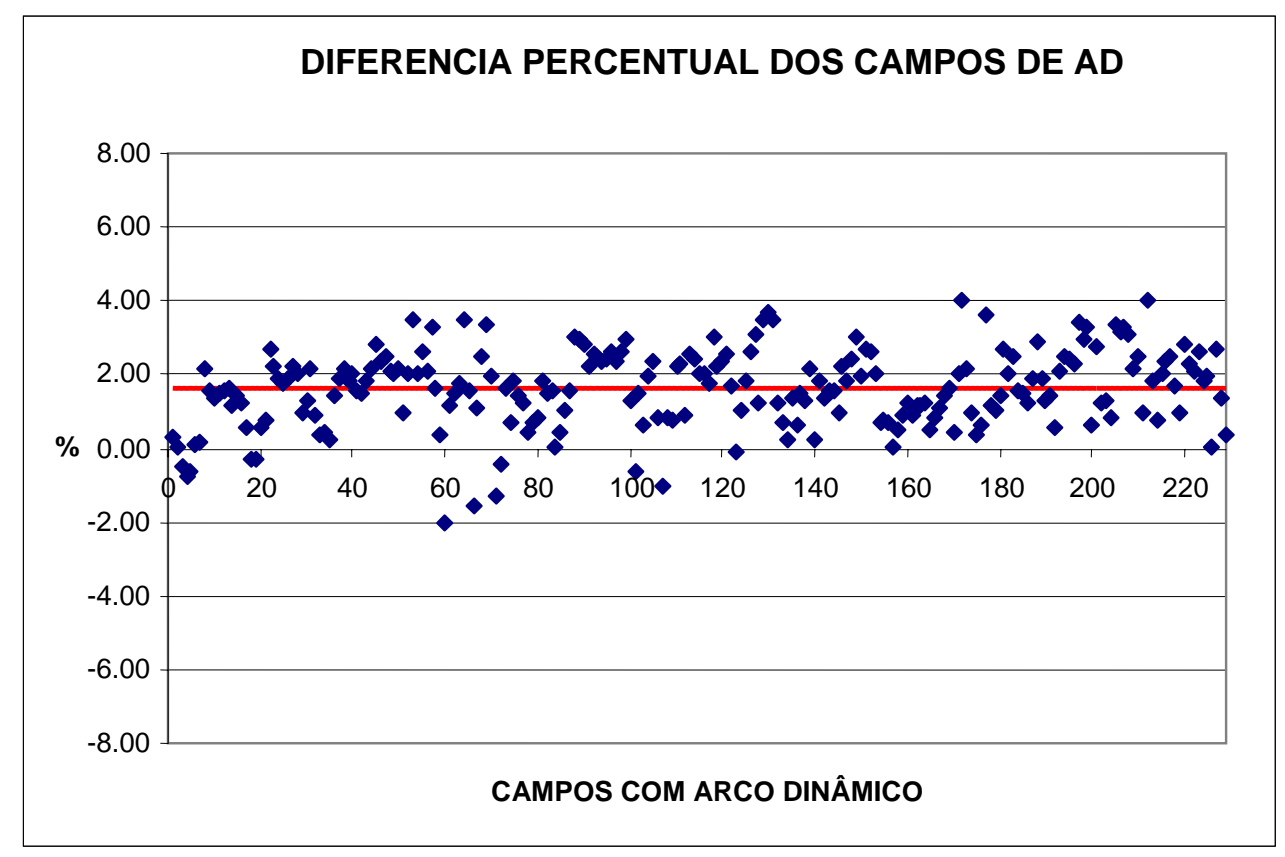

Figura a4. Comparação entre a dose calculada pelo programa de verificação e pelo sistema de planejamento para os 229 arcos testados. 
Os 229 arcos foram analisados segundo o meio no qual foi feito o cálculo do sistema de planejamento. Os resultados são apresentados na Figura a5, para as imagens de tomografia do paciente, na Figura a6, para as imagens do objeto simulador de PMMA, na Figura a7, para as imagens do objeto simulador de SW, e na Tabela a1.

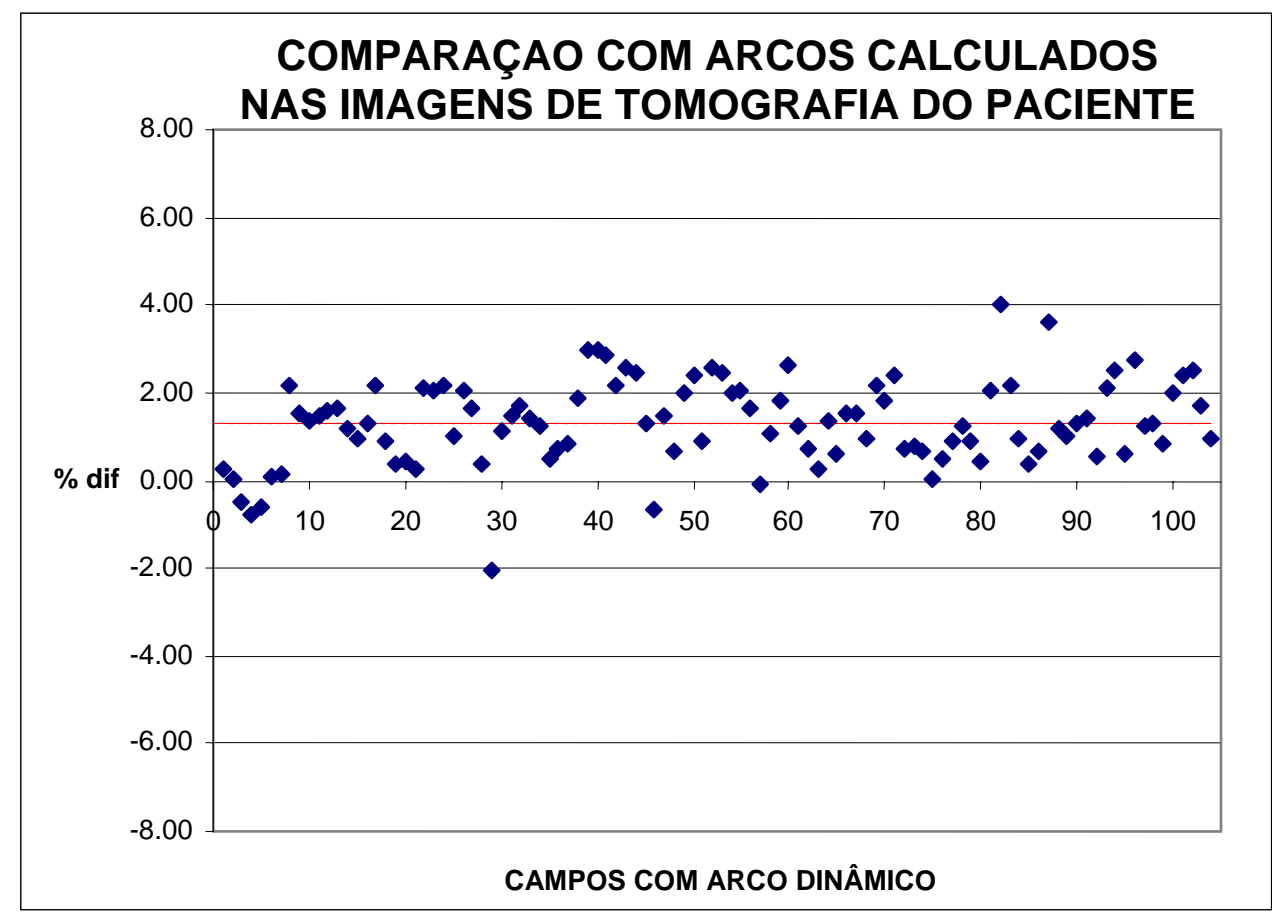

Figura a5. Comparação entre as doses calculada e planejada nas imagens de tomografia do paciente. 


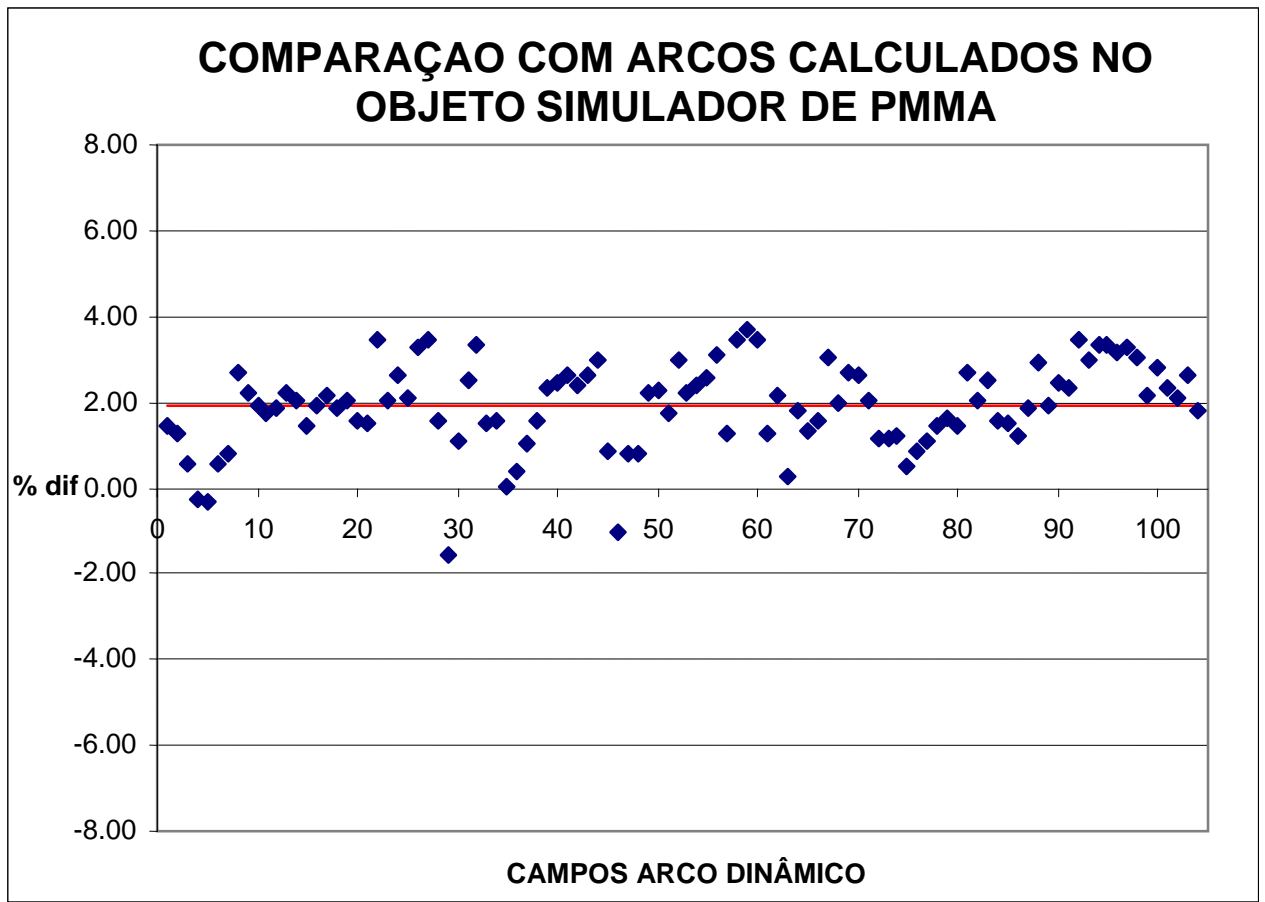

Figura a6. Comparação entre as doses calculada e planejada no objeto simulador de PMMA.

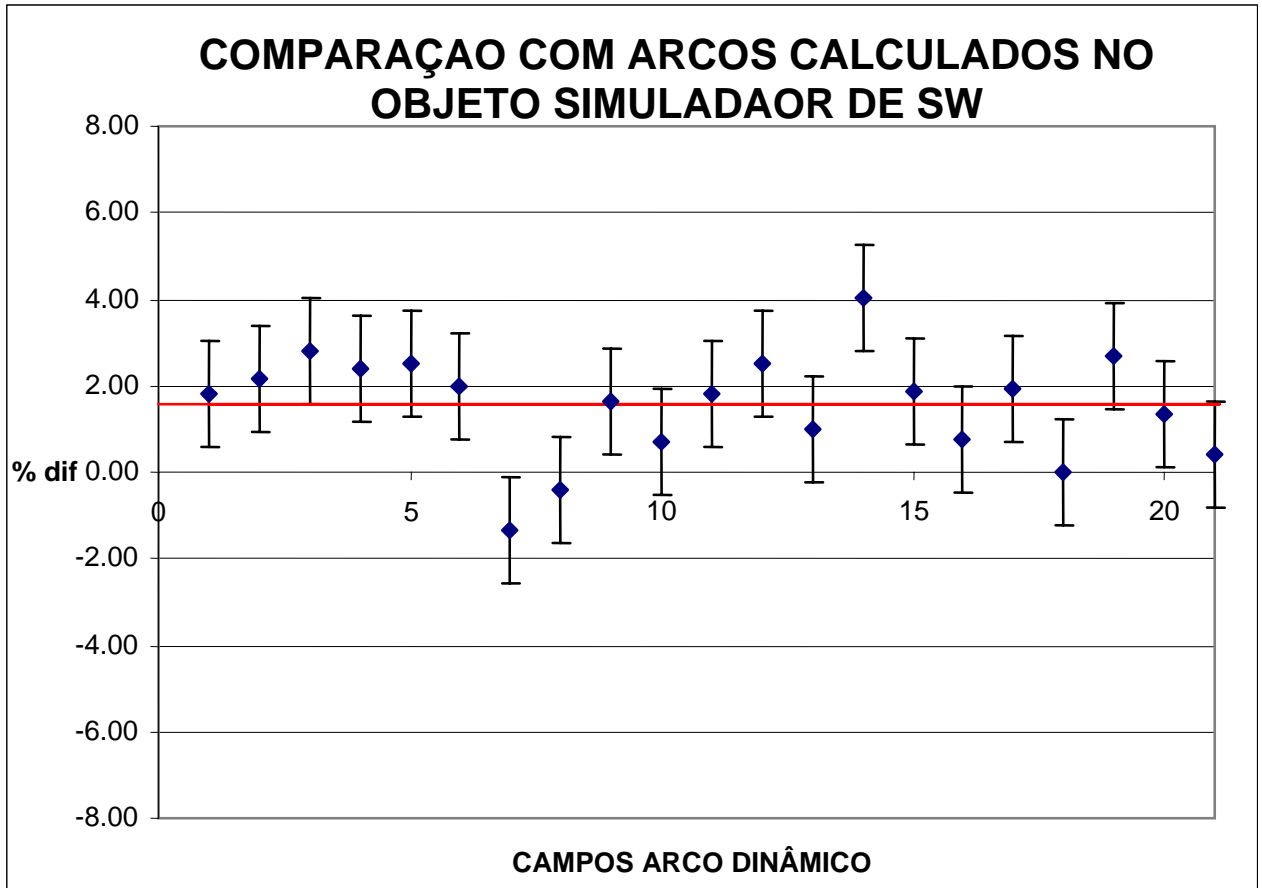

Figura a7. Comparação entre as doses calculada e planejada no objeto simulador de SW.

Tabela a1. Comparação entre os resultados do programa de verificação e os cálculos do sistema de planejamento em meios diferentes. 


\begin{tabular}{|c|c|c|c|c|c|}
\hline Meio & $\begin{array}{c}\text { Diferença } \\
\text { média }\end{array}$ & $\begin{array}{c}\text { Desvio- } \\
\text { padrão }\end{array}$ & $\begin{array}{c}\text { Percentual } \\
\text { máximo }\end{array}$ & $\begin{array}{c}\text { Percentual } \\
\text { mínimo }\end{array}$ & $\begin{array}{c}\mathrm{N}^{\circ} \text { de campos } \\
\text { estudados }\end{array}$ \\
\hline Paciente & 1,32 & 0,97 & 4,00 & $-2,04$ & 104 \\
\hline PMMA & 1,92 & 1,00 & 3,71 & $-1,59$ & 104 \\
\hline SW & 1,55 & 1,22 & 4,01 & $-1,32$ & 21 \\
\hline
\end{tabular}

PMMA, polimetilmetacrilato; SW, solid-water.

Do total de casos, $80,35 \%$ dos feixes testados encontram-se na faixa de $\pm 2,5 \%$ de diferença com relação às doses geradas pelo sistema de planejamento. Os valores encontrados se encontram de acordo com os citados na literatura por Linthout ${ }^{(14)}$ e Linthout et al. ${ }^{(15)}$.

\section{DISCUSSÃO}

Uma causa dos desvios encontrados é a utilização de uma única profundidade média, chamada pelo sistema de planejamento de equivalent depth, para todos os segmentos de um mesmo arco, situação que é aproximada. Para se ter um cálculo mais exato, deveria ser utilizada a profundidade de cada segmento, e não a média das profundidades dos segmentos. No entanto, este dado é utilizado por ser o fornecido no relatório do tratamento, podendo ser facilmente inserido na planilha para o respectivo cálculo. Já no caso de utilizar este método para verificação independente de campos de IMRT, esta profundidade é a mesma para todos os segmentos que formam um campo.

Outra causa das diferenças encontradas é que o algoritmo do programa de verificação considera o meio de cálculo um meio homogêneo, sem heterogeneidades (ossos, cavidades de ar, etc.), apesar de sanar, em parte, o problema ao utilizar a profundidade equivalente.

O algoritmo utilizado permite que o método seja extrapolado para campos de IMRT, uma vez que o cálculo desses campos no sistema de planejamento é realizado através do algoritmo de feixe estreitamente colimado ${ }^{(16)}$. Para isso, deve ser levado em consideração que nos campos de IMRT o número de segmentos por campo de tratamento é maior, e que muitos desses segmentos contribuirão à dose total devido apenas à transmissão das lâminas. 


\section{CONCLUSÕES.}

O programa de verificação desenvolvido é uma ferramenta útil dentro do programa de controle de qualidade dos tratamentos de arco dinâmico com o sistema BrainLab e com campos gerados pelo algoritmo de feixe estreitamente colimado do BrainScan.

O uso do programa descrito neste trabalho é recomendado para os serviços de radioterapia que utilizam esse tipo de equipamento e técnica, já que adiciona um método a mais na conferência dos dados resultantes do cálculo do sistema de planejamento para os tratamentos de arco dinâmico. Em 80,35\% dos arcos testados, as doses calculadas encontram-se na faixa de $\pm 2,5 \%$ de diferença com relação às doses geradas pelo sistema de planejamento.

Este algoritmo pode ser implementado em serviços de radioterapia que possuem o sistema de mMLC BrainLab m3, desde que os dados dosimétricos do equipamento sejam alimentados junto com os valores de penumbra e transmissão obtidos no comissionamento.

\section{REFERÊNCIAS}

1. Informações técnicas e especificações do micro colimador multi-lâminas m3 BrainLab. Disponível em: <http:॥www.brainlab.com>. Acessado em: 8/4/2005.

2. Mohan R, Chui C, Lidofsky L. Differential pencil beam dose computation model for photons. Med Phys 1986;13:64-73.

3. Mohan R, Chui C, Lidofsky L. Energy and angular distributions of photons from medical linear accelerators. Med Phys 1985;12:592-597.

4. Almond PR, Biggs PJ, Coursey BM, et al. AAPM's TG-51 protocol for clinical reference dosimetry of high-energy photon and electron beams. Med Phys 1999;26:1847-1870.

5. International Atomic Energy Agency. Absorbed dose determination in external beam radiotherapy: an international code of practice for dosimetry based on standards of absorbed dose to water. Technical Reports Series No. 398. Vienna: IAEA, 2002.

6. Kutcher GJ, Loia L, Gillin M, et al. Comprehensive QA for radiation oncology: Report of AAPM Radiation Therapy Committee Task Group 40. Med Phys 1994;21:518-618.

7. Fraass B, Doppke K, Hunt M, et al. American Association of Physicists in Medicine Radiation Therapy Committee Task Group 53: Quality assurance for clinical radiotherapy treatment planning. Med Phys 1998;25:1773-1829. 
8. International Atomic Energy Agency. Aspectos físicos de la garantía de calidad en radioterapia: Protocolo de control de calidad. Technical Document No. 1151. Vienna: IAEA, 2000.

9. International Atomic Energy Agency. Commissioning and quality assurance of computerized planning systems for radiation treatment of cancer.Technical Reports Series No. 430. Vienna: IAEA, 2004.

10. Boyer A, Xing L, Ma CM, et al. Theoretical considerations of monitor unit calculations for intensity modulated beam treatment planning. Med Phys 1999;26:187-195.

11. Khan FM. The physics of radiation therapy. 2nd ed. Maryland: Williams \& Wilkins, 1994.

12. Cosgrove VP, Jahn U, Pfaender M, Bauer S, Budach V, Wurm RE. Commissioning of a micro multi-leaf collimator and planning system for stereotactic radiosurgery. Radiother Oncol 1999;50: 325-336.

13. Delgado JF, Cruz JC, Cecilio PJ, Caprioglio L, Vieira AM. Testes de aceitação, comissionamento e controle da qualidade com colimador micro multilâminas. Rev Imagem 2005;27(Supl n ${ }^{\circ}$ ): 62-63.

14. Linthout N. Evaluation of conformal radiation therapy techniques using various multileaf collimators. (Tese de Doutorado). Brussels: Vrije Universiteit Brussels, Faculteit Geneeskunde en Farmacie, 2003.

15. Linthout N, Verellen D, Van Acker S, Storme G. A simple theoretical verification of monitor unit calculation for intensity modulated beams using dynamic mini-multileaf collimation. Radiother Oncol 2004;71:235-241.

16. Software Guide BrainScan. Version 5.3. Art. No. 60900-90 EN. Heimstetten, Germany: BrainLAB AG. 


\section{REFERÊNCIAS BIBLIOGRÁFICAS}

[1] Webb S (1993) The Physics of Three-Dimensional Radiation Therapy Conformal Radiotherapy, Radiosurgery and Treatment Planning. IOP Publishing, London.

[2] Attix FH (1986) Introduction to Radiological Physics and Radiation Dosimetry. John Wiley \& Sons, New York.

[3] Johns HE, Cunningham JR (1983) The Physics of Radiology, $4^{\text {th }}$ Edition. Charles C. Thomas Publisher, Springfield, IL.

[4] Khan FM (1994) The Physics of Radiation Therapy. 2nd ed. Maryland. Williams \& Wilkins, Baltimore.

[5] Intensity Modulated Radiation Therapy Collaborative Working Group (2001) Intensity-Modulated Radiotherapy: Current Status and Issues of Interest. Int. J. Radiat. Oncol. Biol. Phys. 51: 880-914.

[6] Boyer A, Biggs P, Galvin J, Klein E, LoSasso T, Low D, Mah K, Yu C (2001) AAPM Report 72. Basic Applications of Multileaf Collimators, Report of Task Group No. 50. Medical Physics Publishing. Madison.

[7] LoSasso T, Chui CS, and Ling CC (2001) Comprehensive Quality Assurance for the Delivery of Intensity Modulated Radiotherapy with a Multileaf Collimator Used in the Dynamic Mode. Med. Phys. 28(11): 2209-2219.

[8] Organismo Internacional de Energia Atomica (2000) Aspectos Físicos de la Garantia de Calidad en Radioterapia: Protocolo de Control de Calidad IAEA TECDOC 1151. OIEA. Vienna.

[9] Hartmann GH (1995) Quality assurance program on stereotactic radiosurgery: Report from a quality assurance task group. Springer-Verlag.

[10] Schell MC, et al (1995) Stereotactic Radiosurgery: Report of Task Group 42 AAPM Radiation Therapy Committee. American Institute of Physics. 
[11] Podgorsak, E.; editor (2005) Review of Radiation Oncology Physics: A Handbook for Teachers and Students. International Atomic Energy Agency. Educational Reports Series. Vienna, Austria.

[12] Andreo P. (1991) Monte Carlo techniques in medical radation physics. Phys. Med. Biol. 36: 861-920.

[13] Verhaegen F, and Seuntjens J (2003) Monte Carlo modelling of external radiotherapy photon beams. PhysMedBiol. 48: R107-R164.

[14] International Commission on Radiation Units and Measurements (ICRU) (1993) "Prescribing, recording and reporting photon beam therapy". International Commission on Radiation Units and Measurements. ICRU Report 50, ICRU, Bethesda, Maryland, USA.

[15] International Commission on Radiation Units and Measurements (ICRU) (1999) "Prescribing, recording and reporting photon beam therapy (Supplement to ICRU Report 50)”, ICRU Report 62, ICRU, Bethesda, Maryland, USA.

[16] International Atomic Energy Agency (2000) Absorbed dose; an international code of practice Technical Report 398. IAEA. Vienna.

[17] Software Guide BrainScan. Version 5.3. Art. No. 60900-90 EN. Heimstetten, Germany: BrainLAB AG.

[18] Kutcher GJ, Coia L, et al (1994) Comprehensive QA for radiation oncology: Report of AAPM Radiation Therapy Committee Task Group 40. Med. Phys. 21(4):581618.

[19] Fraass B, Doppke K, Hunt M, Kutcher G, Starkschall G, Stern R, Van Dyke J (1998) AAPM Radiation Therapy Committee Task Group 53: Quality assurance for clinical radiotherapy treatment planning. Med. Phys. 25(10):1773-1829.

[20] International Atomic Energy Agency (2004) Commissioning and quality assurance of computerized planning systems for radiation treatment of cancer - TRS 430. IAEA Vienna.

[21] International Atomic Energy Agency (2007) Specification and Acceptance Testing of Radiotherapy Treatment Planning Systems - TECDOC-1540. IAEA Vienna. 
[22] Bielajew A F (2000) Fundamentals of the Monte Carlo Method for Neutral and Charged Particle Transport. The University of Michigan.

[23] Linthout N, Verellen D, Van Acker S, Voordeckers M, Bretz A and Storme G (2002) Evaluation of dose calculation algorithms for dynamic arc treatments of head and neck tumors. Rad. Onc. 64: 85-95.

[24] Cardinale RM, Benedict SH, Wu Q, Zwicker RD, Gaballa HE, and Mohan R (1998) A Comparison of Three Stereotactic Radiotherapy Techniques; Arcs Vs. Noncoplanar Fixed Fields Vs. Intensity Modulation. Int. J .Radiat. Oncol. Biol. Phys. 42:431-436.

[25] Delgado-Viteri JF (2006) Intercomparação de colimadores de múltiplas lâminas para implementação de terapia de feixes de intensidade modulada. Dissertação de Mestrado - Instituto de Pesquisas Energéticas e Nucleares, Universidade de São Paulo.

[26] Das IJ, Desobry GE, McNeeley SW Cheng EC and Schultheiss TE (1998) Beam characteristics of a retrofitted double-focused multileaf collimator.. Med Phys 25:16761684.

[27] Associação Brasileira de Normas Técnicas, Instituto Nacional de Metrologia, Sociedade Brasileira de Metrologia (1998) Guia para a Expressão da Incerteza de Medição - Segunda Edição Brasileira do “Guide to the Expression of Uncertainty in Measurement”. ABNT, INMETRO, SBM, Rio de Janeiro.

[28] Bucciolini M. et al. (2003) Diamond detector versus silicon diode and ion chamber in photon beams of different energy and field size. Med. Phys. 30(8): 2149-54. [29] Stasi M. et al. (2004) The behavior of several microionization chambers in small intensity modulated radiotherapy fields. Med. Phys. 31(10): 2792-5.

[30] Lovelock DMJ, Chui CS, and Mohan R (1995) A Monte Carlo model of photon beams used in radiation therapy. Med. Phys. 22: 1387-94.

[31] Libby B, Siebers J, and Mohan R (1999) Validation of Monte Carlo generated phase-space descriptions of medical linear accelerators. Med. Phys. 26(8): 1476-83.

[32] Siebers JV, Keall PJ, Kim JO, and Mohan R (2002) A method for photon beam Monte Carlo multileaf collimator particle transport. Phys. Med. Biol. 47: 3225-49. 
[33] Liu HH, Verhaegen F, and Dong L (2001) A method for simulating dynamic multileaf collimators using Monte Carlo techniques for intensity-modulated radiation therapy. Phys. Med. Biol. 46: 2283-98.

[34] De Vlamynck K, Palmans H, Verhaegen F, De Wagter C, De Neve W, and Thierens H (1999) Dose Measurements Compared with Monte Carlo Simulations of Narrow 6MV Multileaf Collimator Shaped Photon Beams. Med. Phys. 26(9): 18741882.

[35] Sánchez-Doblado F et al (2003) Ionization chamber Dosimetry of Small Photon Fields: a Monte Carlo Study on Stopping-Power Ratios for Radiosurgery and IMRT Beams. Phys. Med. Biol. 48: 2081-2099.

[36] Cosgrove V P, et al. (1999) Commissioning of a micro multi-leaf collimator and planning system for stereotactic radiotherapy. Radiother. Oncol. 50: 325-336.

[37] Xia P, et al. (1999) Physical characteristics of a miniature multileaf collimator. Med. Phys. 26: 65-70.

[38] Aaronson RF, DeMarco JJ, Chetty IJ, Solberg TD (2002) A Monte Carlo Based Phase Space Model for Quality Assurance of Intensity Modulated Radiotherapy Incorporating Leaf Specific Characteristics. Med. Phys. 29(12): 2952-2958.

[39] Jordan TJ. (1996) Central axis depth dose data for use in radiotherapy. Brit $\boldsymbol{J}$ Radiol (Suppl. 25) 5:62-109.

[40] Varian Oncology Systems (1996) Monte Carlo Modeling Information Package. Varian Oncology Systems, California, USA.

[41] Siebers JV, Keall PJ, Libby B and Mohan R (1999) Comparison of EGS4 and MCNP4b Monte Carlo Codes for Generation of Photon Phase Space Distributions for a Varian 2100C. Phys. Med. Biol. 44: 3009-3026.

[42] Salvat F, Fernandez-Varea JM, Sempau J (2003) PENELOPE - A Code System for Monte Carlo Simulation of Electron and Photon Transport, Version 2003, NUCLEAR ENERGY AGENCY.

[43] International Commission on Radiation Units and Measurements (ICRU) (1984) Stopping Powers for Electrons and Positrons. ICRU Report 37, ICRU, Bethesda, Maryland, USA. 
[44] Briesmeister JF (1997) MCNP - A General Monte Carlo N-Particle Transport Code, Los Alamos National Laboratory LA-12625-M Version 4B, Los Alamos.

[45] Rogers DWO and Bielajew AF (1988) A comparison of EGS and ETRAN Monte Carlo Transport of electrons and photons. Ed. Jenkins TM, Nelson WR and Rindi A. p. 323-41. New York.

[46] Delgado JF, Vieira AMM, Cruz JC, Rodrigues LN (2006) Cálculo independente de dose para tratamentos de arco dinâmico com colimador micro-multi-lâminas. Radiologia Brasileira. v.39, p.355 - 359. 